DOC. 20041008.0004

QA: QA

ANL-NBS-MD-000010 REV 01

October 2004

\title{
Recharge and Lateral Groundwater Flow Boundary Conditions for the Saturated Zone Site-Scale Flow and Transport Model
}

Prepared for:

U.S. Department of Energy

Office of Civilian Radioactive Waste Management

Office of Repository Development

1551 Hillshire Drive

Las Vegas, Nevada 89134-6321

Prepared by:

Bechtel SAIC Company, LLC

1180 Town Center Drive

Las Vegas, Nevada 89144

Under Contract Number

DE-AC28-01RW12101 


\section{DISCLAIMER}

This report was prepared as an account of work sponsored by an agency of the United States Government. Neither the United States Government nor any agency thereof, nor any of their employees, nor any of their contractors, subcortractors or their employees, makes any warranty, express or implied, or assumes any legal liability or responlibility for the accuracy, completeness, or any third party's use or the results of such use of any information, apparatus, product, or process disclosed, or represents that its use would not infringe privately owned rights. Reference herein to any specific commercial product, process, or service by trade name, trademark, manufacturer, or otherwise, does not necessarily constitute or imply its endorsement, recommendation, or favoring by the United States Government or any agency thereof or its contractors or subcontractors. The views and opinions of authors expressed herein do not necessarily state or reflect those of the United States Government or any agency thereof. 
QA: QA

Recharge and Lateral Groundwater Flow Boundary Conditions for the Saturated Zone Site-Scale Flow and Transport Model

ANL-NBS-MD-000010 REV 01

October 2004 
2. Scientific Analysis Title

Recharge and Lateral Groundwater Flow Boundary Conditions for the Saturated Zone Site-Scale Flow and Transport Model

3. DI (including Revision Number)

ANL-NBS-MD-000010 REV 01

4. Total Appendices

5. Number of Pages in Each Appendix

3

A-6, B-18, C-8

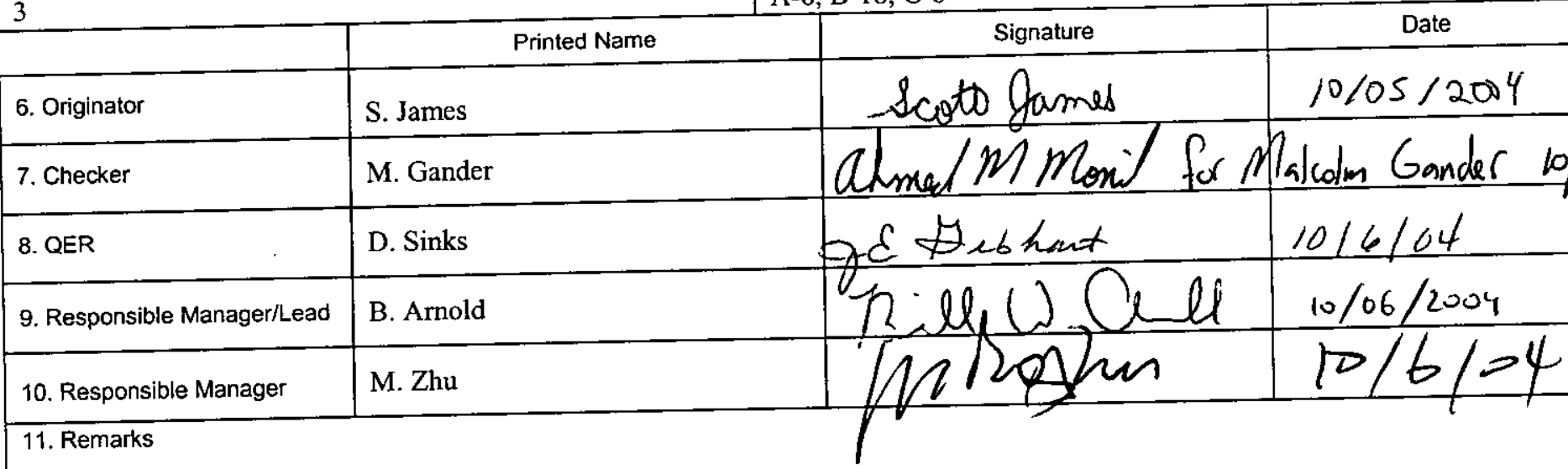

\section{Change History}

\begin{tabular}{|c|l|}
\hline 12. Revision No. & 13. Description of Change \\
\hline REV 00 & Initial Issue \\
\hline
\end{tabular}




\begin{tabular}{|c|c|}
\hline REV 00 ICN 01 & $\begin{array}{l}\text { This ICN resolves TBVs 1249,1250,1251,3105, and } 4255 \text { that were associated with previously } \\
\text { unqualified DTNs used as direct input to the analysis. To resolve the TBVs, one DTN } \\
\text { (GS960808312144.003 [DIRS 105121]) was internally qualified for use in this report. One DTN } \\
\text { (LB971212001254.001 [DIRS 104749]) was incorporated into an assumption in this ICN. References } \\
\text { to unqualified DTN: LB970601233129.001 were incorrect in Rev. 00 and have been deleted in this } \\
\text { ICN; the correct citation is DTN: LB971212001254.001 [DIRS } 104749 \text { ]. Two unqualified DTNs } \\
\text { have been replaced with qualified DTNs: GS970308312133.001 was replaced with } \\
\text { MO0102DQRGWREC.001 [DIRS 155523], MO9907YMP99025.001 was replaced with } \\
\text { MO9906GPS98410.000. } \\
\text { An Acronym and Abbreviations page was added. } \\
\text { Sections } 1 \text { and } 2 \text { were updated to refer to current technical work plans. Section } 4 \text { was modified to } \\
\text { clarify the files from DTN GS960808312144.003 [DIRS 105121] that were used to develop lateral } \\
\text { boundary conditions. Sections } 4,5.1 .2 \text {, and } 6.1 .2 \text { were corrected to this ICN to clarify that the output } \\
\text { and grid files identified in Table 4-1 were taken from DTN LB971212001254.001 [DIRS 104749]. } \\
\text { Attachment VII, Internal Qualification of the Death Valley Regional Groundwater Flow Model, was } \\
\text { added to document the internal qualification of a primary data source. } \\
\text { Attachments I through VI of this technical product contain documentation of single-use software } \\
\text { routines that were qualified under procedure AP-SI.1Q, Software Management, prior to the release of } \\
\text { the current revision (Rev. 3) of said procedure. The documentation of these routines was enhanced in } \\
\text { the attachments to this ICN as part of the corrective action for Deficiency Report LVMO-00-D-039. } \\
\text { This ICN did not involve a change to the code of these routines and they were not used to develop } \\
\text { additional quality affecting information, or to modify data in this technical product. Consequently, } \\
\text { these single-use software routines will remain documented herein, in accordance with AP-SI.1Q, REV } \\
\text { 1, ICN 0, which was in effect at the time of the approval REV 00 of this technical product. }\end{array}$ \\
\hline REV 01 & $\begin{array}{l}\text { This revision documents the recharge and lateral boundary conditions for the saturated zone (SZ) site- } \\
\text { scale flow model from the } 2001 \text { Death Valley Regional Flow System model and compares these to the } \\
\text { results from the } 1997 \text { Death Valley Regional Flow System model. Made changes to report in } \\
\text { response to recommendations from Regulatory Integration Team/ Natural Systems Team. Entire } \\
\text { scientific analysis documentation was revised. Changes were too extensive to use Step 5.6e(1) per } \\
\text { AP-SIII.9Q/Rev.1/ICN 7. }\end{array}$ \\
\hline
\end{tabular}




\section{CONTENTS}

Page

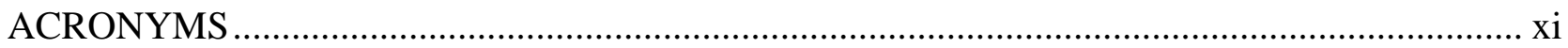

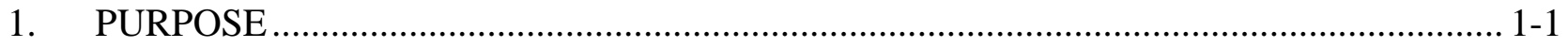

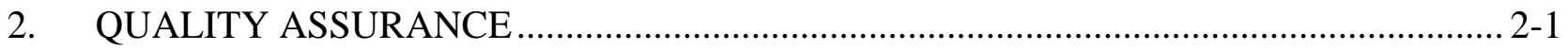

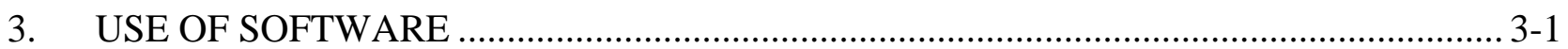

3.1 RECHARGE ............................................................................................... $3-1$

3.1.1 Distributed Recharge from the DVRFS Models.......................................... 3-1

3.1.2 Recharge from the UZ Site-scale Flow Model Area ...................................... 3-1

3.1.3 Focused Recharge from Fortymile Wash ..................................................... 3-2

3.2 LATERAL BOUNDARIES..................................................................... $3-2$

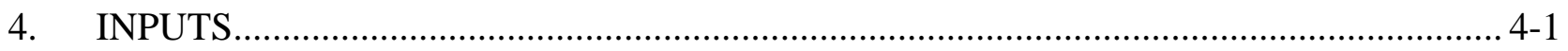

4.1 DIRECT INPUTS ...................................................................................... $4-1$

4.1.1 Fortymile Wash................................................................................... 4-1

4.1.2 1997 DVRFS Model and 1997 UZ Site-Scale Flow Model ........................... 4-1

4.1.3 2001 DVRFS Model and 2003 UZ Site-Scale Flow Model ............................ 4-2

4.2 CRITERIA ................................................................................................ $4-3$

4.3 CODES, STANDARDS, AND REGULATIONS ................................................. 4-4

5. ASSUMPTIONS ........................................................................................... $5-1$

5.1 DISTRIBUTED RECHARGE FROM THE 1997 AND 2003 UZ SITE-SCALE FLOW MODEL AREAS ............................................................... 5-1

5.2 FOCUSED RECHARGE FROM FORTYMILE WASH........................................ 5-2

6. SCIENTIFIC ANALYSIS DISCUSSION ................................................................. 6-1

6.1 FEATURES, EVENTS, AND PROCESSES SUPPORTED BY THIS

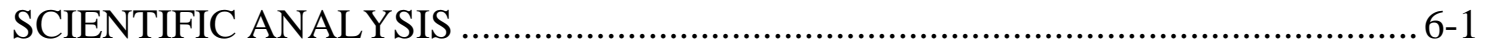

6.2 METHODS FOR CALCULATING DISTRIBUTED RECHARGE ......................... 6-1

6.2.1 Distributed Recharge from the DVRFS Models.......................................... 6-2

6.2.2 Recharge from UZ Site-Scale Flow Model Area.......................................... 6-9

6.2.3 Focused Recharge from Fortymile Wash ................................................ 6-12

6.2.4 Combined Recharge Model ...................................................................... 6-15

6.3 METHODS FOR EXTRACTING LATERAL BOUNDARY FLUXES FROM

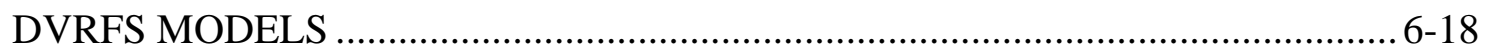

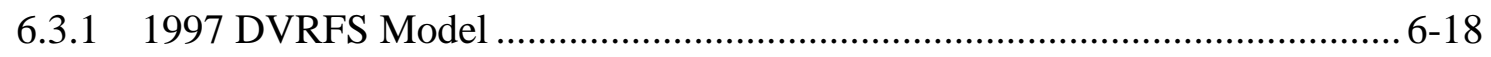

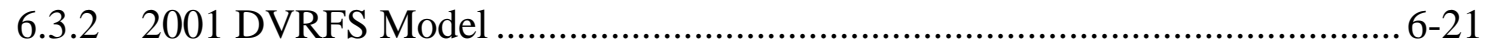

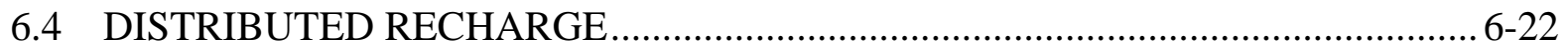

6.4.1 1997 DVRFS Model and 1997 UZ Site-Scale Flow Model ........................... 6-22

6.4.2 2001 DVRFS Model and 2003 UZ Site-Scale Flow Model .......................... 6-22

6.4.3 Differences in Distributed Recharge between 1997 and 2001

DVRFS Models and 1997 and 2003 UZ Site-Scale Flow Models ................. 6-24 


\section{CONTENTS (Continued)}

Page

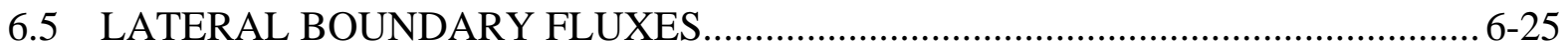

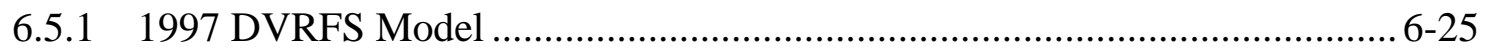

6.5.2 2001 DVRFS Model ........................................................................... 6-30

6.5.3 Differences in Lateral Recharge between 1997 and 2001 DVRFS Models and 1997 and 2003 UZ Site-Scale Flow Models ............................................ 6-35

6.6 COMPARISON OF RESULTS FROM THE 1997 DVRFS AND 1997 UZ SITE-SCALE FLOW MODELS WITH PREVIOUS RESULTS ............................... 6-36

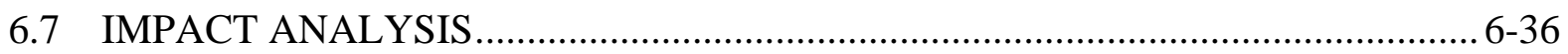

6.7.1 Corrected Distributed Recharge............................................................ 6-36

6.7.2 Correction for Pumping Wells ....................................................................... 6-37

6.7.3 Changes in Potentiometric Surface and Particle Paths .................................... 6-37

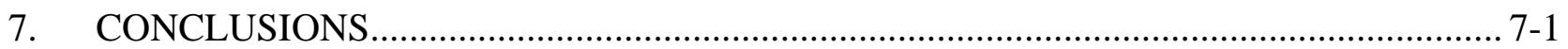

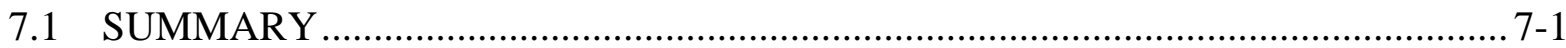

7.2 HOW THE APPLICABLE ACCEPTANCE CRITERIA ARE ADDRESSED............ 7-2

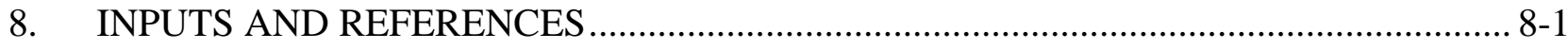

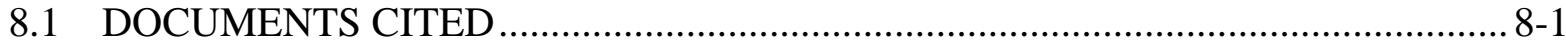

8.2 CODES, STANDARDS, REGULATIONS, AND PROCEDURES............................ 8-3

8.3 SOURCE DATA, LISTED BY DATA TRACKING NUMBER ……………............. 8-4

8.4 OUTPUT DATA, LISTED BY DATA TRACKING NUMBER ………..................... 8-4

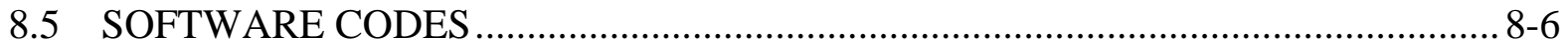

APPENDIX A - DATA TABLES ……………............................................................. A-1

APPENDIX B - ONE-TIME USE OF QUALIFICATION OF DTN: GS960808312144.003 ….................................................................

APPENDIX C - ONE-TIME USE QUALIFICATION OF DTN: LB971212001254.001 .......C-1 


\section{FIGURES}

1-1. Generalized Flow of Information Among Reports Pertaining to Flow and Transport in the SZ $1-3$

6-1. Map of Distributed Recharge from the 1997 DVRFS Model. 6-4

6-2. Flowchart of Utility Codes that Extract Distributed Recharges and Lateral Boundary Fluxes from the 2001 DVRFS Model Used as Boundary Conditions for the SZ Site-Scale Model.

6-3. Map of Distributed Recharge from the 2001 DVRFS Model.

6-4. Map of Groundwater Flux Simulated at the Bottom Boundary of the 1997 UZ Site-Scale Flow Model

6-5. Map of Groundwater Flux Simulated at the Bottom Boundary of the 2003 UZ Site-Scale Flow Model

6-6. Map of Recharge along the Fortymile Wash Stream Channel

6-7. Corrected Detailed Recharge Map to the Base-Case SZ Site-Scale Flow Model

6-8. Detailed Recharge Map to the Base-Case SZ Site-Scale Flow Model

6-9. Detailed Recharge Map to the Alternate SZ Site-Scale Flow Model

6-10. Correct Recharge for the Base-Case SZ Site-Scale Flow Model, which were not used in model calibration, on a 500-m Grid from the 1997 DVRFS, 1997

UZ Site-Scale Flow Model, and Fortymile Wash

6-11. Recharge Used to Calibrate the Base-Case SZ Site-Scale Flow Model on a 500-m Grid from the 1997 DVRFS, 1997 UZ Site-Scale Flow Model, and Fortymile Wash

6-12. Recharge for the Alternate SZ Site-Scale Flow Model on a 500-m Grid from the 2001DVRFS, 2003 UZ Site-Scale Flow Model, and Fortymile Wash

6-13. Comparison of Simulated Heads Measured in Meters Using the Old (erroneous) Recharge (blue) and the New (corrected) Recharge (red dashed) Boundary Conditions

6-14. Simulated Heads Measured in Meters (blue) and Particle Paths (red) for the Old (erroneous) Recharge

6-15. Simulated Heads Measured in Meters (blue) and Particle Paths (red) for the Corrected Recharge. 
Recharge and Lateral Groundwater Flow Boundary Conditions for the Saturated Zone Site-Scale Flow and Transport Model

\section{INTENTIONALLY LEFT BLANK}




\section{TABLES}

1-1. $\quad$ Models Used in this Analysis Model Report (AMR) (References and DIRS Numbers) .................................................................................................... 1-2

3-1. A List of All Codes Written Specifically for Use in this Analysis ..................................... 3-3

3-2. A List of Other Codes Used in this Analysis ....................................................................... 3-3

4-1. Input Data Sources 1997 Models................................................................................ 4-1

4-2. Input Data Sources 2001 and 2003 Models ............................................................... 4-2

4-3. Project Requirements and Yucca Mountain Review Plan Acceptance Criteria Applicable to This Model Report

6-1. Features, Events, and Processes Included in TSPA-LA and Relevant to this Model Report ....

6-2. Definition of Files for the Flowchart in Figure 6-2 …..................................................... 6-7

6-3. Fortymile Wash Recharge Estimates ........................................................................... 6-14

6-4. Comparison of Distributed Recharges between Different Model Simulations ................. 6-26

6-5. Cell-by-Cell Flow Terms ( $\mathrm{m}^{3} /$ day) from the 1997 DVRFS Model along the West Boundary of the Site-Scale Model

6-6. Cell-by-Cell Flow Terms ( $\mathrm{m}^{3} /$ day) from the 1997 DVRFS Model along the East Boundary of the Site-Scale Model

6-7. Cell-by-Cell Flow Terms ( $\mathrm{m}^{3} /$ day) from the 1997 DVRFS Model along the North Boundary of the Site-Scale Model.....

6-8. Cell-by-Cell Flow Terms ( $\mathrm{m}^{3} /$ day) from the 1997 DVRFS Model along the South Boundary of the Site-Scale Model

6-9. Cell-by-Cell Flow Terms ( $\mathrm{m}^{3} /$ day) from the 2001 DVRFS Model along the West Boundary of the Site-Scale Model.

6-10. Cell-by-Cell Flow Terms ( $\mathrm{m}^{3} /$ day) from the 2001 DVRFS Model along the East Boundary of the Site-Scale Model

6-11. Cell-by-Cell Flow Terms ( $\mathrm{m}^{3} /$ day) from the 2001 DVRFS Model along the North Boundary of the Site-Scale Model

6-12. Cell-by-Cell Flow Terms ( $\mathrm{m}^{3} /$ day) from the 2001 DVRFS Model along the South Boundary of the Site-Scale Model 6-33

6-13. Comparison of Fluxes (kg/s) through the Four Lateral Boundaries of the 1997 and 2001 DVRFS Models 6-36

A-1. Cell-by-Cell Flow Terms ( $\mathrm{m}^{3} /$ day) from the 1997 DVRFS Model along the West Boundary of the Site-Scale Model

A-2. Cell-by-Cell Flow Terms ( $\mathrm{m}^{3} /$ day) from the 1997 DVRFS Model along the East Boundary of the Site-Scale Model

A-3. Cell-by-Cell Flow Terms ( $\mathrm{m}^{3} /$ day) from the 1997 DVRFS Model along the North Boundary of the Site-Scale Model

A-4. Cell-by-Cell flow Terms ( $\mathrm{m}^{3 /}$ day) from the 1997 DVRFS Model along the South Boundary of the Site-Scale Model 
Recharge and Lateral Groundwater Flow Boundary Conditions for the Saturated Zone Site-Scale Flow and Transport Model

\section{INTENTIONALLY LEFT BLANK}




\section{ACRONYMS}

DVRFS Death Valley Regional Flow System

FEHM finite element heat and mass transfer

FEP feature, event, and process

GSIS Geoscientific Information Systems

PC personal computer

RMSE root mean squared error

SZ saturated zone

TDMS Technical Data Management System

TSPA-LA Total System Performance Assessment for License Application

TWP technical work plan

USGS United States Geological Survey

UTM Universal Transverse Mercator

UZ unsaturated zone

YMP Yucca Mountain Project

YMRP Yucca Mountain Review Plan 
Recharge and Lateral Groundwater Flow Boundary Conditions for the Saturated Zone Site-Scale Flow and Transport Model

\section{INTENTIONALLY LEFT BLANK}




\section{PURPOSE}

This analysis is designed to use existing modeling and analysis results as the basis for estimated groundwater flow rates into the saturated zone (SZ) site-scale model domains, both as recharge (infiltration) at the upper boundary (water table), and as underflow at the lateral boundaries. Specifically, this work compiles information on the recharge boundary conditions supplied to the base-case and alternate SZ site-scale flow models taken from (1) distributed recharge from the 1997 (D’Agnese et al. 1997 [DIRS 100131]) or 2001 (D’Agnese et al. 2002 [DIRS 158876]) SZ regional-scale (Death Valley Regional Flow System [DVRFS]) model; (2) recharge below the area of the 1997 (Wu et al. 1997 [DIRS 156453]) or 2003 (BSC 2004 [DIRS 169861]) unsaturated zone (UZ) site-scale flow model; and (3) focused recharge along Fortymile Wash. In addition, this analysis includes extraction of the groundwater flow rates simulated by the 1997 and 2001 DVRFS models coincident with the lateral boundaries of the SZ site-scale flow models. The fluxes from the 1997 DVRFS were used to calibrate the base-case SZ site-scale flow model. The 2001 DVRFS fluxes are used in the alternate SZ site-scale flow model.

The purpose of this scientific analysis report is threefold:

1. To redo the analysis performed in Recharge and Lateral Groundwater Flow Boundary Conditions for the Saturated Zone Site-Scale Flow and Transport Model (BSC 2001 [DIRS 164648]) with qualified software codes. In addition, this Scientific Analysis Report demonstrates that results generated in the previous revision of the report (BSC 2001 [DIRS 164648]), while different from those generated here with qualified codes, do not adversely impact input, calibration, or output relating to the base-case SZ site-scale flow model (BSC 2004 [DIRS 170037]). All data generated in this report relating to 1997 DVRFS model and 1997 UZ site-scale flow model results correspond to those discussed by BSC (2001 [DIRS 164648]), although any errors in that analysis are corrected.

2. To extract updated output data from the 2001 DVRFS model and 2003 UZ site-scale flow model that areused as boundary condition inputs to the alternate SZ site-scale flow model. Although these updated data differ from those discussed by both BSC (2001 [DIRS 164648]) and this report (Item 1 above), they are conceptually equivalent: both specify surface recharge boundary conditions and lateral recharge boundary condition targets for the SZ site-scale flow models.

3. To identify differences between Items 1 and 2 above. Specifically, this report will quantitatively assess differences between recharge and lateral boundary fluxes used in the base-case SZ site-scale flow model for license application (LA) and those used in the alternate SZ site-scale flow model.

The Bechtel SAIC Company, LLC, Technical Work Plan for: Natural System - Saturated Zone Analysis and Model Report Integration (BSC 2004 [DIRS 171421]) governs this scientific analysis report. The work documented in this report was conducted in accordance with the quality assurance procedure, AP-SIII.9Q, Scientific Analyses. Table 1-1 lists the models referenced in this report. In addition, this work should be limited in application only to 
developing the distributed recharge and lateral flux boundary conditions for the base-case and alternate SZ site-scale flow models.

Table 1-1. Models Used in this Analysis Report (AMR) (References and DIRS Numbers)

\begin{tabular}{|l|l|l|}
\hline \multicolumn{1}{|c|}{ Name } & \multicolumn{1}{c|}{ Reference } & \multicolumn{1}{c|}{ DIRS } \\
\hline 1997 DVRFS & D'Agnese et al. 1997 & 100131 \\
\hline 2001 DVRFS & D'Agnese et al. 2002 & 158876 \\
\hline 1997 UZ site-scale flow model & Wu et al. 1997 & 156453 \\
\hline 2003 UZ site-scale flow model & BSC 2004 & 169861 \\
\hline
\end{tabular}

Figure 1-1 shows the relationship of this report to other reports that also pertain to flow and transport in the SZ. Figure 1-1 also shows the flow of key information among the SZ reports. It should be noted that Figure 1-1 does not contain a complete representation of the data and parameter inputs and outputs of all SZ reports, nor does it show inputs external to this suite of SZ reports. The primary output from this report is a direct feed to the SZ site-scale flow model in the form of groundwater flow boundary conditions. 
Recharge and Lateral Groundwater Flow Boundary Conditions for the Saturated Zone Site-Scale Flow and Transport Model

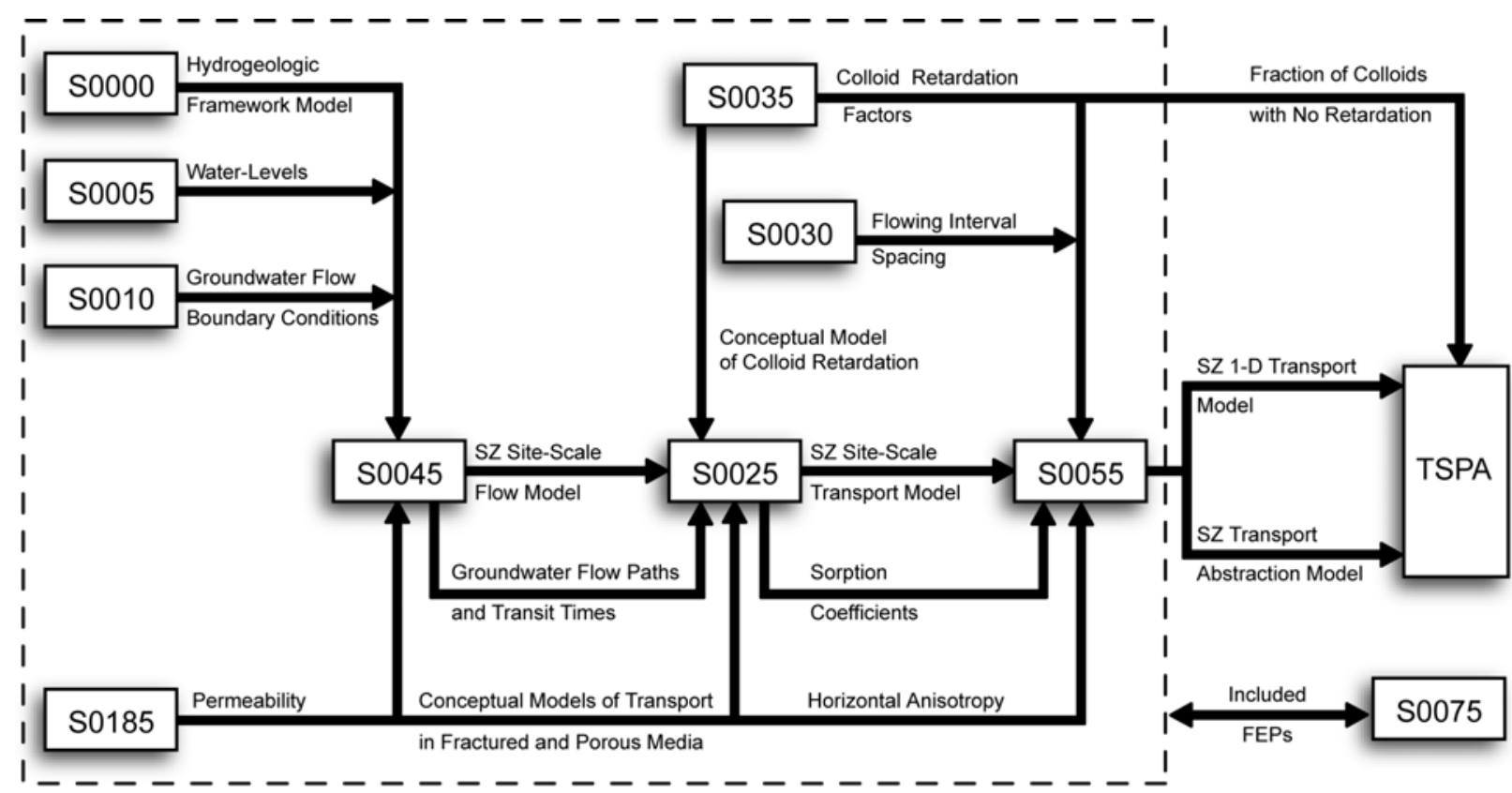

\section{Legend}

S0000 - Hydrogeologic Framework Model

S0005 - Water-Level Data Analysis

S0010 - Recharge and Lateral Groundwater Flow Boundary Conditions

S0025 - Site-Scale Saturated Zone Transport

S0030 - Probability Distribution for Flowing Interval Spacing

S0035 - Saturated Zone Colloid Transport

S0045 - Site-Scale Saturated Zone Flow Model

S0055 - Saturated Zone Flow and Transport Model Abstraction

S0075 - Features, Events, and Processes in SZ Flow and Transport

S0185 - Saturated Zone In-Situ Testing
MDL-NBS-HS-000024

ANL-NBS-HS-000034

ANL-NBS-MD-000010

MDL-NBS-HS-000010

ANL-NBS-MD-000003

ANL-NBS-HS-000031

MDL-NBS-HS-000011

MDL-NBS-HS-000021

ANL-NBS-MD-000002

ANL-NBS-HS-000039

NOTE: This figure is a simplified representation of the flow of information among SZ reports. See the DIRS of each report for a complete listing of data and parameter inputs. This figure does not show inputs external to this suite of SZ reports.

Figure 1-1. Generalized Flow of Information Among Reports Pertaining to Flow and Transport in the SZ 
Recharge and Lateral Groundwater Flow Boundary Conditions for the Saturated Zone Site-Scale Flow and Transport Model

INTENTIONALLY LEFT BLANK 


\section{QUALITY ASSURANCE}

Development of this scientific analysis and the supporting modeling activities is subject to the Yucca Mountain Project (YMP) quality assurance (QA) program as indicated in the technical work plan (TWP) (BSC 2004 [DIRS 171421]). Approved QA procedures have been used to conduct and document the activities described in this Scientific analysis report. The TWP also identifies the methods used to control the electronic management of data (BSC 2004 [DIRS 171421]).

This scientific analysis report provides model calibration boundary values for the base-case and alternate SZ site-scale flow models. In addition, it follows the guidelines outlined in the technical work plan (BSC 2004 [DIRS 171421]). The SZ is part of the natural barrier below the repository and it is classified as "Category 1" with regard to importance to waste isolation, as defined in AP-2.22Q, Classification Analyses and Maintenance of the Q-List. The report contributes to the analysis and modeling data used to support performance assessment; the conclusions do not directly affect engineered features important to safety, as defined in AP-2.22Q. 
Recharge and Lateral Groundwater Flow Boundary Conditions for the Saturated Zone Site-Scale Flow and Transport Model

INTENTIONALLY LEFT BLANK 


\section{USE OF SOFTWARE}

The software codes used in this analysis are discussed in Sections 3.1 and 3.2. In addition, the following industry standard software was used in this analysis and documentation:

- Microsoft Excel 2000 and Surfer 6.03

Microsoft Excel 2000 was used for spreadsheet calculations using standard functions. Surfer 6.03 was used for plotting and visualization of analysis results in the figures included in this report. Specific applications are discussed in Section 6. Both are exempt software products in accordance with LP-SI.11Q, Software Management.

\subsection{RECHARGE}

All codes used to synthesize the estimates of recharge for the boundary conditions of the SZ site-scale model are found in the Software Configuration Management System. Microsoft Excel spreadsheets are used to combine components from flow models and other sources.

\subsubsection{Distributed Recharge from the DVRFS Models}

A set of software routines is used to extract the distributed recharge from the 1997 or 2001 DVRFS model and to write the recharge values for input to the SZ site-scale flow model. The Excel file, read rchg from MFP.xls, is used to calculate distributed recharge applied to the base-case SZ flow model from the 1997 DVRFS model. The use of software routines, Xread_Distr_Rech (V1.0 STN: 10960-1.0-00 [DIRS 163074]) and Xread_Distr_Rech_-UZ (V 1.0 STN: 10961-1.0-00 [DIRS 163075]), is discussed in Section 6. In addition, for the 2001 DVRFS model, the codes Zone (V1.0 STN: 10957-1.0-00 [DIRS 163078]), EXT_RECH (V1.0 STN: 10958-1.0-00 [DIRS 163072]), and Mult_rech (V 1.0 STN: 10959-1.0-00 [DIRS 163073]) are used to extract distributed recharge from 2001 DVRFS flow model input and output files. All of these codes are simple utility codes that read data files, perform any necessary conversions or reorganizations, and then write output files. In addition, they were written explicitly for use in this analysis. These codes are for use on a personal computer (PC) running a Windows operating system and were baselined on December 11, 2002.

\subsubsection{Recharge from the UZ Site-scale Flow Model Area}

A Microsoft Excel spreadsheet is used to perform calculations and unit conversions of data extracted from the output files of the 1997 or 2003 UZ site-scale flow model. To combine the output from the 1997 or 2003 UZ site-scale flow model with the other components of recharge, the location coordinates from the UZ site-scale flow model are converted from the Nevada State Plane coordinate system to the Universal Transverse Mercator (UTM) coordinate system with CORPSCON (V 5.11.08 STN: 10547-5.11.08-00 [DIRS 155082]). 


\subsubsection{Focused Recharge from Fortymile Wash}

A software routine, Xread_Reaches (V1.0 STN: 10962-1.0-00 [DIRS 163076]), is used to designate recharge through Fortymile Wash and to superimpose these values on the distributed recharge from the 1997 or 2001 DVRFS model, as discussed in Section 6.

A software routine, Xwrite_Flow_New (V1.0-125 STN: 10963-1.0-125-00 [DIRS 163077]), is used to superimpose the values of recharge from the three recharge components for use in the SZ site-scale flow models, as discussed in Section 6. These codes were written explicitly for use in this analysis report.

\subsection{LATERAL BOUNDARIES}

Microsoft Excel spreadsheets are used to compile simulated groundwater flux values from the 1997 and 2001 DVRFS models.

The 1997 DVRFS model results are calculated using MODFLOWP. The executable for MODFLOWP (V 2.3 STN: 10144-2.3-00 [DIRS 150454]) was obtained from the Software Configuration Management System and a set of input files was obtained from the Technical Data Management System (TDMS) directory GS960808312144.003/milrep/finalmod/ [DIRS 105121] and copied to a Sun workstation running Solaris 7. Files needed to perform the analyses in this Scientific Analysis Report were obtained from TDMS (DTN: GS960808312144.003 [DIRS 105121]). To extract flow terms from the output of MODFLOWP for the lateral boundaries of the 1997 DVRFS model, the routine, Extract (V1.0 STN: 10955-1.0-00 [DIRS 163070]), which was written specifically for this analysis report, was used as discussed in Section 6.

The 2001 DVRFS model results were calculated using MODFLOW-2000 (Harbaugh et al. 2000 [DIRS 155197]). All files needed to perform the analyses in this Scientific Analysis Report were obtained from DTN: GS040308312144.001 [DIRS 171472]). To extract flow terms from the output of MODFLOW-2000 for the lateral boundaries of the 2001 DVRFS model, the routine Extract (V 1.1 STN: 10955-1.1-00 [DIRS 163071]), written specifically for this analysis report, was used as discussed in Section 6.

All software codes used in this analysis, whether commercial off-the-shelf or written specifically for this analysis, are appropriate for the analyses performed here. All functions used in spreadsheet calculations are standard to the software. At the time of their use, MODFLOWP and $M O D F L O W-2000$ were the current industry standard for groundwater flow calculations. Table 3-1 is a list of all codes written specifically for this analysis report and Table 3-2 is a list of other codes used, but not written specifically for, this analysis. 
Recharge and Lateral Groundwater Flow Boundary Conditions for the Saturated Zone Site-Scale Flow and Transport Model

Table 3-1. Codes Written Specifically for Use in this Analysis

\begin{tabular}{|l|l|l|}
\hline \multicolumn{1}{|c|}{ Code } & Platform/System & \multicolumn{1}{c|}{ DIRS } \\
\hline Extract V 1.0 & PC/Windows & 163070 \\
\hline Extract V 1.1 & PC/Windows & 163071 \\
\hline EXT_RECH V 1.0 & PC/Windows & 163072 \\
\hline Mult_rech V 1.0 & PC/Windows & 163073 \\
\hline Xread_Distr_Rech V 1.0 & PC/Windows & 163074 \\
\hline Xread_Distr_Rech_-UZ V 1.0 & PC/Windows & 163075 \\
\hline Xread_Reaches V 1.0 & PC/Windows & 163076 \\
\hline Xwrite_Flow_New V 1.0 & PC/Windows & 163077 \\
\hline Zone V1.0 & PC/Windows & 163078 \\
\hline
\end{tabular}

Table 3-2. Codes Used in this Analysis

\begin{tabular}{|l|l|l|}
\hline \multicolumn{1}{|c|}{ Code } & Platform/System & \multicolumn{1}{c|}{ DIRS } \\
\hline CORPSCON V 5.11.08 & PC/Windows & 155082 \\
\hline MODFLOWP V 2.3 & Sun/Solaris 7 & 150454 \\
\hline
\end{tabular}


Recharge and Lateral Groundwater Flow Boundary Conditions for the Saturated Zone Site-Scale Flow and Transport Model

INTENTIONALLY LEFT BLANK 


\section{INPUTS}

\subsection{DIRECT INPUTS}

\subsubsection{Fortymile Wash}

Focused recharge data for Fortymile Wash are recorded in DTN: MO0102DQRGWREC.001 [DIRS 155523].

\subsubsection{DVRFS Model and 1997 UZ Site-Scale Flow Model}

Input information used in this analysis comes from several sources, which are summarized in Table 4-1. DTN: GS960808312144.003 [DIRS 105121] contains inputs and outputs from the 1997 DVRFS model (D’Agnese et al. 1997 [DIRS 100131]). Recharge data from the 1997 UZ site-scale flow model are output from a preliminary YMP UZ model and are taken to be representative of site conditions. This use of $1997 \mathrm{UZ}$ site-scale flow model data is further discussed in Section 6.2.2.1 (DTN: LB971212001254.001 [DIRS 104749]). Both of these DTNs are qualified for one-time use in Appendices B and C of this report.

Table 4-1. Input Data Sources 1997 Models

\begin{tabular}{|c|c|c|}
\hline Data Set & Data Description & Data Tracking Number \\
\hline $\begin{array}{l}\text { Distributed recharge files: } \\
\text { aap.fix } 2 \text {, dvparwel14, } \\
\text { rechs13fix3.asc }\end{array}$ & $\begin{array}{l}\text { Recharge input files from } \\
\text { the } 1997 \text { DVRFS model }\end{array}$ & $\begin{array}{l}\text { GS960808312144.003 } \\
\text { [DIRS 105121] } \\
\text { Qualified in this report }\end{array}$ \\
\hline $\begin{array}{l}\text { Recharge from } 1997 \mathrm{UZ} \\
\text { site-scale flow model area } \\
\text { files: mnaqb_p.out and } \\
\text { mesh_bas. } 2 k\end{array}$ & $\begin{array}{l}\text { Output files from the } 1997 \\
\text { UZ site-scale flow model } \\
\text { containing outflow to SZ } \\
\text { and mesh coordinates }\end{array}$ & $\begin{array}{l}\text { LB971212001254.001 } \\
\text { [DIRS 104749] } \\
\text { Qualified in this report }\end{array}$ \\
\hline $\begin{array}{l}\text { Groundwater flow at } \\
\text { lateral boundaries files: } \\
\text { MODFLOWP, aap.fix2, } \\
\text { baspcnst.pahdvfix5, } \\
\text { bcfp2, cnsthd1new, } \\
\text { cnsthd2new, cnsthd3new, } \\
\text { drnp, dvparwel14, } \\
\text { etmpar, flows.new, } \\
\text { ghbp4, heads.sum5.spr, } \\
\text { lay1str170.asc, } \\
\text { lay2str170.asc, } \\
\text { lay3str170.asc, } \\
\text { newfinnd.evt, otc, pcg2, } \\
\text { rchp, rechs13fix3.asc, } \\
\text { and welp }\end{array}$ & $\begin{array}{l}\text { MODFLOWP executable } \\
\text { and input files from the } \\
1997 \text { DVRFS model }\end{array}$ & $\begin{array}{l}\text { GS960808312144.003 } \\
\text { [DIRS 105121] } \\
\text { Qualified in this report }\end{array}$ \\
\hline $\begin{array}{l}\text { Focused recharge from } \\
\text { Fortymile Wash }\end{array}$ & $\begin{array}{l}\text { Estimates of recharge } \\
\text { along four reaches of } \\
\text { Fortymile Wash }\end{array}$ & $\begin{array}{l}\text { MO0102DQRGWREC.001 } \\
\text { [DIRS 155523] }\end{array}$ \\
\hline
\end{tabular}

NOTE: SZ = saturated zone; UZ = unsaturated zone. 


\subsubsection{DVRFS Model and 2003 UZ Site-Scale Flow Model}

Input information used in this analysis comes from several sources that are summarized in Table 4-2. DTN: GS040308312144.001 [DIRS 171472]) contains inputs and outputs from the 2001 DVRFS model. Recharge data from the 2003 UZ site-scale flow model are output from a YMP model and are taken to be representative of site conditions. DTN: LB03023DSSCP9I.001 [DIRS: 163044] contains the output from the 2003 UZ site-scale flow model.

Table 4-2. Input Data Sources 2001 and 2003 Models

\begin{tabular}{|l|l|l|}
\hline \multicolumn{1}{|c|}{ Data Set } & \multicolumn{1}{|c|}{ Data Description } & \multicolumn{1}{c|}{ Source } \\
\hline $\begin{array}{l}\text { Distributed recharge files: } \\
\text { rechg.asc, } \\
\text { rch_zone6.asc, RCH.txt, } \\
\text { SEN.txt }\end{array}$ & $\begin{array}{l}\text { Recharge, zone } \\
\text { designation, and recharge } \\
\text { multipliers input files from } \\
\text { 2001 DVRFS model }\end{array}$ & $\begin{array}{l}\text { GS040308312144.001 } \\
\text { [DIRS 171472] }\end{array}$ \\
\hline $\begin{array}{l}\text { Recharge from 2003 UZ } \\
\text { site-scale flow model area } \\
\text { files: } \\
\text { flow9.dat_preq_mA.dat } \\
\text { and mesh_2kn.v1 }\end{array}$ & $\begin{array}{l}\text { Output files from 2003 UZ } \\
\text { site-scale flow model } \\
\text { containing outflow to SZ } \\
\text { and mesh coordinates }\end{array}$ & $\begin{array}{l}\text { LB03023DSSCP9I.001 } \\
\text { [DIRS 163044] }\end{array}$ \\
\hline $\begin{array}{l}\text { Groundwater flow at } \\
\text { lateral boundaries file: } \\
\text { CBCF.asc }\end{array}$ & $\begin{array}{l}\text { MODFLOW-2000 output } \\
\text { file from 2001 DVRFS } \\
\text { model }\end{array}$ & $\begin{array}{l}\text { GS040308312144.001 } \\
\text { [DIRS 171472] }\end{array}$ \\
\hline $\begin{array}{l}\text { Focused recharge from } \\
\text { Fortymile Wash }\end{array}$ & $\begin{array}{l}\text { Estimates of recharge } \\
\text { along four reaches of } \\
\text { Fortymile Wash }\end{array}$ & MO0102DQRGWREC.001 \\
[DIRS 155523]
\end{tabular}

The data on distributed recharge and lateral fluxes supplied to the alternate SZ site-scale flow model from DTN: GS040308312144.001 [DIRS 171472] are obtained from an outside source and are not established fact. Specifically, the comment section for this data package states that, "This model was not developed entirely within the controls of [the Yucca Mountain Site Characterization Project] and is therefore considered unqualified and a non-YMP product." The suitability of these data is justified for use in this specific application, as outlined in Scientific Analyses (AP-SIII.9Q, Section 5.2.1). U. S. Department of Energy (DOE) partially directed the development of this model as part of the characterization of Yucca Mountain and surrounding regions. This model output is the updated version and conceptual equivalent of the 1997 DVRFS model output (DTN: GS960808312144.003 [DIRS 105121]), which was a YMP product, and is qualified for one time use in this analysis report in Appendix B. Following the same arguments in Appendix B, these data are appropriate for use in this scientific analysis because they were developed with the best methods and practices of the time by the United States Geological Survey (USGS) professional geologists and scientists. Distributed recharge and lateral flux data generally are corroborated by comparison with the 1997 DVRFS, although it must be noted that the 1997 DVRFS model represents conditions in the early 1990s and the 2001 DVRFS model represents predevelopment conditions. 


\subsection{CRITERIA}

The licensing criteria for postclosure performance assessment are stated in 10 CFR 63 [DIRS 156605]. The requirements to be satisfied by TSPA are identified in the Yucca Mountain Project Requirements Document (Canori and Leitner 2003 [DIRS 166275]). The acceptance criteria that will be used by the U.S. Nuclear Regulatory Commission to determine whether the technical requirements for this model report have been met are identified in Yucca Mountain Review Plan, Final Report (YMRP) (NRC 2003 [DIRS 163274]). The pertinent requirements and criteria for this model report are summarized in Table 4-5.

Table 4-3. Project Requirements and Yucca Mountain Review Plan Acceptance Criteria Applicable to This Model Report

\begin{tabular}{|c|c|c|c|}
\hline $\begin{array}{c}\text { Requirement } \\
\text { Number }\end{array}$ & Requirement Title $^{a}$ & $\begin{array}{c}10 \text { CFR } 63 \\
\text { Link }^{b}\end{array}$ & Applicable Criteria $^{c}$ \\
\hline PRD-002/T-015 & $\begin{array}{l}\text { Requirements for } \\
\text { Performance Assessment }\end{array}$ & $\begin{array}{l}10 \text { CFR } 63.114 \\
\text { [DIRS 156605] }\end{array}$ & 2.2.1.3.8.3, Criteria 1 and 2 \\
\hline
\end{tabular}

${ }^{a}$ From Canori and Leitner 2003 [DIRS 166275]).

b 10 CFR 63 [DIRS 156605].

${ }^{c}$ From NRC (2003 [DIRS 163274]), Section 2.2.1.3.8.3.

In this section, the acceptance criteria identified in Section 2.2.1.3.8.3 of the YMRP (NRC 2003 [DIRS 163274]) are given below. In cases where subsidiary criteria are listed in the YMRP for a given criterion, only the subsidiary criteria addressed by this model report are listed below. Where a subcriterion includes several components, only some of those components may be addressed. How these components are addressed is summarized in Section 8.3 of this report.

\section{Acceptance Criteria from Section 2.2.1.3.8.3 Flow Paths in the Saturated Zone}

\section{Acceptance Criterion 1: System Description and Model Integration Are Adequate.}

(1) Total system performance assessment adequately incorporates important design features, physical phenomena, and couplings, and uses consistent and appropriate assumptions, throughout the flow paths in the saturated zone abstraction process.

(2) The description of the aspects of hydrology, geology, geochemistry, design features, physical phenomena, and couplings, that may affect flow paths in the SZ, is adequate. Conditions and assumptions in the abstraction of flow paths in the SZ are readily identified, and consistent with the body of data presented in the description.

(4) Boundary and initial conditions used in the total system performance assessment abstraction of flow paths in the SZ are propagated throughout its abstraction approaches. For example, abstractions are based on initial and boundary conditions consistent with site-scale modeling and regional models of the Death Valley Regional Flow System. 
(10) Guidance in NUREG-1297 (Altman et al. 1988 [DIRS 103597]) and NUREG-1298 (Altman et al., 1988 [DIRS 103750])), or other acceptable approaches for peer review and data qualification is followed.

\section{Acceptance Criterion 2: Data Are Sufficient for Model Justification.}

(1) Geological, hydrological, and geochemical values used in the license application to evaluate flow paths in the SZ are adequately justified. Adequate descriptions of how the data were used, interpreted, and appropriately synthesized into the parameters are provided.

(2) Sufficient data have been collected on the natural system to establish initial and boundary conditions for the abstraction of flow paths in the SZ.

(3) Data on the geology, hydrology, and geochemistry of the SZ used in the total system performance assessment abstraction are based on appropriate techniques. These techniques may include laboratory experiments, site-specific field measurements, natural analogue research, and process-level modeling studies. As appropriate, sensitivity or uncertainty analyses, used to support the U.S. Department of Energy total system performance assessment abstraction, are adequate to determine the possible need for additional data.

(4) Sufficient information is provided to substantiate that the proposed mathematical groundwater modeling approach and proposed model(s) are calibrated and applicable to site conditions.

\subsection{CODES, STANDARDS, AND REGULATIONS}

No codes, standards, or regulations other than those identified in the Project Requirements Document (Canori and Leitner 2003 [DIRS 166275], Table 2-3) and determined to be applicable (Table 4-2) were used in this analysis. 


\section{ASSUMPTIONS}

\subsection{DISTRIBUTED RECHARGE FROM THE 1997 AND 2003 UZ SITE-SCALE FLOW MODEL AREAS}

The patterns of recharge are taken from the bottom boundaries of the 1997 and 2003 UZ site-scale flow model in the area of the SZ site-scale flow model. The output and grid files used in this Scientific Analysis Report were taken from DTN: LB971212001254.001 [DIRS 104749] and LB03023DSSCP9I.001 [DIRS: 163044]. These files provided an estimate of recharge to the SZ within the footprint of the 1997 or 2003 UZ site-scale flow model, respectively. Data in DTN: LB971212001254.001 [DIRS 104749] are qualified for one-time use in Appendix C.

Both the 1997 and 2003 UZ site-scale flow models have variable grid resolutions that are generally finer than the grid resolution for the SZ site-scale flow models. Integration of recharge fluxes extracted from the 1997 or 2003 UZ site-scale flow model for use at the grid resolution of the SZ site-scale flow models is assumed adequate to represent the recharge pattern in this area.

The infiltration parameters employed in the 1997 and 2003 UZ site-scale flow model differ in resolution and conceptual basis from the recharge model used in the DVRFS models. This inconsistency is assumed insignificant when calibrating the SZ site-scale flow models. In addition, the 1997 and 2003 UZ site-scale flow models results used in this analysis are from the expected (base) case among several alternative models that consider uncertainty in the infiltration flux and UZ site-scale flow model parameters. It is assumed that the expected cases of the 1997 and 2003 UZ site-scale flow models are the most representative estimates to use for the recharge analyses. These assumptions are used in Section 6.2.2.1.

In this analysis, it is assumed that the three components of recharge (i.e., distributed recharge from the 1997 or 2001 DVRFS model, recharge from the 1997 or 2003 UZ site-scale flow model, and focused recharge from Fortymile Wash) provide a reasonable estimate of the magnitude and spatial pattern of recharge when combined. In particular, it is assumed that the resulting estimate of groundwater recharge is suitable and adequate for the purposes of model calibration for the SZ site-scale flow models. Although the estimates of recharge for the three different components of the analysis were derived by different methods, it is assumed that the results are sufficiently consistent for the purposes of specifying infiltration into the SZ site-scale flow models. This assumption is considered appropriate and sufficient for this analysis because the total volumetric recharge rate within the SZ site-scale model domains is a relatively small fraction of the total volumetric groundwater flow rate through the domains (see Sections 6.5.1 and 6.5.2). That makes the analysis quite insensitive to any reasonable assumptions about recharge. Mass balance errors are inherently introduced by using recharge estimates from three different sources at the surface of the flow models while using only one of these sources for lateral boundary fluxes. However, mass balance is ensured in the SZ site-scale flow models by using the lateral fluxes as calibration targets instead of fixed boundary conditions. Furthermore, the active pumping wells located within the base-case SZ flow model domain incorporated into the 1997 DVRFS model are not taken into account directly. Although this may appear to be a discrepancy, it is assumed that the base-case SZ site-scale flow model takes drawdown due to these pumping wells into account by calibrating to the resulting heads and increasing the flux 
through the southern boundary such that a mass balance is achieved (see Section 6.7.2). In Appendix B, a one-time qualification is made for DTN: GS960808312144.003 [DIRS 105121] for use in this report only. In addition, it should be noted that the bottom boundary of the SZ site-scale flow model domain is a no-flow boundary. Finally, because the bottoms of the UZ site-scale flow models models do not exactly correspond the the tops of the SZ site-scale flow models, it is assumed that there is no lateral flow over significant distances in the UZ that diverts recharge into cells at the surface of the SZ model that are in different $x-y$ locations than the cells that directly underlie the recharge locations in the DVRFS models or in Fortymile Wash.

The overarching assumption of this analysis is that the best way to constrain SZ site-scale flow models is to extract lateral and recharge fluxes from other models and analyses (DVRFS models, UZ site-scale flow models, and data from Fortymile Wash) and apply these as either boundary conditions or calibration targets. Implicit in this assumption is that these modeled values are more representative than fluxes calculated from local measurements of hydraulic conductivity and hydraulic gradient. Because of the paucity of these data near the site-scale model boundaries, this is a necessary and reasonable assumption. Although some data can be extrapolated to estimate portions of the flow through the boundaries of the site-scale model domain, the sheer magnitude of the area for which boundary conditions are to be specified $\left(412.5 \mathrm{~km}^{2}\right)$ precludes these values from being specified through data collection activities. Finally, it is assumed that all of the underlying assumptions in the models used to prescribe distributed recharge and lateral flux boundary conditions for he SZ site-scale flow models are sufficient.

\subsection{FOCUSED RECHARGE FROM FORTYMILE WASH}

The estimates of recharge from the Fortymile Wash channel were taken from DTN: MO0102DQRGWREC.001 [DIRS 155523] and are based on streamflow losses during brief runoff events over a maximum of 26 years (Savard 1998 [DIRS 102213]). It is assumed that those observations are representative of the long-term recharge from this source. This is reasonable because the SZ site-scale model is designed to model current conditions extrapolated into the future. The specific scenario of a wetter climate is examined through modeling of a decreased depth to the water table and is not within the scope of this analysis. The estimates of recharge for the Fortymile Canyon reach and the Amargosa Desert reach are extrapolated and interpolated, respectively, to estimate the recharge rates for reaches of the wash within the area of the SZ site-scale models (see Section 6.2.3). It is assumed that the recharge is uniform along each of the stream reaches and that the effective width of the Fortymile Wash channel for recharge at the water table is $500 \mathrm{~m}$. It is also assumed that recharge is uniformly distributed over the area of the distributary channels of Fortymile Wash in the Amargosa Desert. These assumptions are reasonable because of the relatively small total groundwater contribution from the focused recharge along Fortymile Wash relative to the distributed recharge model (see Section 6.4.3). There are no updated data for focused recharge from Fortymile Wash; thus, only one data set is considered. 


\section{SCIENTIFIC ANALYSIS DISCUSSION}

This section is organized as follows: Section 6.1 describes important FEPs related to this scientific analysis. Section 6.2 and subsections describe the methods used to extract the distributed recharge from: (1) the 1997 and 2001 DVRFS models; (2) the 1997 and 2003 UZ site-scale models; and (3) Fortymile Wash, as well as how these values are combined. Section 6.3 and subsections describe the methods used to extract the lateral fluxes from the 1997 and 2001 DVRFS models. Sections 6.4 and 6.5 present the distributed recharge and lateral flux results, respectively. Section 6.6 compares these new results to the previous results of BSC (2001 [DIRS 164648]). Finally, Section 6.7 is an impact analysis of how applying the updated distributed recharge and lateral boundary fluxes impact the base-case SZ site-scale flow model.

\subsection{FEATURES, EVENTS, AND PROCESSES SUPPORTED BY THIS SCIENTIFIC ANALYSIS}

As stipulated in Technical Work Plan For: Natural System - Saturated Zone Analysis Model Report Integration (BSC 2004 [DIRS 171421]) this model report addresses the SZ FEPs pertaining to saturated groundwater flow in the geosphere and advection and dispersion in the SZ that are included for TSPA-LA (Table 6-1). Saturated Zone FEPs that were excluded for TSPA-LA are described in Features, Events, and Processes in SZ Flow and Transport (BSC 2004 [DIRS 170013]). Table 6-1 provides a list of FEPs that are relevant to this model analysis in accordance with their assignment in the LA FEP list (DTN: MO0407SEPFEPLA.000 [DIRS 170760]). Specific reference to the various sections within this document where issues related to each FEP are addressed is provided in the table. The detailed discussions of these FEPs, and their implementation in TSPA-LA, are documented by BSC (2004 [DIRS 170013]).

Table 6-1. Features, Events, and Processes Included in TSPA-LA and Relevant to this Model Report

\begin{tabular}{|l|l|c|c|}
\hline FEP No. & \multicolumn{1}{|c|}{ FEP Name } & $\begin{array}{c}\text { Sections Where } \\
\text { Disposition is Described }\end{array}$ & Discussed in Supporting AMRs \\
\hline $\begin{array}{l}2.2 .07 .1 \\
2.0 \mathrm{~A}\end{array}$ & $\begin{array}{l}\text { Saturated groundwater } \\
\text { flow in the geosphere }\end{array}$ & All of Section 6 & $\begin{array}{c}\text { Upstream Feeds - none } \\
\text { Corroborating - BSC (2004 [DIRS 170037]) }\end{array}$ \\
\hline $\begin{array}{l}2.2 .07 .1 \\
5.0 \mathrm{~A}\end{array}$ & $\begin{array}{l}\text { Advection and } \\
\text { dispersion in the SZ }\end{array}$ & Section 6.7.3 & $\begin{array}{c}\text { Upstream Feeds - none } \\
\text { Corroborating - BSC (2004 [DIRS 170010]) }\end{array}$ \\
\hline
\end{tabular}

\subsection{METHODS FOR CALCULATING DISTRIBUTED RECHARGE}

This analysis begins with the estimated distributed recharge used in the DVRFS models. Within the area of the UZ site-scale flow models, these estimates of distributed recharge are replaced by the simulated values of groundwater flow at the water table boundary of the UZ site-scale flow models. In the areas beneath the Fortymile Wash channel, the distributed recharge estimate is replaced by the estimates of recharge based on streamflow loss measurements. As will be demonstrated in the following analysis, within the SZ site-scale flow model boundaries, the bulk inflow and outflow occurs along the lateral boundaries of the model. Groundwater flows into and across the site model boundaries and ultimately discharges to the south of the site model. Inflow generally occurs along the northern and eastern boundaries and, to a lesser extent, the western boundary, and discharge is generally along the southern boundary. Inflow from the 
north is generally the result of regional recharge at Timber Mountain, Pahute Mesa, and Rainer Mesa. Inflow from the east is generally the result of underflow in the regional Paleozoic carbonate aquifers that were recharged in the Specter Range. Outflow to the south is a result of carbonate underflow and flow in the alluvial aquifers that ultimately discharge at Ash Meadows or into wells in Amargosa Valley.

\subsubsection{Distributed Recharge from the DVRFS Models}

\subsubsection{1997 DVRFS Model}

Distributed recharge from the 1997 DVRFS model is extracted from the model output using qualified codes and an Excel spreadsheet similar to the process described in the preceding revision of this analysis report (BSC 2001 [DIRS 164648]), although the results here reflect several corrections as discussed below. The pattern of distributed recharge is extracted from input files used for the 1997 DVRFS model (DTN: GS960808312144.003 [DIRS 105121]), which is constructed with a grid resolution of $1,500 \mathrm{~m}$. It is assumed that this coarser grid resolution is adequate for use at the higher resolution of the base-case SZ site-scale flow model $\left(500 \times 500 \mathrm{~m}^{2}\right)$ because increasing the resolution of the distributed recharge map without changing the total infiltration will not significantly change site-scale model results. All of the underlying assumptions embodied in the recharge model for the 1997 DVRFS model (D'Agnese et al. 1997 [DIRS 100131]) apply to both the input and the results of that model used in this analysis. The basis of these assumptions is that the 1997 DVRFS model is predicated on measurements of groundwater discharge and is therefore constrained by the water balance for the entire system. Thus, the regional-scale flow model results provide the best available estimate of the volumetric groundwater flow rate at the scale of the base-caseSZ site-scale flow model (see the one-time use data qualification of DTN: GS960808312144.003 [DIRS 105121], in Appendix B).

Values of distributed recharge are extracted from the 1997 DVRFS model input files for recharge, aap.fix2, dvparwel14, and rechs13fix3.asc, which were taken from the TDMS (DTN: GS960808312144.003 [DIRS 105121]). The Excel spreadsheet, read rchg from MFP.xls, is used to extract the values of recharge from the input files to calculate the output file rech_site_1997.dat, that contains the UTM coordinates on 1,500 $\mathrm{m}$ centers and the recharge in units of meters per year. The file, aap.fix2, contains recharge data for the 1997 DVRFS model on 1,500-m cells, rechs13fin3.asc gives the corresponding zonation (zone numbers 1-4) for each 1997 DVRFS model cell, and dvparwel14 lists the calibrated multiplicative constants that correspond to each of the four different zones. Specifically, read rchg from MFP.xls takes the recharge values for a cell from aap.fix2, finds the corresponding zone number in rechs13fix3.asc, and multiplies the recharge value by the constant corresponding to the zone number found in dvparwel14. Zones are defined according to the fraction of rainwater that infiltrates through the vadose zone and enters the saturated zone and are discussed in Appendix B3.1.2. They range in magnitude from 0 to 0.227 and because they are simply multiplication factors, they are unitless.

It must be made abundantly clear that the distributed recharge from the 1997 DVRFS model found in DTN: SN9908T0581999.001 has been used as input to the base-case SZ site-scale flow model. These results were derived solely from aap.fix2, which were taken directly from the TDMS (DTN: GS960808312144.003 [DIRS 105121]), without taking into account the zonation 
values in rechs13fix3.asc or the multiplicative constants in dvparwel14. The interested reader is referred to the historical document for further details (BSC 2001 [DIRS 164648] Figure 6.1.1-1). An impact analysis of using distributed recharge values that have not been corrected for zonation is presented in Section 6.7 of this report.

The routine, Xread_Distr_Rech_-UZ (V 1.0 STN: 10961-1.0-00 [DIRS 163075]), which is used for both the 1997 and 2003 UZ site-scale flow model extractions, is used to convert the values of distributed recharge contained in the file, rech_site_1997.dat, to a 500-m grid within the area of the base-case SZ site-scale model and writes the output to the file, rech_distr_1997.dat, in units of millimeters per year. The 500-m grid is used because it is the discretization used for the SZ site-scale flow models (previously, multiple discretizations were used because the size of the SZ site-scale flow models was yet to be determined). In addition, this routine excludes any grid locations within the footprints of the UZ site-scale flow models. A plot of the spatial distribution of recharge in file, rech_distr_1997.dat, from the 1997 DVRFS model is shown in Figure 6-1. Electronic copies of these files are included in the archive, DTN: SN0407T0504404.002, which is output from this report. The same technique was used to convert values of distributed recharge from file rech_site.dat to generate rech_distr.dat, which are both found in DTN: SN9908T0581999.001. With respect to DTN: SN9908T0581999.001, other than the difference in distributed recharge extracted from the 1997 DVRFS with zonation neglected, there are no changes in the methods, techniques, and results discussed below regarding distributed recharge from the UZ site-scale flow model. The methods and techniques for calculating distributed recharge through Fortymile Wash only differ in the grid resolution used $-500 \mathrm{~m}$ in this revision of the analysis report and $125 \mathrm{~m}$ in the previous revision.

\subsubsection{2001 DVRFS Model}

Using the same assumptions described in the preceding section, the pattern of distributed recharge was extracted from the 2001 DVRFS model (note that there are 15 layers in the 2001 model as opposed to three in the 1997 DVRFS model). Input and output model data were retrieved from DTN: GS040308312144.001 [DIRS 171472]. The FORTRAN routine, Xread_Distr_Rech_-UZ (STN: 10961-1.0-00 [DIRS 163075]), is again used to convert the values of distributed recharge contained in the file, rech_site_2001.dat, to a 500-m grid within the area of the alternate SZ site-scale model and writes the output to file, rech_distr_2001.dat, in units of millimeters per year. Because the 2001 DVRFS model was developed for $M O D F L O W-2000$, which has different input and output files, the steps required to extract the pattern of distributed recharge are different. Figure 6-2 is a flowchart illustrating the use of the files listed in Table 6-2 with corresponding definitions. The flowchart in Figure 6-2 indicates that in addition to Xread_Distr_Rech_-UZ (STN: 10961-1.0-00 [DIRS 163075]), the codes Zone (STN: 10957-1.0-00 [DIRS 163078]), EXT_RECH (STN: 10958-1.0-00 [DIRS 163072]), and Mult_rech (STN: 10959-1.0-00 [DIRS 163073]) were used. 
Recharge and Lateral Groundwater Flow Boundary Conditions for the Saturated Zone Site-Scale Flow and Transport Model

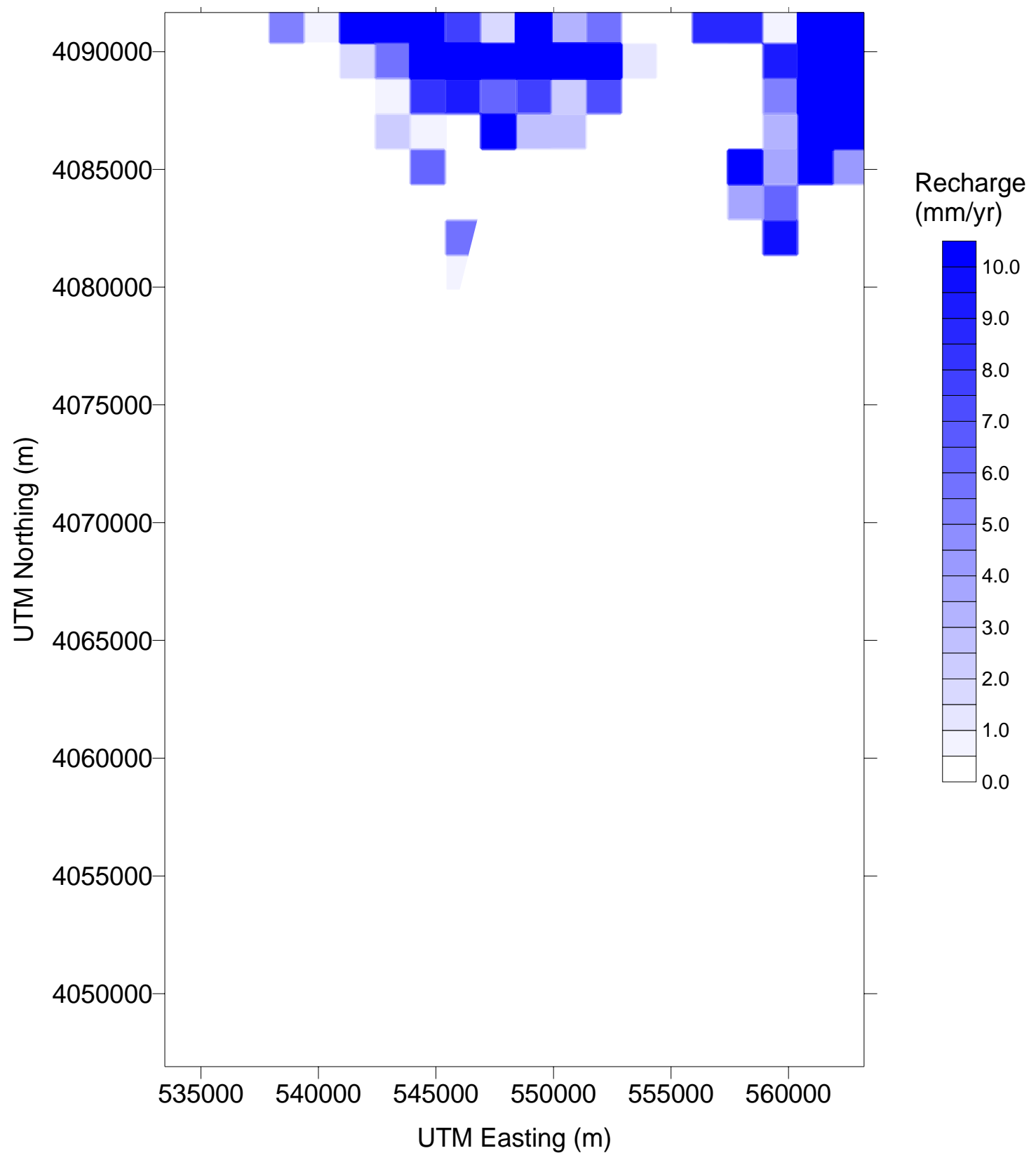

NOTE: Recharge map from the 1997 DVRFS model (DTN: GS960809312144.003 [DIRS 105121]) with values mapped onto the 500-m grid of the base-case SZ site-scale flow model domain. The area of the $1997 \mathrm{UZ}$ site-scale flow model has been removed. Recharge data are taken from DTN: SN0407T0504404.002 in file, rech_distr_1997.dat.

Figure 6-1. Map of Distributed Recharge from the 1997 DVRFS Model 
The code, Zone (STN: 10957-1.0-00 [DIRS 163078]), is used to extract the zone arrays from the 2001 DVRFS model over the site-scale domain. EXT_RECH (STN: 10958-1.0-00 [DIRS 163072]) is used to extract the recharge values over the site-scale domain. Mult_rech (STN: 10959-1.0-00 [DIRS 163073]) uses zone data from Zone (STN: 10957-1.0-00 [DIRS 163078]) to apply multiplication factors to the recharge data from EXT_RECH (STN: 10958-1.0-00 [DIRS 163072]). The multiplication factors are part of MODFLOW-2000 input where, in general, a cell data value (recharge) is calculated from the product of a parameter value that applies to many cells and a cell multiplier (determined by zone number). This method facilitates parameter estimation because only the cell multipliers need to be estimated and not the recharge at every cell within the model. The multiplication factors and the zone name to zone number mapping are found in MODFLOW-2000 input files, SEN.txt and RCH.txt, respectively. The zone number in the input control file to Mult_rech specifies the multipliers. The output file from Mult_rech (STN 10959-1.0-00 [DIRS 163073]), rech_site_2001.dat, contains the distributed recharge over the entire site-scale domain on a 125 -m grid instead of the $1,500-\mathrm{m}$ grid used for the 1997 model. Output is stored electronically in the files, rech_site_2001.dat, and rech_distr_2001.dat, both of which are included in the output DTN: SN0407T0504404.002 from this report. Note the differences between Figures 6-1 and 6-3: there is significantly greater and more widespread infiltration within the SZ site-scale model domain from the 2001 DVRFS model than there is from the 1997 DVRFS model. Because the 1997 DVRFS recharge is applied to the base-case SZ site-scale flow model and the 2001 DVRFS recharge is applied to the alternate SZ site-scale flow model, a direct comparison of the impacts of the change in distributed recharge is impossible.

\subsubsection{Differences between Distributed Recharge from the 1997 and 2001 DVRFS Models}

Clearly, in comparing Figures 6-1 and 6-3, the net distributed recharge from the 2001 DVRFS model is significantly larger. Quantitatively, the 1997 DVRFS model yields $17.6 \mathrm{~kg} / \mathrm{s}$ of recharge to the surface of the SZ site-scale flow model, while the 2001 DVRFS provides $71.4 \mathrm{~kg} / \mathrm{s}$, an increase of over 400 percent. Both values have already had any fluxes removed that would otherwise have made it to the SZ through the UZ model domains. The difference in recharge between the 1997 and 2001 DVRFS models is due to different recharge applied to these models. The interested reader is referred to the model reports of D’Agnese et al. (1997 [DIRS 100131] and 2002 [DIRS 158876]). 
Recharge and Lateral Groundwater Flow Boundary Conditions for the Saturated Zone Site-Scale Flow and Transport Model

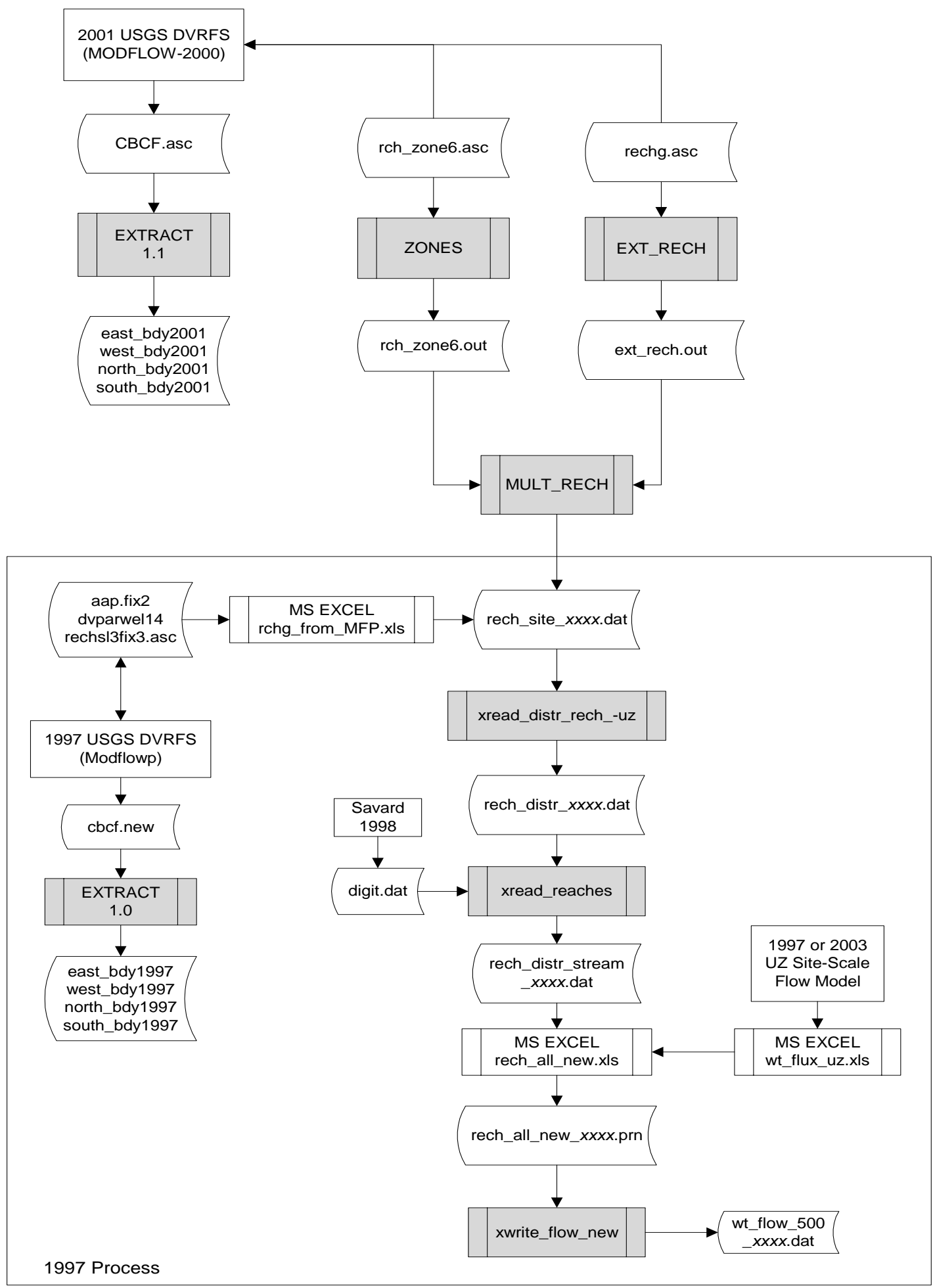

Figure 6-2. Flowchart of Utility Codes that Extract Distributed Recharges and Lateral Boundary Fluxes from the 2001 DVRFS Model Used as Boundary Conditions for the SZ Site-Scale Model 
Recharge and Lateral Groundwater Flow Boundary Conditions for the Saturated Zone Site-Scale Flow and Transport Model

Table 6-2. Definition of Files for the Flowchart in Figure 6-2

\begin{tabular}{|c|c|}
\hline File Name & Description \\
\hline aap.fix2 & preliminary distributed recharge for MODFLOWP \\
\hline CBCF.asc & MODFLOW-2000 cell-by-cell flux file (ASCII) \\
\hline cbcf.new & MODFLOWP cell-by-cell flux file (ASCII) \\
\hline digit.dat & 1997 or 2001 DVRFS model with Fortymile Wash recharge included \\
\hline dvparwel14 & $\begin{array}{l}\text { file listing calibration constants to apply to aap.fix2 according to the zonation } \\
\text { in rechs13fix3.asc for MODFLOWP }\end{array}$ \\
\hline east_bdy1997 & lateral fluxes through the east boundary of the SZ flow model (1997 DVRFS) \\
\hline east_bdy2001 & lateral fluxes through the east boundary of the SZ flow model (2001 DVRFS) \\
\hline EXT_RECH.out & intermediate MODLFOW-2000 recharge output files \\
\hline north_bdy1997 & $\begin{array}{l}\text { lateral fluxes through the north boundary of the SZ flow model (1997 } \\
\text { DVRFS) }\end{array}$ \\
\hline north_bdy2001 & $\begin{array}{l}\text { lateral fluxes through the north boundary of the SZ flow model (2001 } \\
\text { DVRFS) }\end{array}$ \\
\hline rchp & input file for recharge to MODFLOWP \\
\hline read rchg from MFP.xls & Excel file that calculated distributed recharge applied to the 1997 DVRFS \\
\hline rch_zone6.out & intermediate MODLFOW-2000 recharge output files \\
\hline rechg.asc & MODFLOW-2000 input file defining recharge values (ASCII) \\
\hline rech_all_new.xls & $\begin{array}{l}\text { Excel file with all three recharge sources (two worksheets, one for the } 1997 \\
\text { models and one for the } 2001 \text { and } 2003 \text { models) }\end{array}$ \\
\hline rech_all_new_xxxx.prn & text output from rech_all_new.xls for each year (1997 or 2003) \\
\hline rechs13fix3.asc & Zone file for MODFLOWP (ASCII) \\
\hline rech_distr_stream_xxxx.dat & $\begin{array}{l}\text { combined estimates of the distributed recharge from the } 1997 \text { or } 2001 \\
\text { DVRFS model with Fortymile Wash recharge included }\end{array}$ \\
\hline rech_distr_xxxx.dat & 1997 or 2001 DVRFS distributed recharge on a 125-m grid \\
\hline rech_site_xxxx.dat & 1997 or 2001 DVRFS distributed recharge on a 1,500-m grid \\
\hline south_bdy1997 & $\begin{array}{l}\text { lateral fluxes through the south boundary of the SZ flow model (1997 } \\
\text { DVRFS) }\end{array}$ \\
\hline south_bdy2001 & $\begin{array}{l}\text { lateral fluxes through the south boundary of the SZ flow model ( } 2001 \\
\text { DVRFS) }\end{array}$ \\
\hline west_bdy1997 & lateral fluxes through the west boundary of the SZ flow model (1997 DVRFS) \\
\hline west_bdy2001 & lateral fluxes through the west boundary of the SZ flow model (2001 DVRFS) \\
\hline wt_flow_500_xxxx.dat & $\begin{array}{l}\text { final recharge data for use in the SZ site-scale flow model using either the } \\
1997 \text { models (1997) or the } 2001 \text { and } 2003 \text { models (2003) }\end{array}$ \\
\hline wt_flux_uz.xls & $\begin{array}{l}\text { Excel file with } 1997 \text { and } 2003 \text { UZ fluxes to the SZ model (two worksheets, } \\
\text { one for each model year) }\end{array}$ \\
\hline zones\#.asc & MODFLOW-2000 input file defining recharge zones (ASCII) \\
\hline (6)_zones\#.out & intermediate MODLFOW-2000 recharge output files \\
\hline
\end{tabular}


Recharge and Lateral Groundwater Flow Boundary Conditions for the Saturated Zone Site-Scale Flow and Transport Model

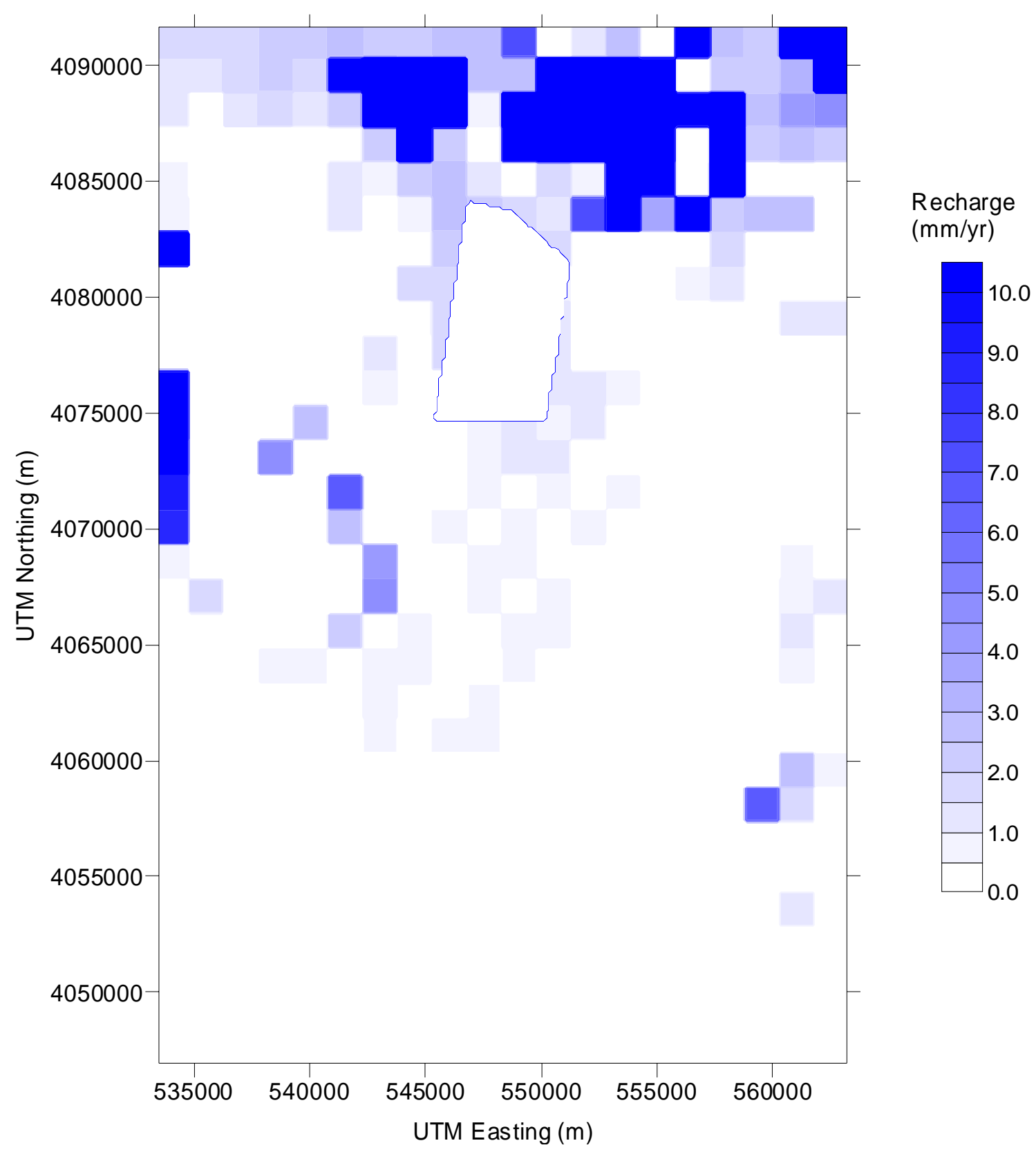

NOTE: Recharge map from the 2001 DVRFS model (DTN: GS040308312144.001 [DIRS 171472]) with values mapped onto the 500-m grid of alternative conceptual SZ site-scale model domain. The area of $2003 \mathrm{UZ}$ site-scale flow model has been removed. Recharge data are taken from files listed in Table 4-2.

Figure 6-3. Map of Distributed Recharge from the 2001 DVRFS Model 


\subsubsection{Recharge from UZ Site-Scale Flow Model Area}

To combine the output from the UZ site-scale flow model with the other components of the recharge model, the geographical coordinates from the UZ site-scale flow model are converted from the Nevada State Plane coordinate system to the UTM coordinate system. The results of these coordinate conversions are given in the spreadsheets in the file, wt_flux_uz.xls. CORPSCON (V 5.11 STN: 10547-5.11.08-00 [DIRS 155082]) was used to perform the coordinate conversion.

\subsubsection{1997 UZ Site-Scale Flow Model}

The recharge in the area of the 1997 UZ site-scale flow model is taken from the output file for the UZ flow simulations, mnaqb_p.out, which is taken from the TDMS (DTN: LB971212001254.001 [DIRS 104749]). This TOUGH2 (V1.4 STN: 10007-1.4-01) output file corresponds to the base-case, mean alpha (van Genuchten unsaturated flow parameter), present day infiltration scenario (Wu et al. 1997 [DIRS 156453]).

Elements in the 1997 UZ site-scale flow model at the bottom boundary of the model (i.e., the water table) are identified by the prefix "BT" in the input and output files. Elements that are associated with fracture flow use the prefix " $F$ " and elements for matrix flow use the prefix " $\mathrm{M}$ " in this dual-permeability model. These prefixes are used to extract the 1,470 elements at the water table in the UZ site-scale flow model using the UNIX "grep" command. The following two commands are used to perform the extraction:

$$
\begin{aligned}
& \text { grep BT.....F mnaqb_p.out>extract_F_1997.out } \\
& \text { grep BT......M mnaqb_p.out>extract_M_1997.out }
\end{aligned}
$$

The two output files, extract_F_1997.out and extract_M_1997.out, contain the groundwater flux $(\mathrm{kg} / \mathrm{s})$ at the water table boundary in the fourth column of the files for the fracture and matrix components of flow, respectively. The first three columns contain element identifier and location information.

The numerical grid file for the 1997 UZ site-scale flow model mesh_bas.2k is taken from the TDMS (DTN: LB971212001254.001 [DIRS 104749]) to obtain information on the $x$ and $y$ coordinates of each element and information on the connection area for each element (area connecting adjacent elements). The following UNIX command is used to perform the extraction:

$$
\text { grep botbd mesh_bas.2k>meshgrep2_1997.out }
$$

The output file, meshgrep2_1997.out, contains the $x$ coordinate (Nevada State Plane in meters) in column numbers 51 to 60 , and the $y$ coordinate in column numbers 61 to 70 .

The following UNIX command is used to extract the connection areas:

$$
\text { grep “BT...M” mesh_bas.2k>conn_M_1997.out }
$$


The output file, conn_M_1997.out, contains the connection area of each element in columns 51 to 60 .

These data are combined in an Excel spreadsheet in the file, wt_flux_uz.xls, under worksheet, 1997. This spreadsheet is constructed by taking columns from the extract_F_1997.out, extract_M_1997.out, meshgrep2_1997.out and conn_M_1997.out files and performing additional operations to calculate total volumetric flow rate and average percolation flux. The first additional operation is to add column $\mathrm{G}$ of the spreadsheet (fracture flux in $\mathrm{kg} / \mathrm{s}$ ) to column $\mathrm{H}$ (matrix flux in $\mathrm{kg} / \mathrm{s}$ ) to get column I (total flux in $\mathrm{kg} / \mathrm{s}$ ). The second operation is to divide the resulting column I by column $\mathrm{J}$ (cell connect area in $\mathrm{m}^{2}$ ) to get column $\mathrm{K}$ (flux per area in $\mathrm{kg} / \mathrm{m}^{2} \mathrm{~s}$ ). The final operation is to multiply the resulting column $\mathrm{K}$ by the constant 31,557,600 to convert the units of flux per area to millimeters per year. This result is stored in column $\mathrm{L}$. The results plotted in Figure 6-4 are overlaid by the 1997 UZ site-scale flow model grid.

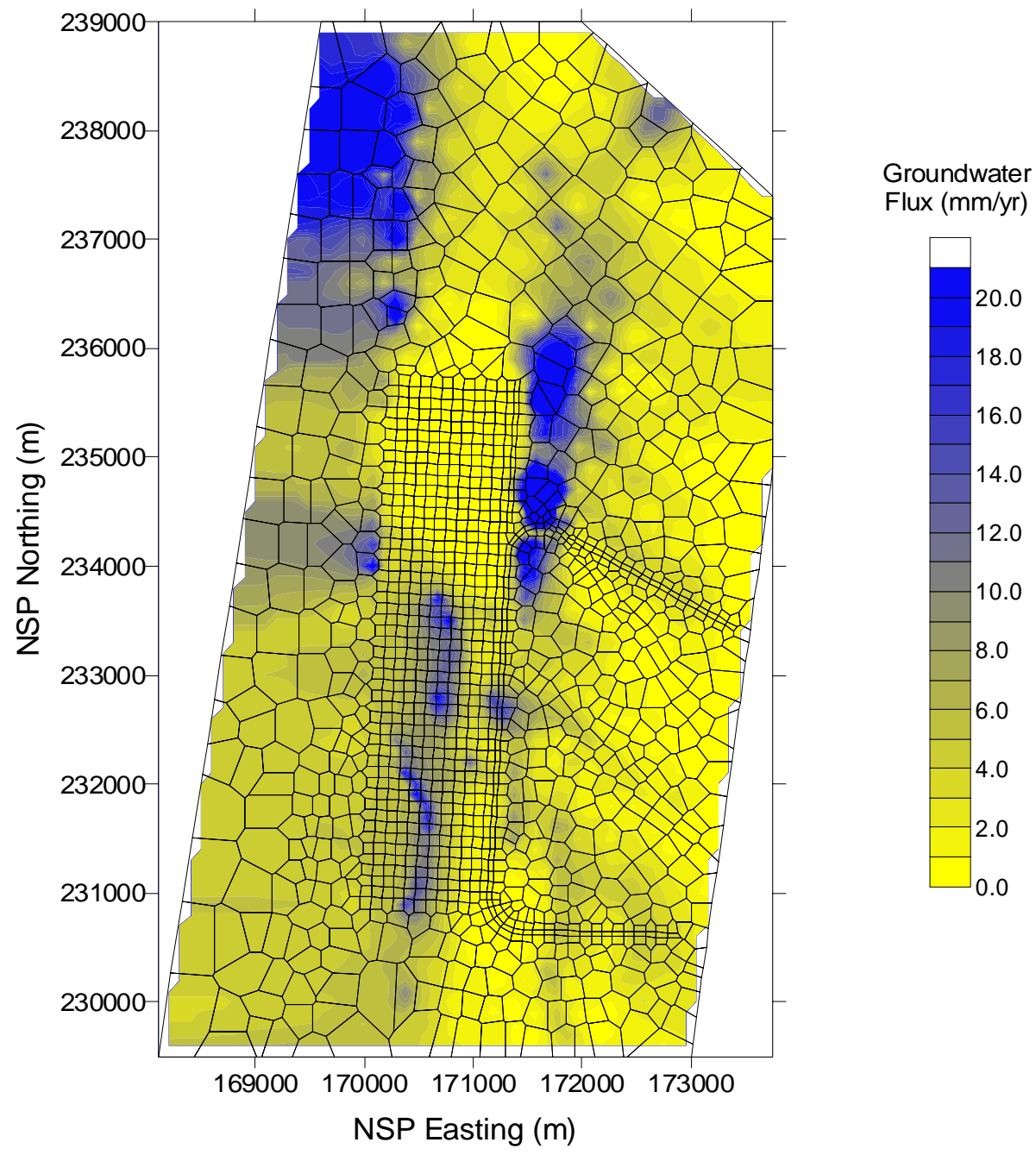

NOTE: The 1997 UZ site-scale flow model grid is shown overlaid on the map of simulated recharge to the SZ for the base case with the present climate from file, mnaqb_p.out (DTN: LB971212001254.001 [DIRS 104749]).

Figure 6-4. Map of Groundwater Flux Simulated at the Bottom Boundary of the 1997 UZ Site-Scale Flow Model 


\subsubsection{2003 UZ Site-Scale Flow Model}

Using the same assumptions, techniques, and procedures described in the preceding section, patterns of distributed recharge were extracted from the $2003 \mathrm{UZ}$ site-scale flow model (TOUGH2, V1.4, STN: 10007-1.4-01). Model data were retrieved from DTN: LB03023DSSCP9I.001 [DIRS: 163044]. The mesh file is mesh_2kn.v1, and the flux data file is flow9.dat_preq_mA.dat. It should be noted that the numerical grid has been updated in the 2003 version of the UZ site-scale flow model. Because of the difference in grids between the 1997 and 2003 versions of the UZ site-scale flow model, there are 2,042 elements at the water table (1,470 in the 1997 model). Note the different infiltration distributions between Figures 6-4 and 6-5. The areas of the 1997 and 2003 UZ site-scale flow models are also slightly different: i.e., the 2003 model area is approximately 17 percent smaller. Results may be found in meshgrep2_2003.out, extract_F_2003.out, extract_M_2003.out, and conn_M_2003.out, as well as in the 2003 worksheets in wt_flux_uz.xls.

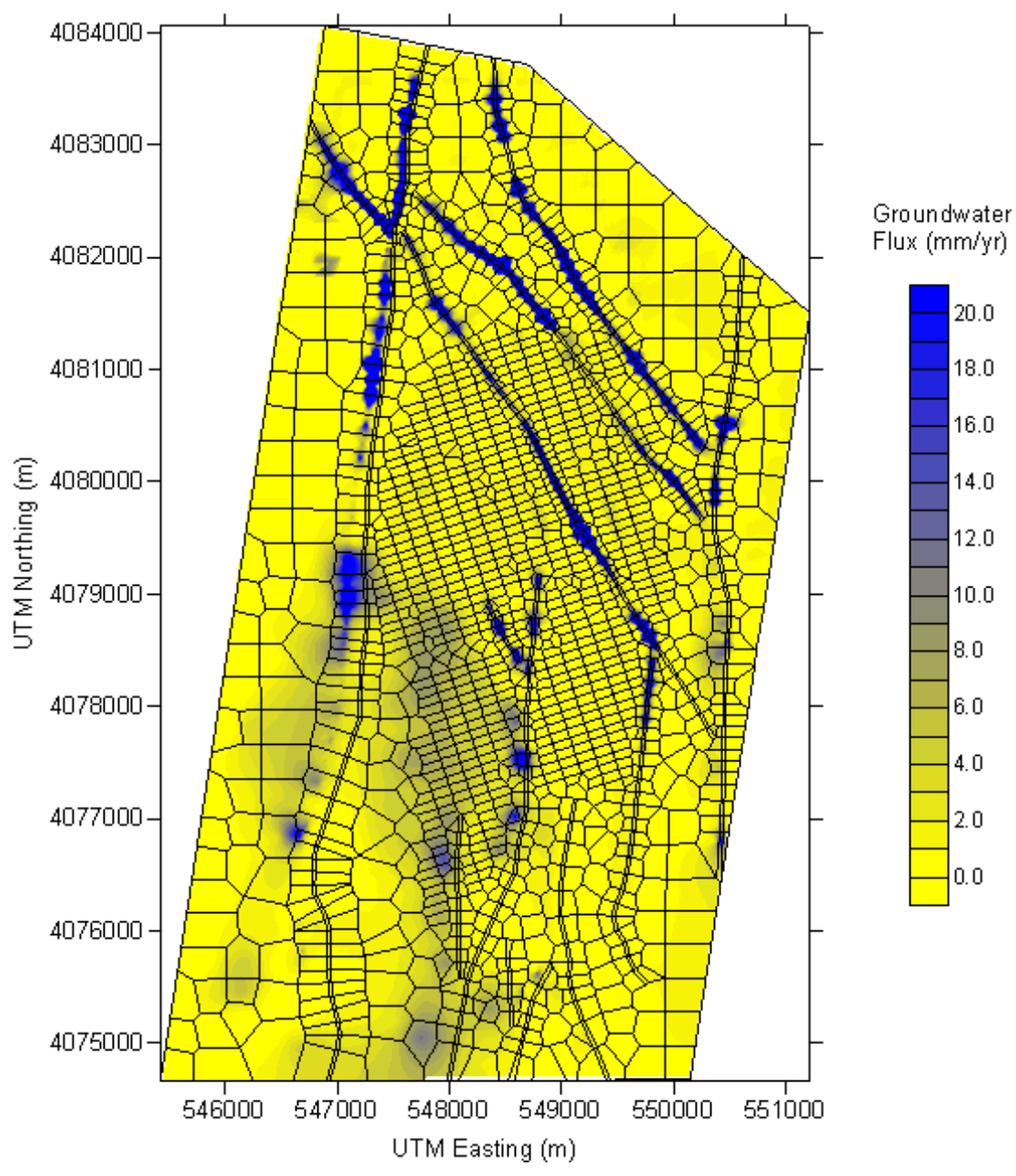

NOTE: The 2003 UZ site-scale flow model grid is shown overlaid on the map of simulated recharge to the SZ for the base case with the present climate from file, flow9.dat_preq_mA.dat (DTN: LB03023DSSCP9I.001 [DIRS 163044]).

Figure 6-5. Map of Groundwater Flux Simulated at the Bottom Boundary of the 2003 UZ Site-Scale Flow Model 


\subsubsection{Differences between Distributed Recharge from the 1997 and 2003 UZ Site-Scale Flow Models}

Clearly, there are differences in SZ site-scale model infiltration between the 1997 and 2003 UZ site-scale flow models. In particular, the faults in the 2003 UZ site-scale flow model apparently focus much of the recharge. Note that the infiltration parameters used in both the 1997 and 2003 UZ site-scale flow models are identical (i.e., the same infiltration rate is used at the top of each model). The only thing that changes is how the UZ redistributes that water within the model domain. Also, because the UZ model boundaries are different (the 2003 UZ site-scale flow model boundary is 17 percent smaller than the $1997 \mathrm{UZ}$ site-scale flow model boundary), there is a corresponding 17 percent decrease in water exiting the $2003 \mathrm{UZ}$ site-scale flow model.

\subsubsection{Focused Recharge from Fortymile Wash}

Recharge data from infiltration along Fortymile Wash were taken from DTN: MO0102DQRGWREC.001 [DIRS 155523]. These data are based on estimates of streamflow loss along four reaches of Fortymile Wash as described by Savard (1998 [DIRS 102213]). These reaches are the Fortymile Canyon reach, Upper Jackass Flats reach, Lower Jackass Flats reach, and Amargosa Desert reach, listed from north to south and shown in Figure 6-6. The estimate of recharge along the northernmost reach of Fortymile Wash (Fortymile Canyon reach) has been extrapolated to the north boundary of the SZ site-scale model domain. The length and width of the Fortymile Canyon reach within the Savard study and within the SZ site-scale model domains were estimated graphically from Figure 6-6. The estimate of recharge along the Upper Jackass Flats reach presented by Savard is anomalously low relative to the other reaches as estimated in the same report (see Savard (1998 [DIRS 102213]) for a full explanation and discussion of this discrepancy). Consequently, an interpolated value of recharge for the Upper Jackass Flats reach is applied. The volumetric groundwater recharge rates per kilometer of reach are weighted and averaged for both the Fortymile Canyon reach and the Lower Jackass Flats reach, and this value is applied to the Upper Jackass Flats reach. Specifically, the upper $1.62 \mathrm{~km}$ of Upper Jackass Flats was assigned recharge equal to that in Fortymile Canyon, and the lower $8.48 \mathrm{~km}$ was assigned recharge equal to that in Lower Jackass Flats. These two numbers were weighted by the entire length of Upper Jackass Flats as follows:

$$
\begin{aligned}
& \frac{L_{\text {Upper Jackass Flats w/ recharge }=\text { Fortymile Canyon }}}{L_{\text {Upper Jackass Flats }}} \times R_{\text {Fortymile Canyon }}+ \\
& \frac{L_{\text {Upper Jackass Flats w/ recharge }=\text { Lower Jackass Flats }}}{L_{\text {Upper Jackass Flats }}} \times R_{\text {Lower Jackass Flats }}= \\
& \frac{1.62 \mathrm{~km}}{10.1 \mathrm{~km}} 5.77 \mathrm{~mm} / \mathrm{yr}+\frac{8.48 \mathrm{~km}}{10.1 \mathrm{~km}} 1.53 \mathrm{~mm} / \mathrm{yr}=2.21 \mathrm{~mm} / \mathrm{yr} .
\end{aligned}
$$

The value of $1.62 \mathrm{~km}$ is derived from a graphical and geographic interpretation of the portion of Upper Jackass Flats likely to have recharge equal to Fortymile Canyon. The recharge rate along the Amargosa Desert reach is scaled in proportion to the length of this reach within the SZ site-scale model areas. The resulting estimates of the recharge rates are summarized in Table 6-3. 


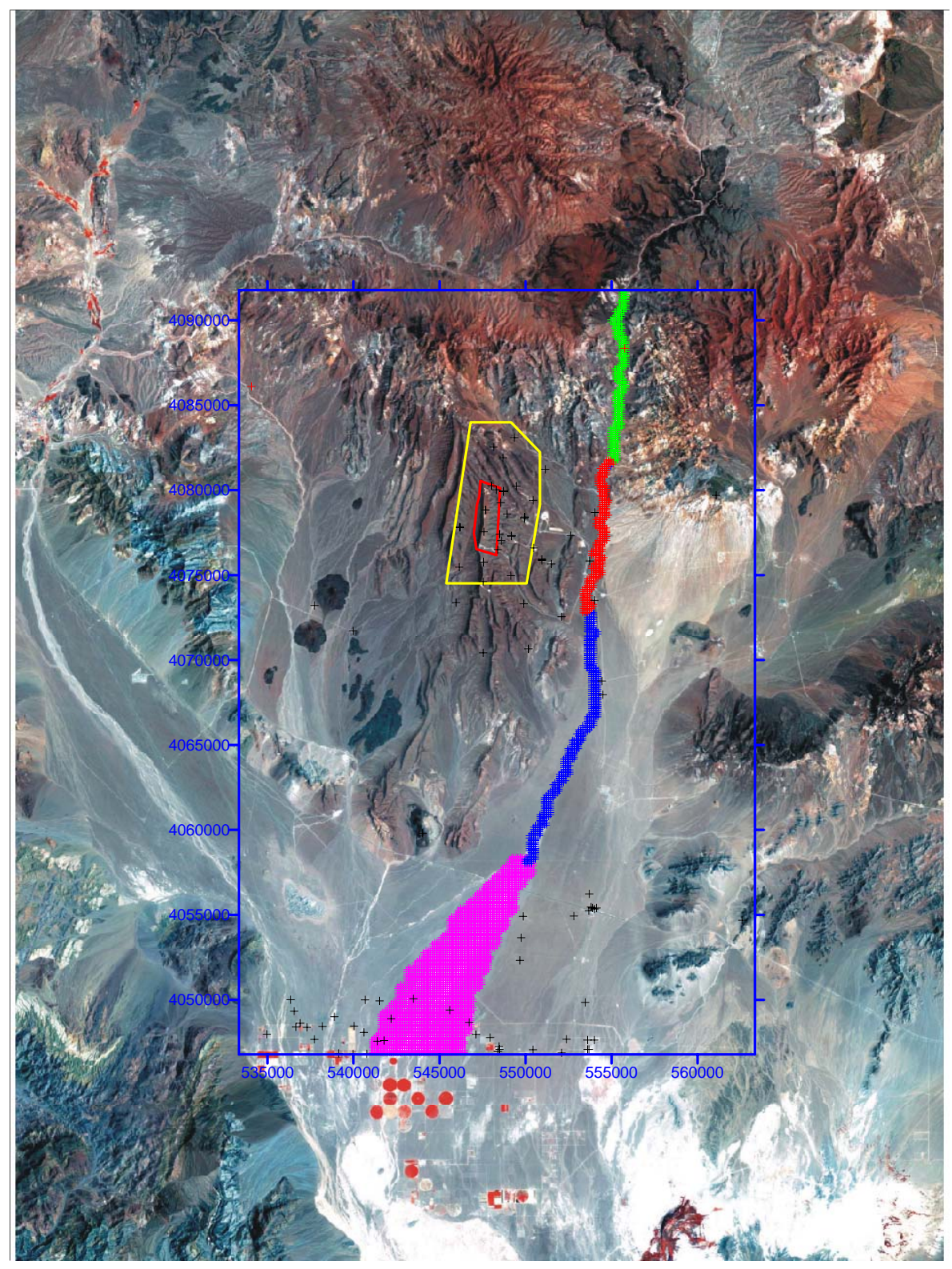

NOTE: The base image of the figure is a false-color satellite photo of the Yucca Mountain area. The four reaches of Fortymile Wash are shown by the different colors overlying the wash: green - Fortymile Canyon, red - Upper Jackass Flats, blue - Lower Jackass Flats, pink - Amargosa Desert (DTN: MO0102DQRGWREC.001 [DIRS 155523]). The blue line delineates boundaries of the SZ site-scale model with UTM coordinates (m) listed. The approximate outline of the repository is shown with the red line and the outline of the UZ site-scale flow model is shown with the yellow line. Black symbols indicate borehole locations.

Figure 6-6. Map of Recharge along the Fortymile Wash Stream Channel 
Recharge and Lateral Groundwater Flow Boundary Conditions for the Saturated Zone Site-Scale Flow and Transport Model

Table 6-3. Fortymile Wash Recharge Estimates

\begin{tabular}{|c|c|c|c|c|c|}
\hline $\begin{array}{c}\text { Fortymile } \\
\text { Wash Reach }\end{array}$ & $\begin{array}{c}\text { Reach Length }^{\mathrm{a}} \\
(\mathrm{km})\end{array}$ & $\begin{array}{l}\text { Estimated } \\
\text { Recharge }^{\text {bechar }} \\
\text { ( }^{3} / \text { lyear) }\end{array}$ & $\begin{array}{c}\text { Reach Length } \\
\text { in SZ } \\
\text { Site-Scale } \\
\text { Model (km) } \\
\end{array}$ & $\begin{array}{c}\text { Estimated } \\
\text { Recharge in SZ } \\
\text { Site-Scale } \\
\text { Model Area } \\
\left(\mathrm{m}^{3} / \text { lyear }\right) \\
\end{array}$ & $\begin{array}{c}\text { Estimated } \\
\text { Recharge } \\
\text { Flux } \\
\text { (mm/year) }\end{array}$ \\
\hline $\begin{array}{l}\text { Fortymile } \\
\text { Canyon }\end{array}$ & 6.50 & 27,000 & 9.50 & $39,500^{c}$ & 5.77 \\
\hline $\begin{array}{l}\text { Upper Jackass } \\
\text { Flats }\end{array}$ & 10.1 & $13,600^{d}$ & 10.1 & 13,600 & 2.21 \\
\hline $\begin{array}{l}\text { Lower Jackass } \\
\text { Flats }\end{array}$ & 16.8 & 16,400 & 16.8 & 16,400 & 1.53 \\
\hline $\begin{array}{l}\text { Amargosa } \\
\text { Desert }\end{array}$ & 25.0 & 64,300 & 10.0 & $25,700^{c}$ & 0.22 \\
\hline
\end{tabular}

${ }^{a}$ Source: Savard 1998 [DIRS 102213].

bSource: DTN: MO0102DQRGWREC.001 [DIRS 155523].

${ }^{\mathrm{c}} \mathrm{S}$ caled in proportion to length within the SZ site-scale model area.

dInterpolated value.

The first step of the analysis is to identify those nodes that correspond to the Fortymile Wash channel for each of the reaches on a 500-m grid, as shown in Figure 6-6. Along most of the length of the Fortymile Wash channel, nodes within an approximately 500-m wide zone are designated to receive recharge from the wash. The nodes corresponding to a broad area of distributary channels in the Amargosa Desert are identified for the southernmost reach within the area of the SZ site-scale model domain. For the base-case SZ site-scale model domain (southwest corner at $\mathrm{X}, \mathrm{Y}=533,340,4,046,780$ ), there are 317 nodes in the Fortymile Canyon reach, 304 nodes in the Upper Jackass Flats reach, 499 nodes in the Lower Jackass Flats reach, and 2,880 nodes in the Amargosa Desert reach (from file rech_distr_stream_1997.dat in DTN: SN0407T0504404.002). This yields a net flux of $1.93 \mathrm{~kg} / \mathrm{s}$ through Fortymile Wash.

In the previous version of this analysis report, the first step was to identify nodes that correspond to the Fortymile Wash channel for each of the reaches on a 125-m resolution grid. This is different from the 500-m resolution grid used in the preceding analysis. The 125-m grid resolution was not used in this analysis because the base-case SZ site-scale flow model uses a $500-\mathrm{m}$ grid resolution and at the time the $125-\mathrm{m}$ grid was originally used, the cell dimensions of the base-case SZ site-scale flow model were undetermined. The same base-case SZ site-scale flow model is used with southwest corner at $\mathrm{X}, \mathrm{Y}=533,340,4,046,780$. The results are 438 nodes in the Fortymile Canyon reach, 394 nodes in the Upper Jackass Flats reach, 687 nodes in the Lower Jackass Flats reach, and 7,544 nodes in the Amargosa Desert reach. This yielded a net flux of $3.00 \mathrm{~kg} / \mathrm{s}$ through Fortymile Wash. These data are contained in file rech_distr_stream.dat in DTN: SN9908T0581999.001.

Because of the translation of the alternate SZ site-scale flow model domain (southwest corner at $\mathrm{X}, \mathrm{Y}=533,000,4,046,500$ ), there are 327 nodes in the Fortymile Canyon reach, 315 nodes in the Upper Jackass Flats reach, 485 nodes in the Lower Jackass Flats reach, and 2,952 nodes in the Amargosa Desert reach (from file rech_distr_stream_2001.dat in DTN: SN0407T0504404.002). A grid spacing of $500 \mathrm{~m}$ was used for this analysis. This yields a net recharge of $1.97 \mathrm{~kg} / \mathrm{s}$ through Fortymile Wash. 
Data processing is performed with the routine, Xread_Reaches (STN: 10962-1.0-00 [DIRS 163076]). This routine reads in the file, digit.dat, which contains a set of digitized points defining the stream channel location for the four reaches of Fortymile Wash within the SZ site-scale model domains and the recharge rates for those reaches as tabulated in Table 6-2. The file, digit.dat, was generated using the digitize function in Surfer from Figure 6-6. The routine also reads in files rech_distr_xxxx.dat (where $x x x x$ is a place holder for the years 1997 or 2001), which contain the values of distributed recharge within the SZ site-scale model domain, as described in Sections 6.2.1.1 and 6.2.1.2. The routine, Xread_Reaches (STN: 10962-1.0-00 [DIRS 163076]), combines the estimates of distributed recharge from the 1997 or 2001 DVRFS model and the estimates of focused recharge, and outputs the file, rech_distr_stream_xxxx.dat. This file contains location coordinates (UTM m) and recharge (millimeters per year) on a 125-m grid for all locations with nonzero values of recharge. Note that the $125-\mathrm{m}$ grid was generated anticipating that the SZ site-scale flow model might be refined to this level. Such discretization has little impact on this analysis report, which has results upscaled to a 500-m grid. Where 1997 or 2001 DVRFS model recharge overlaps with focused recharge from Fortymile Wash, only the recharge from Fortymile Wash is used. The file, rech_distr_stream_xxxx.dat, also excludes grid locations within the areas of the UZ site-scale flow models.

\subsubsection{Combined Recharge Model}

\subsubsection{1997 DVRFS Model, 1997 UZ Site-Scale Flow Model, and Fortymile Wash}

The estimates of distributed recharge and focused recharge that are contained in the file, rech_distr_stream_1997.dat, are combined with the simulated recharge at the water table boundary of the 1997 UZ site-scale flow model contained in file, wt_flux_uz.xls, in an Excel spreadsheet. The combined recharge is in the file, rech_all_new.xls, under worksheet 1997. In the rech_all_new.xls spreadsheet (worksheet 1997), the groundwater mass flux (kilograms per second) into each grid node is calculated (units of mass flux are required by finite element heat and mass transfer code [FEHM]). The first 1,470 entries in the spreadsheet are for the output of the 1997 UZ site-scale flow model and the remaining entries are for the distributed recharge and focused recharge components of the analysis. The result of the combined estimates is mapped in Figure 6-7.

These results are reformatted for input to the FEHM code (V2.21, STN: 10086-2.21-00) using

the routine, Xwrite_Flow_New (STN: 10963-1.0-125-00 [DIRS 163077]). The Xwrite_Flow_New routine reads in the data in the rech_all_new.xls spreadsheet (saved in the text file rech_all_new_1997.prn, which has the header lines removed). The Xwrite_Flow_New (STN: 10963-1.0-125-00 [DIRS 163077]) routine writes output in a format suitable for input to the 'flow' macro of FEHM for specified groundwater mass flux (kg/s). The 500-m resolution of the grid nodes in the output from the Xwrite_Flow_New (STN: 10963-1.0-125-00 [DIRS 163077]) routine is specified as input to the routine. The output is formatted so that grid nodes are numbered sequentially from the southwest corner of the SZ site-scale model domain, moving from west to east and south to north. An output file is generated for 500-m nodal resolutions in the file, wt_flow_500_1997.dat in DTN: SN0407T0504404.002.

For completeness, the recharge extracted from the 1997 DVRFS with zonation neglected and the 125-m grid resolution used to calculate the recharge through Fortymile Wash, which was used to 
Recharge and Lateral Groundwater Flow Boundary Conditions for the Saturated Zone Site-Scale Flow and Transport Model

calibrate the base-case SZ site-scale flow model, is presented in Figure 6-8. The output file generated for 500-m nodal resolutions is in the file, wt_flow_500.dat in DTN: SN9908T0581999.001.

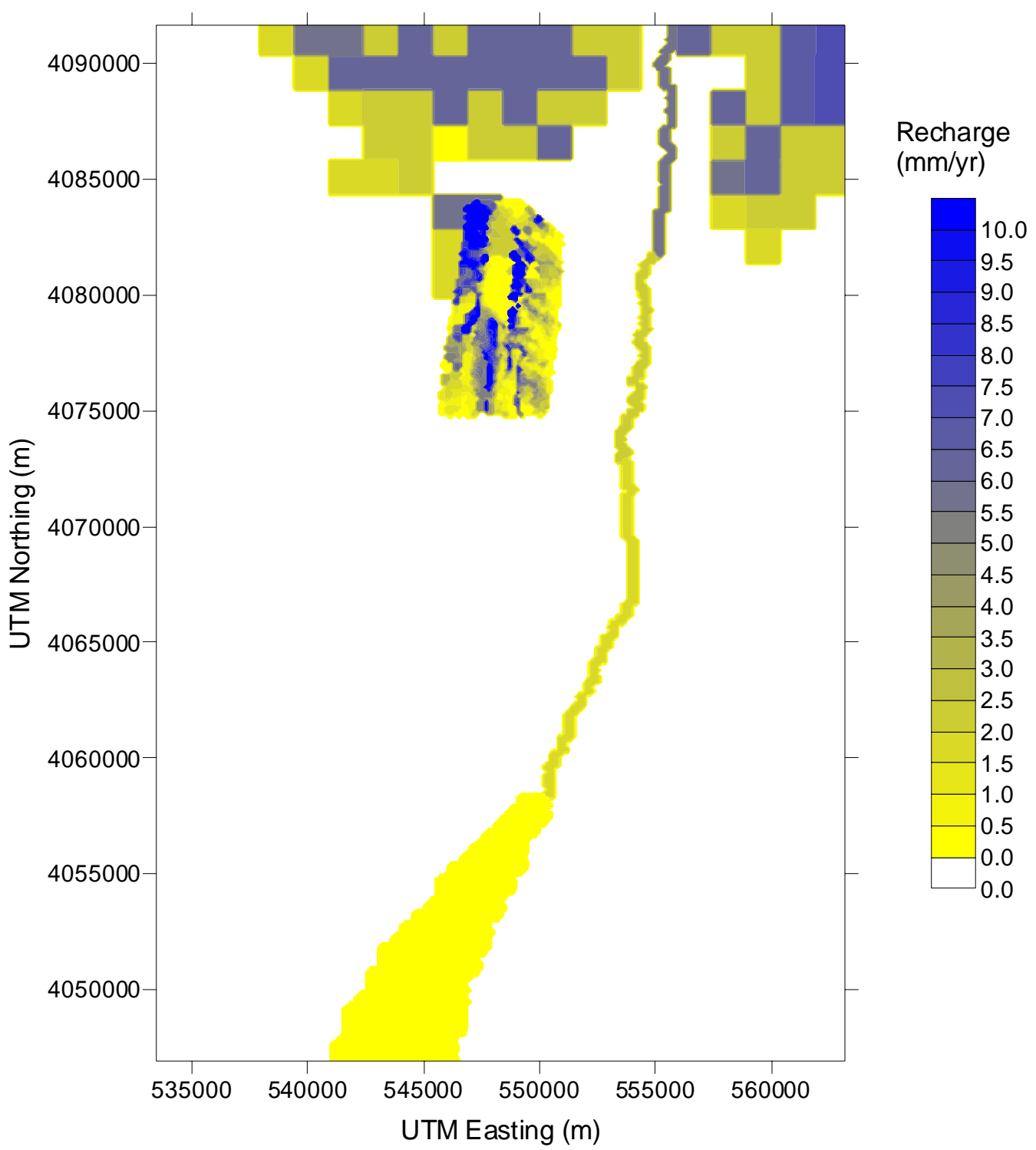

NOTES: Recharge map from the 1997 DVRFS model from output files: aap.fix2, dvparwel14, and rech13fix3.asc (DTN: GS960809312144.003 [DIRS 105121]). Recharge along Fortymile Wash is taken from DTN: MO0102DQRGWREC.001 [DIRS 155523]. Groundwater flux at the water table is from the $1997 \mathrm{UZ}$ site-scale flow model, base case, present climate from output file: mnaqb_p.out (DTN: LB971212001254.001 [DIRS 104749]). This figure shows the correct distributed recharge.

This map combines the components of distributed recharge from the 1997 DVRFS model, recharge below the 1997 UZ site-scale flow model domain, and focused recharge along Fortymile Wash.) Because this map is not distributed on a 500-m grid, it is not direct input to the model.

Figure 6-7. Corrected Detailed Recharge Map to the Base-Case SZ Site-Scale Flow Model 
Recharge and Lateral Groundwater Flow Boundary Conditions for the Saturated Zone Site-Scale Flow and Transport Model

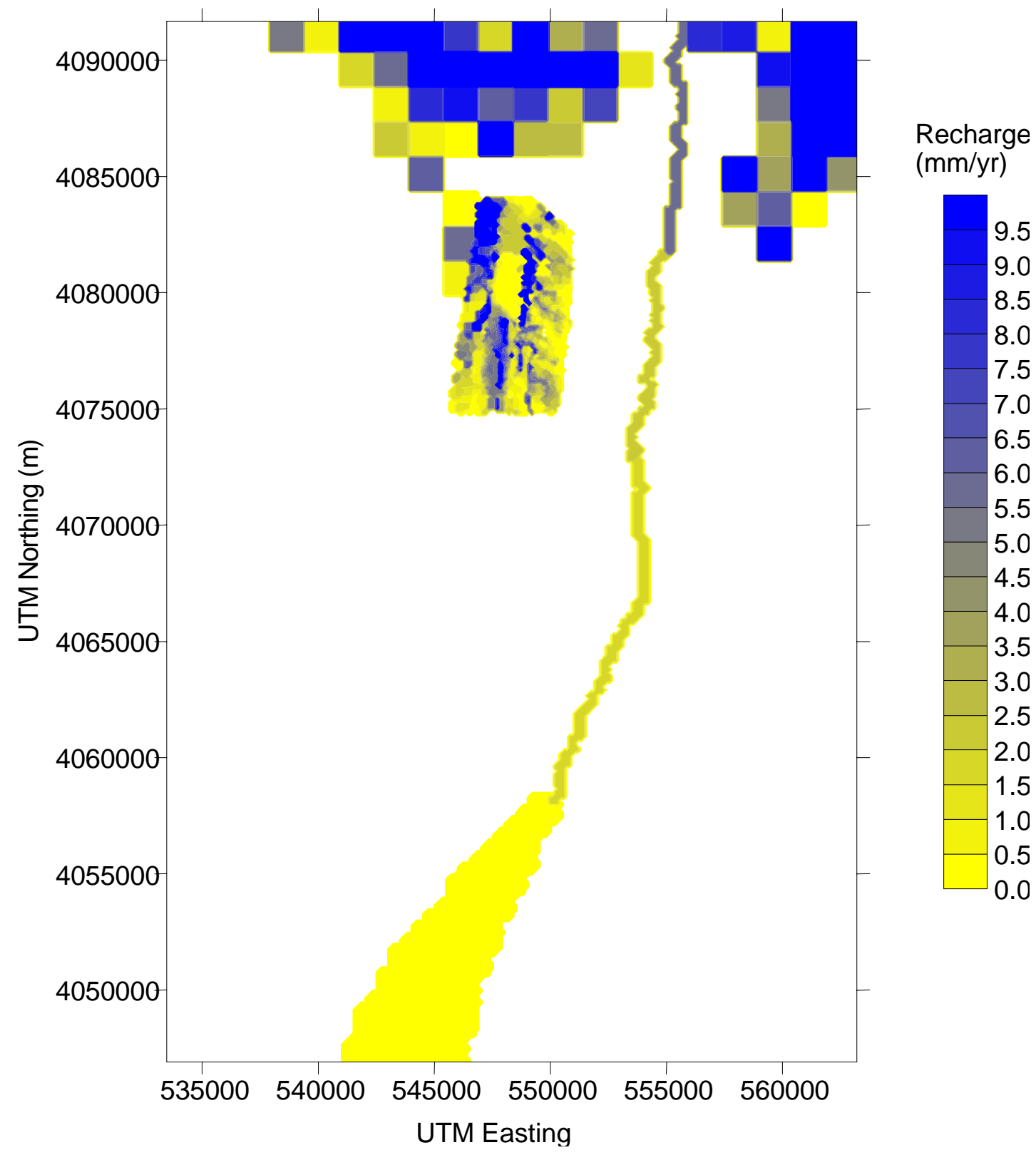

NOTES: Recharge map from the 1997 DVRFS model from output file: aap.fix2 (DTN: GS960809312144.003 [DIRS 105121]). Recharge along Fortymile Wash is taken from DTN: MO0102DQRGWREC.001 [DIRS 155523] with a 125-m grid resolution. Groundwater flux at the water table is from the 1997 UZ site-scale flow model, base case, present climate from output file: mnaqb p.out (DTN: LB971212001254.001 [DIRS 104749]). This figure shows the incorrect distributed recharge. See Figure 6-10 for the 500-m resolution grid supplied to the base-case SZ site-scale flow model.

This map combines the components of distributed recharge from the 1997 DVRFS model without correcting for zonation, recharge below the $1997 \mathrm{UZ}$ site-scale flow model domain, and focused recharge along Fortymile Wash using 125-m grid resolution.) Because this map is not distributed on a 500-m grid, it is not direct input to the model.

Figure 6-8. Detailed Recharge Map to the Base-Case SZ Site-Scale Flow Model 


\subsubsection{2001 DVRFS Model, 2003 UZ Site-Scale Flow Model, and Fortymile Wash}

Using the same assumptions, techniques, and procedures described in the preceding section, patterns of distributed recharge were extracted from the $2003 \mathrm{UZ}$ site-scale flow model (data were retrieved from DTN: LB03023DSSCP9I.001 [DIRS: 163044]). It should be noted that the numerical grid has been updated in the 2003 UZ site-scale flow model, thus the first 2,042 entries in the spreadsheet are output from this model. In addition, the 2001 DVRFS model was developed using MODFLOW-2000, while the 1997 model used MODFLOWP (V 2.3 STN: 10144-2.3-00 [DIRS 150454]). Output is stored in the 2003 worksheets of the wt_flux_uz.xls and rech_all_new.xls spreadsheets and rech_all_new_2003.prn. Figure 6-9 shows the distributed recharge from the three different sources on a $125-\mathrm{m}$ grid, which should be compared to Figure 6-7. Output for 500-m nodal resolution is in the file, wt_flow_500_2003.dat in DTN: SN0407T0504404.002.

\subsection{METHODS FOR EXTRACTING LATERAL BOUNDARY FLUXES FROM DVRFS MODELS}

\subsubsection{DVRFS Model}

The TDMS contains input files in DTN: GS960808312144.003 [DIRS 105121]. MODFLOWP is maintained in Software Configuration Management (SCM) (STN: 10144-2.3-00 [DIRS 150454]). It is assumed that minor modification of the input files as discussed below (e.g., changing file reference names), does not alter the calculated flow terms. The basis of this assumption is that the authors of the 1997 DVRFS model provided the executable file for MODFLOWP (V 2.3 STN: 10144-2.3-00 [DIRS 150454]) to allow generation of the output files from the input files contained therein.

The 1997 DVRFS states that the density of water is constant, but does not specify a specific value. A value of $1,000 \mathrm{~kg} / \mathrm{m}^{3}$ is used for fluid density in this analysis to convert from volumetric flows (cubic meters per day) to mass flows (kilograms per second) by dividing by 86.4. The mass flow rates presented by this analysis could be easily modified to represent an alternative value for fluid density; however, density changes due to salinity or temperature variation would only be on the order of a few percent at most. This is well within the uncertainty of the distributed recharge and lateral fluxes that were determined in this analysis, as modeled by the DVRFS and UZ site-scale flow models.

Flux extraction from the 1997 DVRFS model is performed in three steps. Because the TDMS does not include output files from the 1997 DVRFS model, the first step is to re-run the model to generate an unformatted output file containing cell-by-cell flow values. Secondly, a FORTRAN routine is used to read the unformatted file and write selected values to formatted files. Finally, an Excel spreadsheet is used to sum the flow terms for selected segments along the site-scale boundaries and to convert from volumetric to mass flow rates. 
Recharge and Lateral Groundwater Flow Boundary Conditions for the Saturated Zone Site-Scale Flow and Transport Model

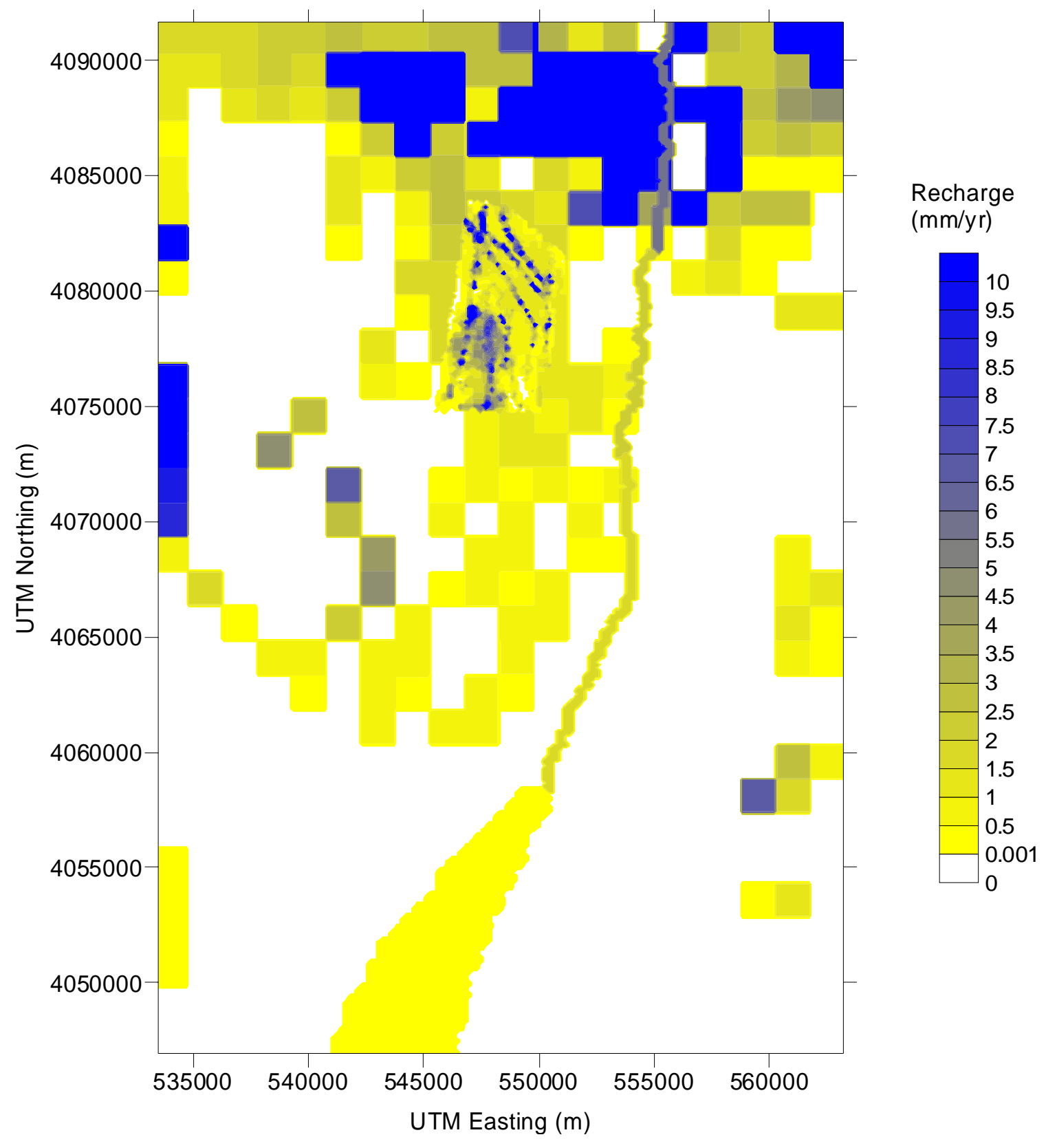

NOTES: Recharge map from the 2001 DVRFS model from output files listed in Table 4-2 (DTN: GS040308312144.001 [DIRS 171472]). Recharge along Fortymile Wash is taken from DTN: MO0102DQRGWREC.001 [DIRS 155523]. Groundwater flux at the water table is from the $2003 \mathrm{UZ}$ site-scale flow model with base case, present climate from output file: flow9.dat_preq_mA.dat (DTN: LB03023DSSCP9I.001 [DIRS 163044]). (Because this map is not distributed on a 500-m grid, it is not direct input to the model.) See Figure 6-12 for the 500-m resolution grid supplied to the alternate SZ site-scale flow model.

This map combines the components of distributed recharge from the 2001 DVRFS model, recharge below the 2003 UZ site-scale flow model domain, and focused recharge along Fortymile Wash).

Figure 6-9. Detailed Recharge Map to the Alternate SZ Site-Scale Flow Model 
Running the regional model requires three steps:

1. The 1997 DVRFS model results are calculated using the MODFLOWP (V 2.3, STN: 10144-2.3-00 [DIRS 150454]) computer code. An executable file, MODFLOWP, was obtained from the Software Configuration Management System and a set of input files are obtained from the TDMS (DTN: GS960808312144.003 [DIRS 105121]) and copied to a Sun workstation (Solaris 7).

2. The input files for the 1997 DVRFS model in the TDMS are set up to calculate certain statistics, but the input files required for these statistics (BEALE.DAT and BEALE2.DAT) are not present. Because these statistics are not required for this analysis, two changes are made to the input files to allow MODFLOWP (V 2.3 STN: 10144-2.3-00 [DIRS 150454]) to run without these files. First, in the input file, dvparwel14, the fifth entry of line 7 (in columns 24 and 25) is changed from 72 to 0 . This is a flag that tells MODFLOWP (V 2.3 STN: 10144-2.3-00 [DIRS 150454]) not to calculate the statistics that require BEALE.DAT and BEALE2.DAT. Second, the lines containing the file names, BEALE.DAT and $B E A L E 2 . D A T$, are deleted from the input file, Files. This file contains file names and their corresponding logical unit numbers. Deleting these file names from Files prevents MODFLOWP (V 2.3 STN: 10144-2.3-00 [DIRS 150454]) from trying to open files that are not present.

3. The executable (MODFLOWP) is then run. The output file which is used in this analysis is the cbcf.new file, which contains cell-by-cell flow terms, which are extracted along the boundaries of the base-case SZ site-scale model domain, the coordinates of which are:

$$
\begin{aligned}
& x_{\min }=533,340 \mathrm{~m} \mathrm{E} \\
& x_{\text {max }}=563,340 \mathrm{~m} \mathrm{E} \\
& y_{\text {min }}=4,046,780 \mathrm{~m} \mathrm{~N} \\
& y_{\text {max }}=4,091,780 \mathrm{~m} \mathrm{~N}
\end{aligned}
$$

The regional model is 163 rows by 153 columns by 3 layers (74,817 cells) with the southwest corner at $X, Y=(440,340,3,944,782)$ (D'Agnese et al. 1997 [DIRS 100131], p. 75). Row 1 is to the north. Column 1 is to the west. Each model cell is $1,500 \times 1,500 \mathrm{~m}^{2}$ in the longitudinal directions. Then,

the $x$ coordinates at the east face of column $62=440,340+(62)(1,500)=533,340$ the $x$ coordinates at the east face of column $82=440,340+(82)(1,500)=563,340$ the $y$ coordinates at the south face of row $95=3,944,782+(163-95)(1,500)=4,046,782$ the $y$ coordinates at the south face of row $65=3,944,782+(163-65)(1,500)=4,091,782$

Thus, the domain outlined by the east faces of columns 62 and 82, and the south faces of rows 65 and 95 of the regional model form a domain that is shifted $2 \mathrm{~m}$ north of the base-case SZ site-scale model domain. The west boundary of the base-case SZ site-scale model consists of the east face of column 62 for rows 66-95. The east boundary consists of the east face of column 82 for rows 66-95. The north boundary consists of the south face of row 65 for columns 63-82. The south boundary consists of the south face of row 95 for columns 63-82. 
The routine, Extract (V1.0 STN: 10955-1.0-00 [DIRS 163070]), was used to extract and write the cell-by-cell flow terms along the boundaries. This routine writes the flow terms along each boundary to a separate file. The files are named west_bdy1997, east_bdy1997, north_bdy1997, and south_bdy1997. Details of the routine are given in comment statements in the source code of the routine.

These files were entered into an Excel workbook (boundaries.xls). Excel is used for two calculations: to sum flow terms for segments along the site model boundaries, and to convert the volumetric flows $\left(\mathrm{m}^{3} / \mathrm{day}\right)$ to mass flows $(\mathrm{kg} / \mathrm{s})$. The segments are selected to group fluxes of similar direction and magnitude.

\subsubsection{DVRFS Model}

Using the same assumptions, techniques, and procedures described in the preceding section, patterns of distributed recharge were extracted from the 2001 DVRFS model. Input and output model data were retrieved from DTN: GS040308312144.001 [DIRS 171472]). It should be noted that the 2001 DVRFS model was developed for MODFLOW-2000 and therefore has different input and output files. Recall that the 1997 DVRFS model was constructed for MODFLOWP (V 2.3 STN: 10144-2.3-00 [DIRS 150454]). The cell-to-cell flux file, CBCF.asc, was retrieved from DTN: GS040308312144.001 [DIRS 171472]). It is a text rather than binary file, thus Extract (V1.1 STN: 10955-1.1-00 [DIRS 163071]) was used. Outputs are written to the files, west_bdy2001, east_bdy2001, north_bdy2001, and south_bdy2001, and then copied to the spreadsheet that contains the 2001 DVRFS lateral boundary data onto the corresponding worksheets. In this spreadsheet, flow terms are summed for segments with similar properties along the site model boundaries and units are converted from volumetric flows $\left(\mathrm{m}^{3} /\right.$ day) to mass flows (kg/s). The segments (different from the 1997 DVRFS segments) are selected to group fluxes of similar direction and magnitude. These segments are explicitly defined in Sections 6.5.1 and 6.5.2.

The coordinates of an alternate conceptual SZ site-scale model domain are:

$$
\begin{aligned}
& x_{\min }=533,000 \mathrm{~m} \mathrm{E} \\
& x_{\max }=563,000 \mathrm{~m} \mathrm{E} \\
& y_{\min }=4,046,500 \mathrm{~m} \mathrm{~N} \\
& y_{\max }=4,091,500 \mathrm{~m} \mathrm{~N}
\end{aligned}
$$

The 2001 DVRFS model consists of 194 rows by 160 columns by 15 layers. The 465,600-cell model is oriented exactly north-south. The lower left-corner origin of the grid is located at UTM coordinates $(X, Y=437,000,3,928,000)$. Grid discretization along both rows and columns was set to 1,500 m (D’Agnese et al. 2002 [DIRS 158876], p. 47). Row 1 is to the north. Column 1 is to the west. Then,

the $x$ coordinates at the east face of column $64=437,000+(64)(1,500)=533,000$ the $x$ coordinates at the east face of column $84=437,000+(84)(1,500)=563,000$ the $y$ coordinates at the south face of row $115=3,928,000+(194-115)(1,500)=4,046,500$ the $y$ coordinates at the south face of row $85=3,928,000+(194-85)(1,500)=4,091,500$

Thus, the domain outlined by the east faces of columns 64 and 84, and the south faces of rows 85 and 115 of the regional model form the alternate SZ site-scale model domain. The west 
boundary of this site-scale model consists of the east face of column 64 for rows $86-115$. The east boundary consists of the east face of column 84 for rows 86-115. The north boundary consists of the south face of row 85 for columns $65-84$. The south boundary consists of the south face of row 115 for columns 65-84. The flowchart in Figure 6-2 describes the steps necessary to extract distributed recharge and lateral boundary fluxes. It should be noted that the alternate SZ site-scale flow model domain is translated $340 \mathrm{~m}$ west and $280 \mathrm{~m}$ south in comparison to the base-case version of this model. Because this translation is less than one grid cell in either direction, it has no impact on the boundary conditions derived in this report or in interpretation of model results.

\subsection{DISTRIBUTED RECHARGE}

\subsubsection{DVRFS Model and 1997 UZ Site-Scale Flow Model}

The results of the combined estimates of recharge rate from distributed recharge on a $500 \times 500 \mathrm{~m}^{2}$ grid from the 1997 DVRFS model (D'Agnese et al. (1997 [DIRS 100131]), recharge in the area of the 1997 UZ site-scale flow model (DTN: LB971212001254.001 [DIRS 104749]), and focused recharge along Fortymile Wash (DTN: MO0102DQRGWREC.001 [DIRS 155523]) are shown graphically in Figure 6-10 and presented in output DTN: SN0407T0504404.002. Because the zones in the 1997 DVRFS model were overlooked in the previous version of this Scientific Analysis Report, there are differences between output DTNs: SN9908T0581999.001 and SN0407T0504404.002. However, these changes have no significant impact in the calibration or flow paths of the base-case SZ site-scale model that affect the performance of the SZ barrier (see Section 6.7). The majority of the recharge entering the base-case SZ site-scale flow model occurs in the northern part of the model domain. An estimated rate of $24.4 \mathrm{~kg} / \mathrm{s}\left(7.70 \times 10^{5} \mathrm{~m}^{3} /\right.$ year $)$ of groundwater enters the saturated-zone system as recharge in the base-case SZ site-scale model area. Of this rate, about $6.70 \mathrm{~kg} / \mathrm{s}$ $\left(2.11 \times 10^{5} \mathrm{~m}^{3} /\right.$ year$)$ occurs in the area of the $1997 \mathrm{UZ}$ site-scale flow model and about $1.93 \mathrm{~kg} / \mathrm{s}$ $\left(6.09 \times 10^{4} \mathrm{~m}^{3} /\right.$ year$)$ is a result of focused recharge along Fortymile Wash.

For completeness, the recharge extracted from the 1997 DVRFS with zonation neglected, which was used in the base-case SZ site-scale flow model, is presented in Figure 6-11. An estimated rate of $48.9 \mathrm{~kg} / \mathrm{s}\left(1.54 \times 10^{6} \mathrm{~m}^{3} /\right.$ year $)$ of groundwater enters the system as recharge in the base-case SZ site-scale model area. Of this rate, about $6.70 \mathrm{~kg} / \mathrm{s}\left(2.11 \times 10^{5} \mathrm{~m}^{3} /\right.$ year $)$ occurs in the area of the 1997 UZ site-scale flow model and about $3.00 \mathrm{~kg} / \mathrm{s}\left(9.47 \times 10^{4} \mathrm{~m}^{3} /\right.$ year $)$ is a result of focused recharge along Fortymile Wash. These values were used when calibrating the base-case SZ site-scale flow model.

\subsubsection{DVRFS Model and 2003 UZ Site-Scale Flow Model}

The results of the combined estimates of recharge from distributed recharge on a $500 \times 500 \mathrm{~m}^{2}$ grid from the 2001 DVRFS model (DTN: GS040308312144.001 [DIRS 171472]), recharge in the area of the 2003 UZ site-scale flow model (LB03023DSSCP9I.001 [DIRS: 163044]), and focused recharge along Fortymile Wash (DTN: MO0102DQRGWREC.001 [DIRS 155523]), are shown graphically in Figure 6-12 and presented in output DTN: SN0407T0504404.002. The majority of the recharge entering the system in the area of the alternate SZ site-scale flow model occurs in the northern part of the model domain. An estimated rate of $77.3 \mathrm{~kg} / \mathrm{s}$ 
$\left(2.44 \times 10^{6} \mathrm{~m}^{3} /\right.$ year$)$ of groundwater enters the system as recharge in the alternate SZ site-scale model domain. Of this rate, about $5.58 \mathrm{~kg} / \mathrm{s}\left(1.76 \times 10^{5} \mathrm{~m}^{3} /\right.$ year $)$ occurs in the area of the UZ site-scale flow model, and about $1.97 \mathrm{~kg} / \mathrm{s}\left(6.22 \times 10^{4} \mathrm{~m}^{3} /\right.$ year $)$ is a result of focused recharge along Fortymile Wash.

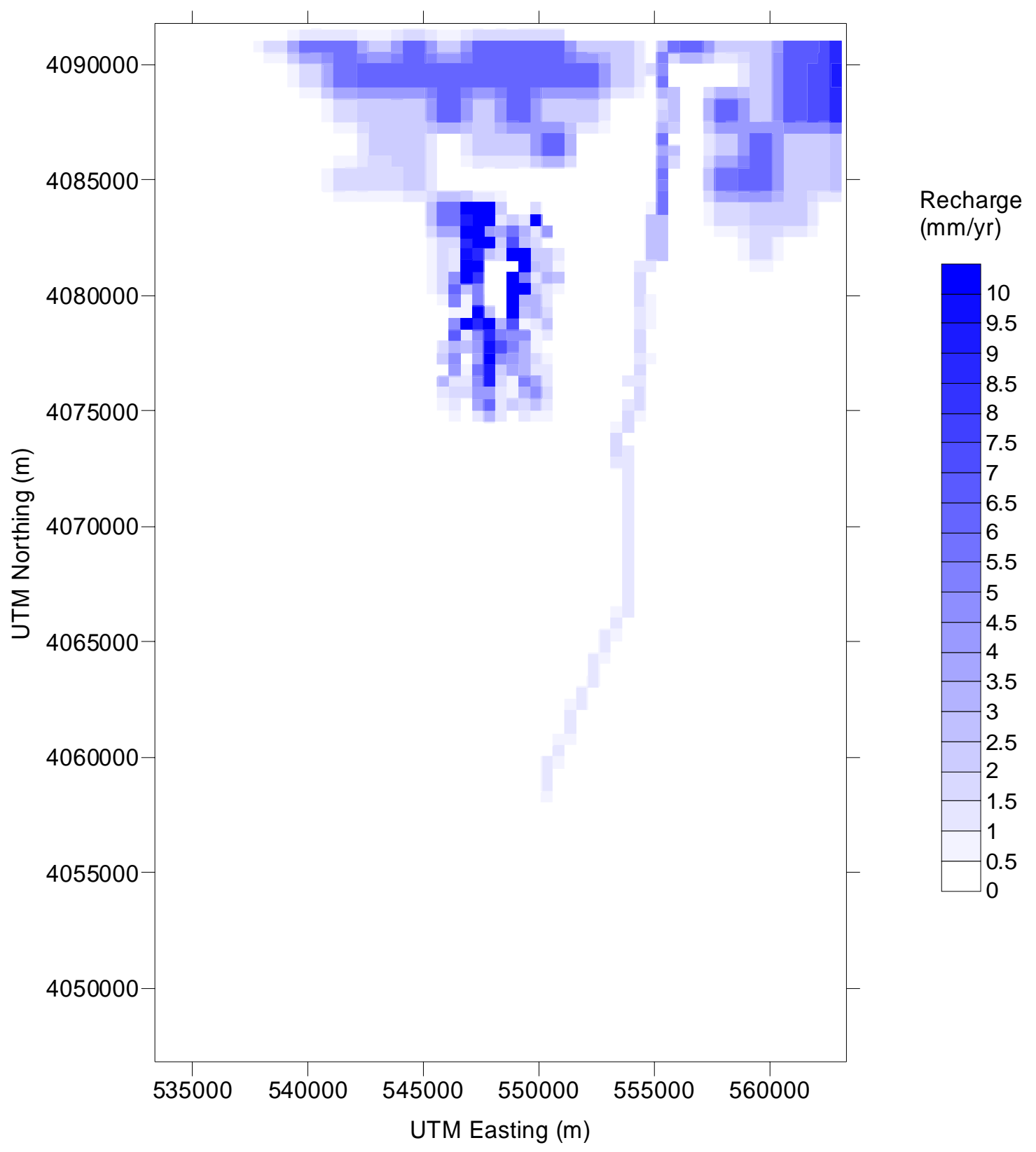

Output DTN: SN0407T0504404.002.

Figure 6-10. Correct Recharge for the Base-Case SZ Site-Scale Flow Model, which were not used in model calibration, on a 500-m Grid from the 1997 DVRFS, 1997 UZ Site-Scale Flow Model, and Fortymile Wash 


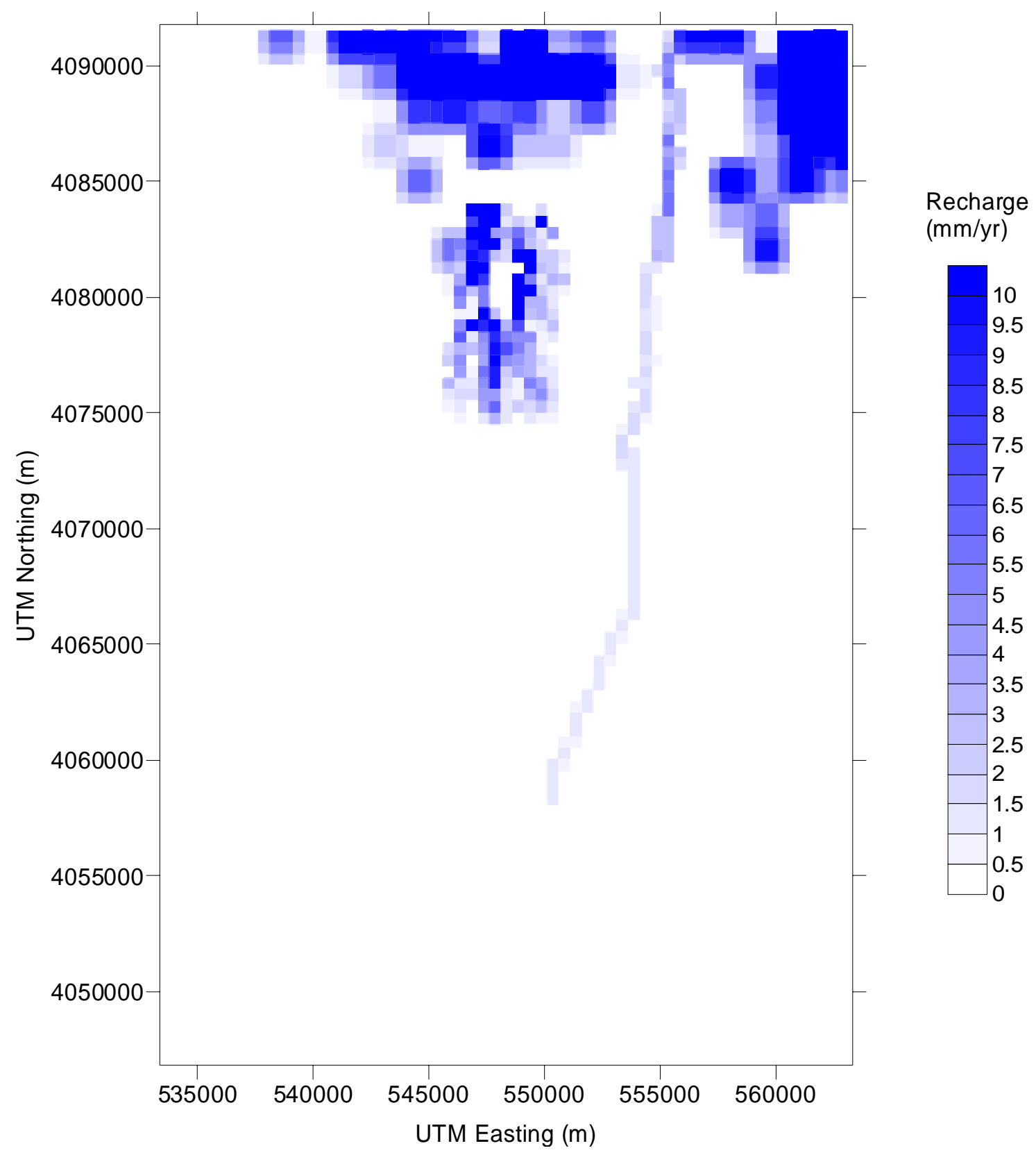

Output DTN: SN9908T0581999.001.

Figure 6-11. Recharge Used to Calibrate the Base-Case SZ Site-Scale Flow Model on a 500-m Grid from the 1997 DVRFS, 1997 UZ Site-Scale Flow Model, and Fortymile Wash

\subsubsection{Differences in Distributed Recharge between 1997 and 2001 DVRFS Models and 1997 and 2003 UZ Site-Scale Flow Models}

Table 6-4 compares the distributed recharges of the 1997 DVRFS and 1997 UZ site-scale models and Fortymile Wash, to the distributed recharges of the 2001 DVRFS and the 2003 UZ site-scale flow models and Fortymile Wash. Differences in infiltration through Fortymile Wash are due to the translation of the alternate SZ site-scale flow model with respect to the base-case SZ site-scale flow model (see Section 6.3.2). 


\subsection{LATERAL BOUNDARY FLUXES}

\subsubsection{DVRFS Model}

The cell-by-cell flow terms extracted from the 1997 DVRFS model (using qualified codes) are given in Tables 6-5 to 6-8 and presented in file, boundaries.xls, in output DTN: SN0407T0504404.002. Note that results are identical to those presented in DTN: SN9908T0581999.001 (compare Tables A-1 and 6-5, Tables A-2 and 6-6, Tables A-3 and 6-7, and Tables A-4 and 6-8).

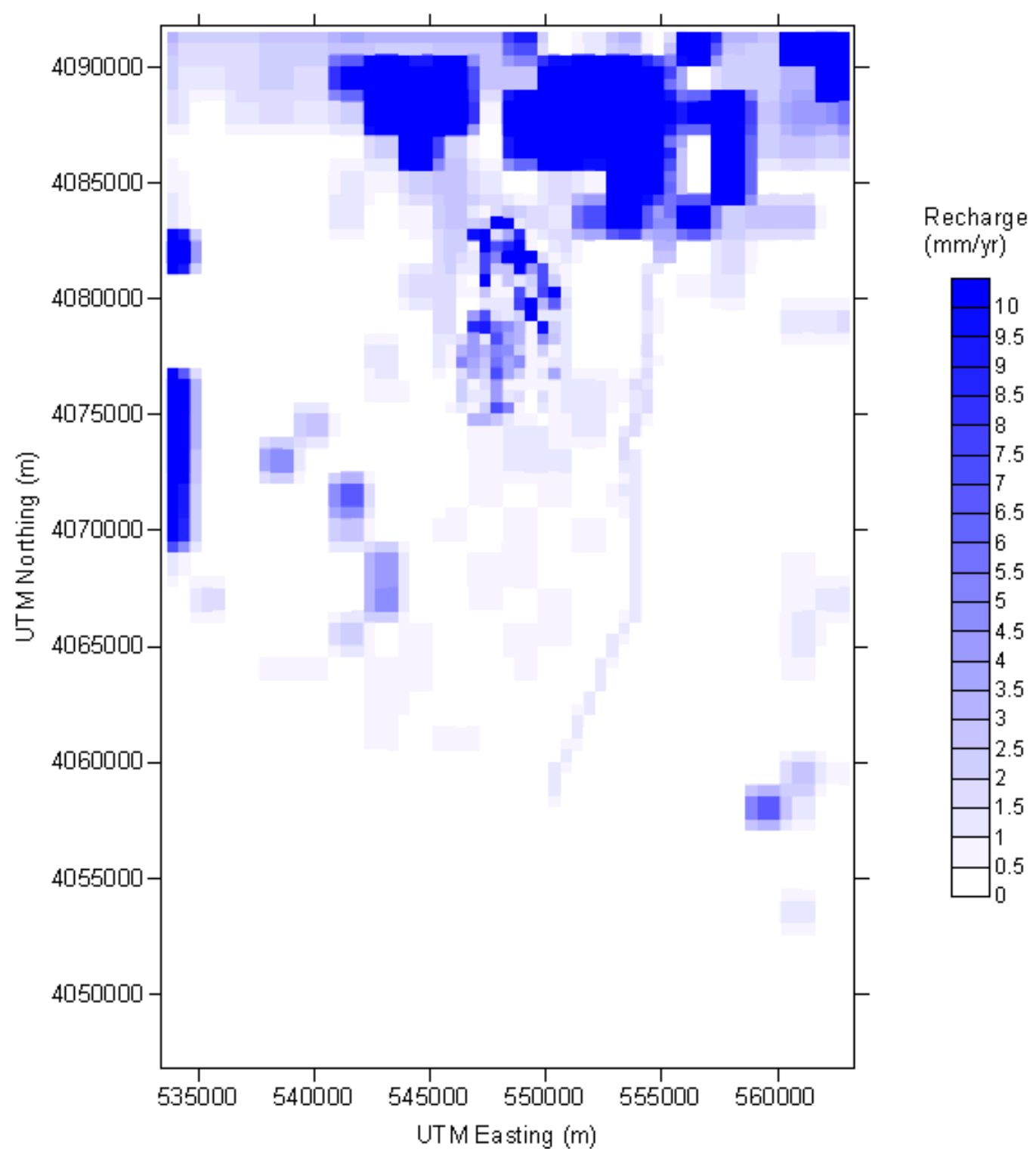

Output DTN: SN0407T0504404.002.

Figure 6-12. Recharge for the Alternate SZ Site-Scale Flow Model on a 500-m Grid from the 2001 DVRFS, 2003 UZ Site-Scale Flow Model, and Fortymile Wash 
Recharge and Lateral Groundwater Flow Boundary Conditions for the Saturated Zone Site-Scale Flow and Transport Model

Table 6-4. Comparison of Distributed Recharges between Different Model Simulations

\begin{tabular}{|c|c|c|c|}
\hline Models & $\begin{array}{c}\text { Fortymile Wash } \\
\mathbf{( k g / s )}\end{array}$ & $\begin{array}{c}\text { DVRFS model } \\
\mathbf{( k g / s )}\end{array}$ & $\begin{array}{c}\text { Uz site-scale flow model } \\
\mathbf{( k g / s )}\end{array}$ \\
\hline $1997^{\mathrm{a}}$ & 1.93 & 18.9 & 6.70 \\
\hline $1997^{\mathrm{b}}$ & $3.00^{\mathrm{C}}$ & $48.9^{\mathrm{d}}$ & 6.70 \\
\hline $2001 / 2003^{\mathrm{a}}$ & $1.97^{\mathrm{e}}$ & 74.3 & 5.58 \\
\hline
\end{tabular}

aDTN: SN0407T0504404.002.

bDTN: SN9908T0581999.001.

'Output from 1997 DVRFS using 125-m grid resolution (see Section 6.2.3).

${ }^{\mathrm{d}}$ Output from 1997 DVRFS without taking zonation into account (see Section 6.2.1.1).

${ }^{\mathrm{e}}$ The difference between $1997^{\mathrm{a}}$ and $2001 / 2003^{\mathrm{a}}$ models is due to translation of SZ site-scale model domain (see Section 6.2.3).

One important feature must be pointed out. Summing the lateral and only the 1997 DVRFS distributed recharge fluxes (no UZ or Fortymile Wash data used) does not yield a mass balance. This is because in the 1997 DVRFS there were 25 pumping wells represented in the model that lie within the domain of the base-case SZ site-scale flow model. Thus, the sum of fluxes is $101 \mathrm{~kg} / \mathrm{s}$ too high, an amount equal to that pumped from the 1997 DVRFS model within the base-case SZ site-scale domain. This discrepancy was handled implicitly in the SZ site-scale flow model because flow through the south boundary was allowed to fluctuate to ensure conservation of mass. Lateral flow data developed from the 1997 DVRFS model are found in output DTN: SN0407T0504404.002. These tables contain the flow terms as calculated by MODFLOWP (V 2.3 STN: 10144-2.3-00 [DIRS 150454]) in units of cubic meters per day. The final column of each table is the sum of the terms for the three model layers for each row/column position. Flow terms for the west and east boundaries are for the right (east) cell faces, and terms for the north and south boundaries are for the south (front) faces. Row, column, and layer numbers are those of the 1997 DVRFS model grid.

The total mass fluxes (kg/s) for segments along the west, north, and east site model boundaries follow. These boundaries are used as target boundary conditions in the base-case SZ site-scale flow model. The fluxes are for the boundaries of a region that is shifted $2 \mathrm{~m}$ north relative to the domain of the base-case SZ site-scale model, because the cell faces of the regional and site-scale models did not precisely match. This 2-m shift is assumed to have negligible impact on the interpretation of the lateral boundary conditions because the fluxes change by no more than 0.1 percent over a $2-\mathrm{m}$ distance (across a 1,500-m cell). The coordinates of the boundary segments are in UTM (meters). Fluxes are the total flux for that boundary segment, from the water table to a depth of 2,750 m (i.e., all three layers of the 1997 DVRFS model). A positive value indicates flow into the base-case SZ site-scale model domain.

West Boundary:

$$
\begin{array}{ll}
\text { from } y=4,046,780 \text { to } 4,054,280: & \text { flux }=-3.45 \mathrm{~kg} / \mathrm{s} \\
\text { from } y=4,054,280 \text { to } 4,063,280: & \text { flux }=+71.0 \\
\text { from } y=4,063,280 \text { to 4,072,280: } & \text { flux }=+6.90 \\
\text { from } y=4,072,280 \text { to 4,082,780: } & \text { flux }=-2.73 \\
\text { from } y=4,082,780 \text { to 4,091,780: } & \text { flux }=+47.0 \\
& \text { Sum }=+119
\end{array}
$$


Recharge and Lateral Groundwater Flow Boundary Conditions for the Saturated Zone Site-Scale Flow and Transport Model

East Boundary:

from $y=4,046,780$ to $4,058,780$ : flux $=+555 \mathrm{~kg} / \mathrm{s}$

from $y=4,058,780$ to $4,081,280$ : flux $=+5.46$

from $y=4,081,280$ to $4,087,280$ : flux $=-2.65$

from $y=4,087,280$ to $4,091,780$ : flux $=+3.07$

Sum $=+561$

North Boundary:

from $x=533,340$ to 543,840 :

flux $=+102 \mathrm{~kg} / \mathrm{s}$

from $x=543,840$ to 552,840 :

flux $=+18.9$

from $x=552,840$ to 560,340 :

flux $=+64.7$

from $x=560,340$ to 563,340 :

flux $=+10.6$

Sum $=+196$

South Boundary:

from $x=533,000$ to $563,000: \quad$ flux $=-790 \mathrm{~kg} / \mathrm{s}$

Table 6-5. Cell-by-Cell Flow Terms ( $\mathrm{m}^{3} /$ day) from the 1997 DVRFS Model along the West Boundary of the Site-Scale Model

\begin{tabular}{|l|l|l|l|l|l|}
\hline Column & \multicolumn{1}{|c|}{ Row } & \multicolumn{1}{|c|}{ Layer1 } & \multicolumn{1}{|c|}{ Layer2 } & \multicolumn{1}{c|}{ Layer3 } & \multicolumn{1}{c|}{ Sum } \\
\hline 62 & 66 & $3.00 \times 10^{2}$ & $1.16 \times 10^{2}$ & $1.73 \times 10^{2}$ & $5.89 \times 10^{2}$ \\
\hline 62 & 67 & $3.85 \times 10^{2}$ & $1.29 \times 10^{2}$ & $2.84 \times 10^{2}$ & $7.98 \times 10^{2}$ \\
\hline 62 & 68 & $9.13 \times 10^{1}$ & $1.19 \times 10^{2}$ & $1.83 \times 10^{2}$ & $3.93 \times 10^{2}$ \\
\hline 62 & 69 & $8.16 \times 10^{1}$ & $5.29 \times 10^{2}$ & $1.64 \times 10^{2}$ & $7.74 \times 10^{2}$ \\
\hline 62 & 70 & $1.20 \times 10^{2}$ & $7.62 \times 10^{2}$ & $1.18 \times 10^{2}$ & $9.99 \times 10^{2}$ \\
\hline 62 & 71 & $1.02 \times 10^{2}$ & $2.26 \times 10^{2}$ & $1.77 \times 10^{2}$ & $5.06 \times 10^{2}$ \\
\hline 62 & 72 & $3.59 \times 10^{0}$ & $4.58 \times 10^{0}$ & $4.59 \times 10^{0}$ & $1.28 \times 10^{1}$ \\
\hline 62 & 73 & $9.55 \times 10^{-1}$ & $1.60 \times 10^{0}$ & $-2.02 \times 10^{-1}$ & $2.35 \times 10^{0}$ \\
\hline 62 & 74 & $-4.32 \times 10^{1}$ & $-7.44 \times 10^{-1}$ & $2.24 \times 10^{-1}$ & $-4.37 \times 10^{1}$ \\
\hline 62 & 75 & $-2.30 \times 10^{1}$ & $-5.38 \times 10^{-1}$ & $1.96 \times 10^{0}$ & $-2.15 \times 10^{1}$ \\
\hline 62 & 76 & $-2.66 \times 10^{1}$ & $-5.57 \times 10^{-1}$ & $2.17 \times 10^{0}$ & $-2.50 \times 10^{1}$ \\
\hline 62 & 77 & $-1.33 \times 10^{2}$ & $-6.12 \times 10^{-1}$ & $1.85 \times 10^{0}$ & $-1.31 \times 10^{2}$ \\
\hline 62 & 78 & $-3.07 \times 10^{1}$ & $-1.97 \times 10^{-1}$ & $1.39 \times 10^{0}$ & $-2.95 \times 10^{1}$ \\
\hline 62 & 79 & $6.78 \times 10^{1}$ & $1.51 \times 10^{-1}$ & $1.05 \times 10^{0}$ & $6.90 \times 10^{1}$ \\
\hline 62 & 80 & $9.91 \times 10^{1}$ & $2.88 \times 10^{-1}$ & $9.30 \times 10^{-1}$ & $1.00 \times 10^{2}$ \\
\hline 62 & 81 & $1.03 \times 10^{2}$ & $2.19 \times 10^{-1}$ & $6.03 \times 10^{-1}$ & $1.03 \times 10^{2}$ \\
\hline 62 & 82 & $1.51 \times 10^{2}$ & $5.85 \times 10^{-1}$ & $4.22 \times 10^{-1}$ & $1.52 \times 10^{2}$ \\
\hline 62 & 83 & $3.38 \times 10^{1}$ & $4.75 \times 10^{-1}$ & $6.81 \times 10^{-1}$ & $3.50 \times 10^{1}$ \\
\hline 62 & 84 & $2.35 \times 10^{1}$ & $1.12 \times 10^{2}$ & $8.07 \times 10^{-1}$ & $1.36 \times 10^{2}$ \\
\hline 62 & 85 & $1.16 \times 10^{2}$ & $1.57 \times 10^{2}$ & $4.55 \times 10^{1}$ & $3.18 \times 10^{2}$ \\
\hline 62 & 86 & $5.45 \times 10^{2}$ & $2.27 \times 10^{2}$ & $6.57 \times 10^{2}$ & $1.43 \times 10^{3}$ \\
\hline 62 & 87 & $4.35 \times 10^{2}$ & $6.45 \times 10^{2}$ & $7.99 \times 10^{2}$ & $1.88 \times 10^{3}$ \\
\hline & & & & &
\end{tabular}


Recharge and Lateral Groundwater Flow Boundary Conditions for the Saturated Zone Site-Scale Flow and Transport Model

Table 6-5. Cell-by-Cell Flow Terms ( $\mathrm{m}^{3} /$ day) from the 1997 DVRFS Model along the West Boundary of the Site-Scale Model (Continued)

\begin{tabular}{|l|l|l|l|l|l|}
\hline Column & \multicolumn{1}{|c|}{ Row } & \multicolumn{1}{|c|}{ Layer1 } & \multicolumn{1}{|c|}{ Layer2 } & \multicolumn{1}{c|}{ Layer3 } & \multicolumn{1}{c|}{ Sum } \\
\hline 62 & 88 & $3.89 \times 10^{2}$ & $5.83 \times 10^{2}$ & $3.17 \times 10^{1}$ & $1.00 \times 10^{3}$ \\
\hline 62 & 89 & $3.40 \times 10^{2}$ & $4.82 \times 10^{2}$ & $1.60 \times 10^{1}$ & $8.38 \times 10^{2}$ \\
\hline 62 & 90 & $6.31 \times 10^{1}$ & $6.05 \times 10^{2}$ & $-1.81 \times 10^{0}$ & $6.66 \times 10^{2}$ \\
\hline 62 & 91 & $-7.49 \times 10^{-1}$ & $7.44 \times 10^{0}$ & $-1.93 \times 10^{0}$ & $4.75 \times 10^{0}$ \\
\hline 62 & 92 & $-5.17 \times 10^{1}$ & $-1.19 \times 10^{0}$ & $-2.17 \times 10^{0}$ & $-5.51 \times 10^{1}$ \\
\hline 62 & 93 & $-5.98 \times 10^{1}$ & $-2.57 \times 10^{0}$ & $-2.68 \times 10^{0}$ & $-6.51 \times 10^{1}$ \\
\hline 62 & 94 & $-8.07 \times 10^{1}$ & $-3.55 \times 10^{0}$ & $-3.71 \times 10^{0}$ & $-8.80 \times 10^{1}$ \\
\hline 62 & 95 & $-8.60 \times 10^{1}$ & $-4.20 \times 10^{0}$ & $-4.31 \times 10^{0}$ & $-9.45 \times 10^{1}$ \\
\hline
\end{tabular}

NOTE: A qualified version of MODFLOWP was used to generate these data.

Source: DTN: SN0407T0504404.002 in file boundaries.xls.

Table 6-6. Cell-by-Cell Flow Terms ( $\mathrm{m}^{3} /$ day) from the 1997 DVRFS Model along the East Boundary of the Site-Scale Model

\begin{tabular}{|c|c|c|c|c|c|}
\hline Column & Row & Layer1 & Layer2 & Layer3 & Sum \\
\hline 82 & 66 & $3.51 \times 10^{1}$ & $1.04 \times 10^{2}$ & $1.03 \times 10^{0}$ & $1.40 \times 10^{2}$ \\
\hline 82 & 67 & $3.25 \times 10^{1}$ & $5.95 \times 10^{1}$ & $2.87 \times 10^{0}$ & $9.49 \times 10^{1}$ \\
\hline 82 & 68 & $1.03 \times 10^{1}$ & $1.79 \times 10^{1}$ & $1.85 \times 10^{0}$ & $3.01 \times 10^{1}$ \\
\hline 82 & 69 & $-3.49 \times 10^{0}$ & $-6.73 \times 10^{0}$ & $1.90 \times 10^{-3}$ & $-1.02 \times 10^{1}$ \\
\hline 82 & 70 & $-2.13 \times 10^{1}$ & $-3.07 \times 10^{1}$ & $1.63 \times 10^{-2}$ & $-5.19 \times 10^{1}$ \\
\hline 82 & 71 & $-3.12 \times 10^{1}$ & $-4.06 \times 10^{1}$ & $2.09 \times 10^{-2}$ & $-7.18 \times 10^{1}$ \\
\hline 82 & 72 & $-9.51 \times 10^{1}$ & $-1.51 \times 10^{-2}$ & $8.80 \times 10^{-3}$ & $-9.51 \times 10^{1}$ \\
\hline 82 & 73 & $9.57 \times 10^{-2}$ & $2.22 \times 10^{1}$ & $1.12 \times 10^{-1}$ & $2.24 \times 10^{1}$ \\
\hline 82 & 74 & $-2.53 \times 10^{-2}$ & $-4.91 \times 10^{0}$ & $3.11 \times 10^{-1}$ & $-4.63 \times 10^{0}$ \\
\hline 82 & 75 & $5.17 \times 10^{0}$ & $3.82 \times 10^{1}$ & $3.19 \times 10^{-1}$ & $4.36 \times 10^{1}$ \\
\hline 82 & 76 & $5.32 \times 10^{0}$ & $3.25 \times 10^{1}$ & $1.42 \times 10^{1}$ & $5.21 \times 10^{1}$ \\
\hline 82 & 77 & $2.31 \times 10^{1}$ & $2.99 \times 10^{1}$ & $3.69 \times 10^{1}$ & $8.99 \times 10^{1}$ \\
\hline 82 & 78 & $2.12 \times 10^{1}$ & $1.98 \times 10^{1}$ & $1.42 \times 10^{1}$ & $5.52 \times 10^{1}$ \\
\hline 82 & 79 & $5.62 \times 10^{0}$ & $1.58 \times 10^{1}$ & $4.42 \times 10^{0}$ & $2.58 \times 10^{1}$ \\
\hline 82 & 80 & $1.43 \times 10^{0}$ & $1.89 \times 10^{0}$ & $-6.96 \times 10^{-1}$ & $2.62 \times 10^{0}$ \\
\hline 82 & 81 & $4.41 \times 10^{0}$ & $1.34 \times 10^{0}$ & $-4.22 \times 10^{-2}$ & $5.71 \times 10^{0}$ \\
\hline 82 & 82 & $1.43 \times 10^{1}$ & $3.25 \times 10^{0}$ & $4.38 \times 10^{-2}$ & $1.76 \times 10^{1}$ \\
\hline 82 & 83 & $1.34 \times 10^{1}$ & $3.52 \times 10^{0}$ & $-7.69 \times 10^{-1}$ & $1.61 \times 10^{1}$ \\
\hline 82 & 84 & $7.09 \times 10^{0}$ & $2.99 \times 10^{0}$ & $-1.49 \times 10^{0}$ & $8.59 \times 10^{0}$ \\
\hline 82 & 85 & $6.22 \times 10^{0}$ & $5.05 \times 10^{0}$ & $1.85 \times 10^{-1}$ & $1.14 \times 10^{1}$ \\
\hline 82 & 86 & $2.93 \times 10^{1}$ & $5.40 \times 10^{0}$ & $3.13 \times 10^{1}$ & $6.61 \times 10^{1}$ \\
\hline 82 & 87 & $1.97 \times 10^{0}$ & $1.62 \times 10^{1}$ & $4.11 \times 10^{1}$ & $5.93 \times 10^{1}$ \\
\hline 82 & 88 & $2.85 \times 10^{-1}$ & $1.55 \times 10^{3}$ & $3.12 \times 10^{3}$ & $4.67 \times 10^{3}$ \\
\hline 82 & 89 & $3.89 \times 10^{-1}$ & $2.09 \times 10^{3}$ & $4.15 \times 10^{3}$ & $6.24 \times 10^{3}$ \\
\hline 82 & 90 & $4.16 \times 10^{-1}$ & $2.23 \times 10^{3}$ & $4.42 \times 10^{3}$ & $6.65 \times 10^{3}$ \\
\hline 82 & 91 & $4.11 \times 10^{-1}$ & $2.20 \times 10^{3}$ & $4.39 \times 10^{3}$ & $6.59 \times 10^{3}$ \\
\hline 82 & 92 & $3.20 \times 10^{0}$ & $2.14 \times 10^{3}$ & $4.30 \times 10^{3}$ & $6.45 \times 10^{3}$ \\
\hline
\end{tabular}


Recharge and Lateral Groundwater Flow Boundary Conditions for the Saturated Zone Site-Scale Flow and Transport Model

Table 6-6. Cell-by-Cell Flow Terms ( $\mathrm{m}^{3} /$ day) from the 1997 DVRFS Model along the East Boundary of the Site-Scale Model (Continued)

\begin{tabular}{|l|l|l|l|l|l|}
\hline Column & \multicolumn{1}{|c|}{ Row } & \multicolumn{1}{|c|}{ Layer1 } & \multicolumn{1}{c|}{ Layer2 } & \multicolumn{1}{c|}{ Layer3 } & Sum \\
\hline 82 & 93 & $5.17 \times 10^{0}$ & $2.06 \times 10^{3}$ & $4.21 \times 10^{3}$ & $6.27 \times 10^{3}$ \\
\hline 82 & 94 & $1.45 \times 10^{1}$ & $1.85 \times 10^{3}$ & $3.99 \times 10^{3}$ & $5.86 \times 10^{3}$ \\
\hline 82 & 95 & $1.38 \times 10^{1}$ & $1.56 \times 10^{3}$ & $3.69 \times 10^{3}$ & $5.26 \times 10^{3}$ \\
\hline
\end{tabular}

NOTE: A qualified version of MODFLOWP was used to generate these data.

Source: DTN: SN0407T0504404.002 in file boundaries.xls.

Table 6-7. Cell-by-Cell Flow Terms ( $\mathrm{m}^{3} /$ day) from the 1997 DVRFS Model along the North Boundary of the Site-Scale Model

\begin{tabular}{|l|l|l|l|l|l|}
\hline Column & \multicolumn{1}{|c|}{ Row } & \multicolumn{1}{|c|}{ Layer1 } & \multicolumn{1}{c|}{ Layer2 } & \multicolumn{1}{c|}{ Layer3 } & \multicolumn{1}{c|}{ Sum } \\
\hline 63 & 65 & $4.37 \times 10^{2}$ & $1.59 \times 10^{2}$ & $8.89 \times 10^{1}$ & $6.84 \times 10^{2}$ \\
\hline 64 & 65 & $4.45 \times 10^{2}$ & $6.66 \times 10^{2}$ & $1.27 \times 10^{2}$ & $1.24 \times 10^{3}$ \\
\hline 65 & 65 & $4.70 \times 10^{2}$ & $7.05 \times 10^{2}$ & $1.42 \times 10^{2}$ & $1.32 \times 10^{3}$ \\
\hline 66 & 65 & $4.97 \times 10^{2}$ & $7.43 \times 10^{2}$ & $1.46 \times 10^{2}$ & $1.39 \times 10^{3}$ \\
\hline 67 & 65 & $5.11 \times 10^{2}$ & $7.67 \times 10^{2}$ & $1.41 \times 10^{2}$ & $1.42 \times 10^{3}$ \\
\hline 68 & 65 & $5.13 \times 10^{2}$ & $7.71 \times 10^{2}$ & $1.31 \times 10^{2}$ & $1.42 \times 10^{3}$ \\
\hline 69 & 65 & $5.00 \times 10^{2}$ & $7.03 \times 10^{2}$ & $1.17 \times 10^{2}$ & $1.32 \times 10^{3}$ \\
\hline 70 & 65 & $9.00 \times 10^{1}$ & $1.24 \times 10^{2}$ & $9.94 \times 10^{1}$ & $3.14 \times 10^{2}$ \\
\hline 71 & 65 & $9.43 \times 10^{1}$ & $1.36 \times 10^{2}$ & $7.92 \times 10^{1}$ & $3.09 \times 10^{2}$ \\
\hline 72 & 65 & $8.19 \times 10^{1}$ & $1.26 \times 10^{2}$ & $5.47 \times 10^{1}$ & $2.63 \times 10^{2}$ \\
\hline 73 & 65 & $7.92 \times 10^{1}$ & $1.22 \times 10^{2}$ & $4.55 \times 10^{1}$ & $2.47 \times 10^{2}$ \\
\hline 74 & 65 & $8.18 \times 10^{1}$ & $1.24 \times 10^{2}$ & $2.46 \times 10^{0}$ & $2.08 \times 10^{2}$ \\
\hline 75 & 65 & $7.81 \times 10^{0}$ & $2.08 \times 10^{2}$ & $3.32 \times 10^{0}$ & $2.89 \times 10^{2}$ \\
\hline 76 & 65 & $7.14 \times 10^{1}$ & $8.35 \times 10^{2}$ & $2.45 \times 10^{1}$ & $9.31 \times 10^{2}$ \\
\hline 77 & 65 & $7.71 \times 10^{1}$ & $9.12 \times 10^{2}$ & $2.49 \times 10^{1}$ & $1.01 \times 10^{3}$ \\
\hline 78 & 65 & $8.48 \times 10^{1}$ & $9.90 \times 10^{2}$ & $2.64 \times 10^{1}$ & $1.10 \times 10^{3}$ \\
\hline 79 & 65 & $1.61 \times 10^{2}$ & $1.06 \times 10^{3}$ & $2.73 \times 10^{1}$ & $1.25 \times 10^{3}$ \\
\hline 80 & 65 & $1.67 \times 10^{2}$ & $1.10 \times 10^{3}$ & $2.75 \times 10^{1}$ & $1.30 \times 10^{3}$ \\
\hline 81 & 65 & $2.05 \times 10^{2}$ & $3.22 \times 10^{2}$ & $3.82 \times 10^{1}$ & $5.65 \times 10^{2}$ \\
\hline 82 & 65 & $8.24 \times 10^{1}$ & $2.26 \times 10^{2}$ & $4.55 \times 10^{1}$ & $3.54 \times 10^{2}$ \\
\hline
\end{tabular}

NOTE: A qualified version of MODFLOWP was used to generate these data.

Source: DTN: SN0407T0504404.002 in file boundaries.xls. 
Recharge and Lateral Groundwater Flow Boundary Conditions for the Saturated Zone Site-Scale Flow and Transport Model

Table 6-8. Cell-by-Cell Flow Terms ( $\mathrm{m}^{3} /$ day) from the 1997 DVRFS Model along the South Boundary of the Site-Scale Model

\begin{tabular}{|l|l|l|l|l|l|}
\hline Column & \multicolumn{1}{|c|}{ Row } & \multicolumn{1}{|c|}{ Layer1 } & \multicolumn{1}{c|}{ Layer2 } & \multicolumn{1}{c|}{ Layer3 } & \multicolumn{1}{c|}{ Sum } \\
\hline 63 & 95 & $-1.02 \times 10^{1}$ & $-2.70 \times 10^{1}$ & $-2.39 \times 10^{0}$ & $-3.96 \times 10^{1}$ \\
\hline 64 & 95 & $-1.62 \times 10^{2}$ & $-6.53 \times 10^{1}$ & $-3.15 \times 10^{0}$ & $-2.31 \times 10^{2}$ \\
\hline 65 & 95 & $-8.26 \times 10^{1}$ & $-7.57 \times 10^{2}$ & $-1.66 \times 10^{2}$ & $-1.01 \times 10^{3}$ \\
\hline 66 & 95 & $-3.59 \times 10^{2}$ & $-6.01 \times 10^{2}$ & $-1.93 \times 10^{2}$ & $-1.15 \times 10^{3}$ \\
\hline 67 & 95 & $-3.71 \times 10^{2}$ & $-6.12 \times 10^{2}$ & $-2.43 \times 10^{2}$ & $-1.23 \times 10^{3}$ \\
\hline 68 & 95 & $-5.12 \times 10^{2}$ & $-7.55 \times 10^{2}$ & $-2.49 \times 10^{2}$ & $-1.52 \times 10^{3}$ \\
\hline 69 & 95 & $-5.56 \times 10^{2}$ & $-8.30 \times 10^{2}$ & $-1.31 \times 10^{3}$ & $-2.70 \times 10^{3}$ \\
\hline 70 & 95 & $-5.92 \times 10^{2}$ & $-8.86 \times 10^{2}$ & $-1.35 \times 10^{3}$ & $-2.82 \times 10^{3}$ \\
\hline 71 & 95 & $-6.10 \times 10^{2}$ & $-9.14 \times 10^{2}$ & $-1.43 \times 10^{3}$ & $-2.96 \times 10^{3}$ \\
\hline 72 & 95 & $-5.58 \times 10^{2}$ & $-8.54 \times 10^{2}$ & $-1.37 \times 10^{3}$ & $-2.78 \times 10^{3}$ \\
\hline 73 & 95 & $-4.87 \times 10^{2}$ & $-7.49 \times 10^{2}$ & $-1.28 \times 10^{3}$ & $-2.52 \times 10^{3}$ \\
\hline 74 & 95 & $-2.97 \times 10^{2}$ & $-4.63 \times 10^{2}$ & $-1.19 \times 10^{3}$ & $-1.95 \times 10^{3}$ \\
\hline 75 & 95 & $-1.34 \times 10^{2}$ & $-4.55 \times 10^{1}$ & $-1.07 \times 10^{3}$ & $-1.25 \times 10^{3}$ \\
\hline 76 & 95 & $-7.59 \times 10^{1}$ & $-3.54 \times 10^{1}$ & $-5.42 \times 10^{1}$ & $-1.66 \times 10^{2}$ \\
\hline 77 & 95 & $-1.03 \times 10^{0}$ & $1.62 \times 10^{1}$ & $2.18 \times 10^{1}$ & $3.70 \times 10^{1}$ \\
\hline 78 & 95 & $-1.02 \times 10^{1}$ & $-9.78 \times 10^{1}$ & $-1.52 \times 10^{2}$ & $-2.60 \times 10^{2}$ \\
\hline 79 & 95 & $-6.43 \times 10^{0}$ & $-3.47 \times 10^{3}$ & $-7.41 \times 10^{3}$ & $-1.09 \times 10^{4}$ \\
\hline 80 & 95 & $-5.33 \times 10^{0}$ & $-3.42 \times 10^{3}$ & $-7.54 \times 10^{3}$ & $-1.10 \times 10^{4}$ \\
\hline 81 & 95 & $-3.20 \times 10^{1}$ & $-3.66 \times 10^{3}$ & $-7.83 \times 10^{3}$ & $-1.15 \times 10^{4}$ \\
\hline 82 & 95 & $-3.58 \times 10^{1}$ & $-4.12 \times 10^{3}$ & $-8.15 \times 10^{3}$ & $-1.23 \times 10^{4}$ \\
\hline
\end{tabular}

NOTE: A qualified version of MODFLOWP was used to generate these data.

Source: DTN: SN0407T0504404.002 in file boundaries.xls

\subsubsection{DVRFS Model}

The cell-by-cell flow terms extracted from the 2001 DVRFS model are presented in Tables 6-9 to 6-12 (note that the 2001 DVRFS model has 15 layers as opposed to three in the 1997 DVRFS model). The data are also found in boundaries.xls in output DTN: SN0407T0504404.002. This file contains the flow terms as calculated by MODFLOW-2000 in units of cubic meters per day.

The total mass fluxes (kilograms per second) from the 2001 DVRFS model for segments along the west, north, and east site model boundaries that follow are grouped according to flow similarities. These boundary fluxes are used as calibration targets for the alternate SZ site-scale flow model. The coordinates of the boundary segments are in UTM (m). Fluxes are the total flux for that boundary segment, from the water table to a depth of 2,750 m (i.e., all 15 layers of the 2001 DVRFS model). A positive value indicates flow into the alternate SZ site-scale flow model. Flux segments differ from the 1997 model because of the different distribution of flow. Segments were partitioned to group like flows (i.e., high and low flow areas were grouped separately). 
Table 6-9. Cell-by-Cell Flow Terms ( $\mathrm{m}^{3} /$ day) from the 2001 DVRFS Model along the West Boundary of the Site-Scale Model

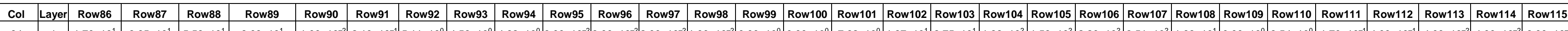

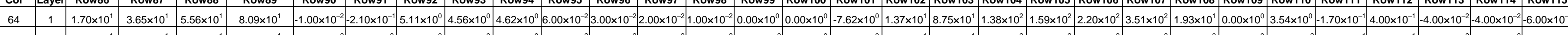

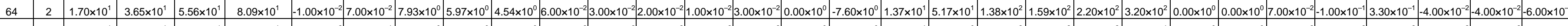

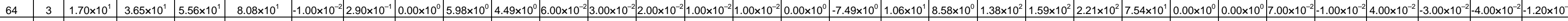

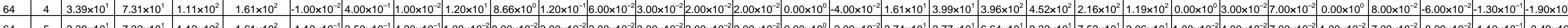

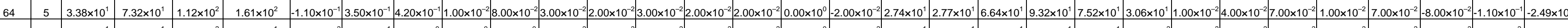

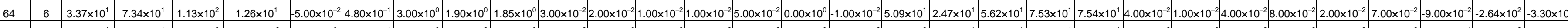

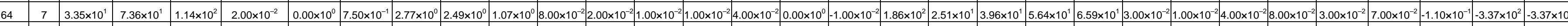

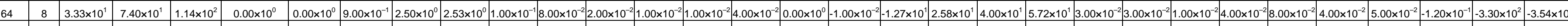

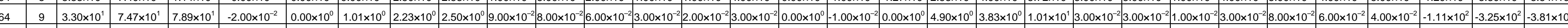

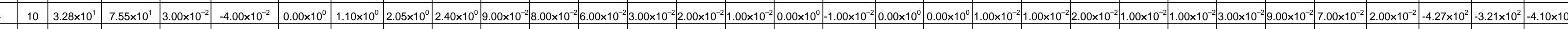

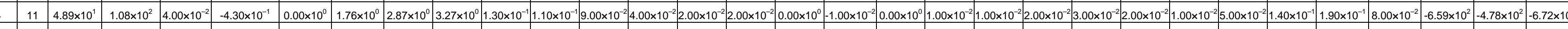

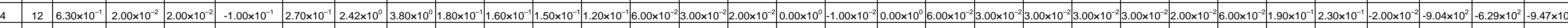

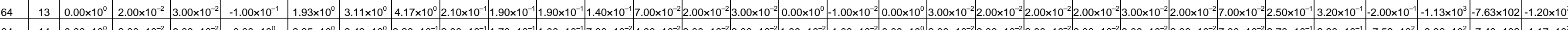

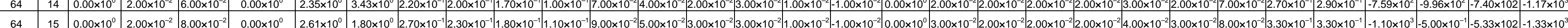
Source: DTN: SN0407T05044404.002 in file boundaries.xls.

Table 6-10. Cell-by-Cell Flow Terms ( $\mathrm{m}^{3} / \mathrm{day}$ ) from the 2001 DVRFS Model along the East Boundary of the Site-Scale Mode

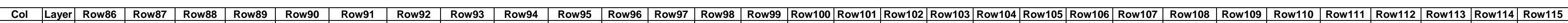

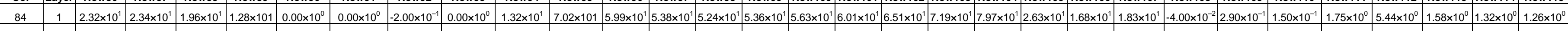

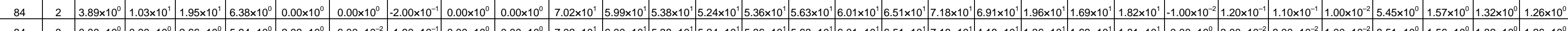

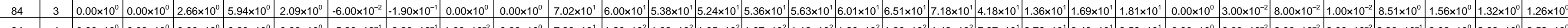

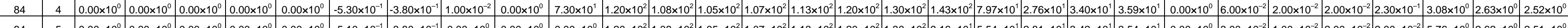

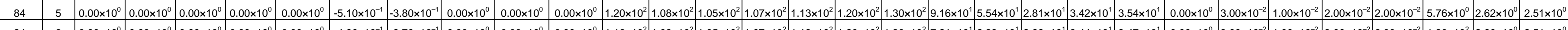

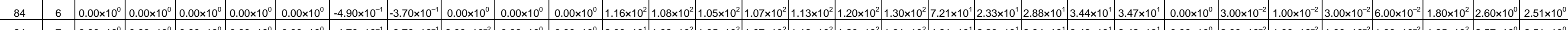

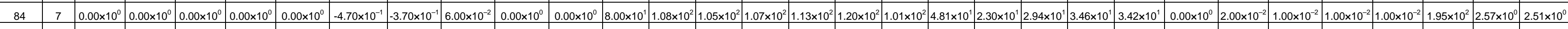

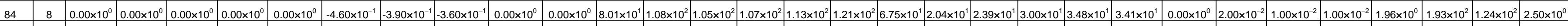

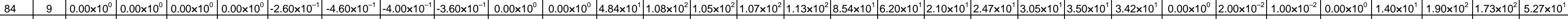

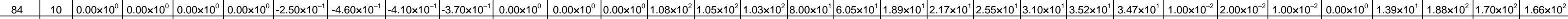

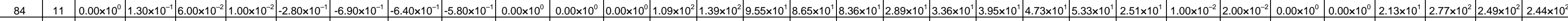

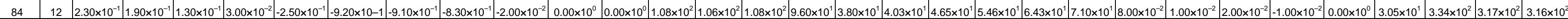

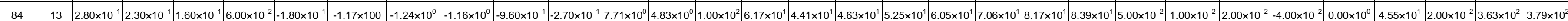

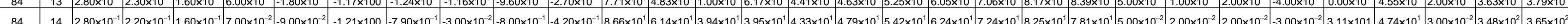

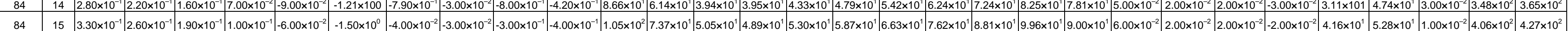
Source: DTN: SN0407T0504404.002 in file boundaries. $x / 5$. 
Table 6-11. Cell-by-Cell Flow Terms ( $\mathrm{m}^{3} /$ day) from the 2001 DVRFS Model along the North Boundary of the Site-Scale Model

\begin{tabular}{|c|c|c|c|c|c|c|c|c|c|c|c|c|c|c|c|c|c|c|c|c|c|}
\hline \multicolumn{2}{|c|}{ Row Layer } & Col65 & Col66 & Col67 & Col68 & Col69 & Col70 & Col71 & Col72 & Col73 & Col74 & Col75 & Col76 & Col77 & Col78 & Col79 & Col80 & Col81 & Col82 & Col83 & Col84 \\
\hline 85 & 1 & $9.44 \times 10^{1}$ & $1.05 \times 10^{2}$ & $1.14 \times 10^{2}$ & $1.22 \times 10^{2}$ & $1.30 \times 10^{2}$ & $1.41 \times 10^{2}$ & $1.52 \times 10^{2}$ & $1.59 \times 10^{2}$ & $1.58 \times 10^{2}$ & $1.37 \times 10^{2}$ & $8.69 \times 10^{1}$ & $4.93 \times 10^{1}$ & $2.15 \times 10^{1}$ & $-9.40 \times 10^{-1}$ & $-9.30 \times 10^{1}$ & $-8.07 \times 10^{1}$ & $-2.63 \times 10^{1}$ & $5.61 \times 10^{0}$ & $4.28 \times 10^{1}$ & $5.54 \times 10^{0}$ \\
\hline 85 & 2 & $9.44 \times 10^{1}$ & $1.05 \times 10^{2}$ & $1.14 \times 10^{2}$ & $1.22 \times 10^{2}$ & $1.30 \times 10^{2}$ & $1.41 \times 10^{2}$ & $1.52 \times 10^{2}$ & $1.59 \times 10^{2}$ & $1.58 \times 10^{2}$ & $1.37 \times 10^{2}$ & $8.70 \times 10^{1}$ & $4.93 \times 10^{1}$ & $2.15 \times 10^{1}$ & $-8.60 \times 10^{-1}$ & $-1.22 \times 10^{1}$ & $-8.10 \times 10^{1}$ & $-2.66 \times 10^{1}$ & $5.20 \times 10^{0}$ & $4.26 \times 10^{1}$ & $2.79 \times 10^{0}$ \\
\hline 85 & 3 & $9.45 \times 10^{1}$ & $1.05 \times 10^{2}$ & $1.14 \times 10^{2}$ & $1.22 \times 10^{2}$ & $1.30 \times 10^{2}$ & $1.41 \times 10^{2}$ & $1.52 \times 10^{2}$ & $1.59 \times 10^{2}$ & $1.58 \times 10^{2}$ & $1.37 \times 10^{2}$ & $8.70 \times 10^{1}$ & $4.93 \times 10^{1}$ & $2.15 \times 10^{1}$ & $-7.90 \times 10^{-1}$ & $-1.22 \times 10^{1}$ & $-8.07 \times 10^{1}$ & $-2.69 \times 10^{1}$ & $0.00 \times 10^{0}$ & $4.35 \times 10^{0}$ & $2.71 \times 10^{0}$ \\
\hline 85 & 4 & $1.89 \times 10^{2}$ & $2.10 \times 10^{2}$ & $2.28 \times 10^{2}$ & $2.43 \times 10^{2}$ & $.59 \times 10^{2}$ & $2.82 \times 10^{2}$ & $3.03 \times 10^{2}$ & $3.18 \times 10^{2}$ & $3.16 \times 10^{2}$ & $2.74 \times 10^{2}$ & $1.74 \times 10^{2}$ & $9.86 \times 10^{1}$ & $4.29 \times 10^{1}$ & $-1.38 \times 10^{0}$ & $-2.40 \times 10^{1}$ & $-4.72 \times 10^{0}$ & $-4.21 \times 10^{1}$ & $4.70 \times 10^{-1}$ & $3.85 \times 10^{0}$ & \\
\hline 85 & 5 & $\times 10^{2}$ & & $8 \times 10^{2}$ & & & & & & & & & & & & & & & & & \\
\hline 85 & 6 & $1.89 \times 10^{2}$ & $2.10 \times 10^{2}$ & $2.28 \times 10^{2}$ & $2.44 \times 10^{2}$ & $2.60 \times 10^{2}$ & $2.82 \times 10^{2}$ & $3.04 \times 10^{2}$ & $3.18 \times 10^{2}$ & $3.16 \times 10^{2}$ & $2.75 \times 10^{2}$ & $1.74 \times 10^{2}$ & $9.90 \times 10^{1}$ & $4.30 \times 10^{1}$ & $-9.30 \times 10^{-1}$ & $-2.25 \times 10^{1}$ & $4.34 \times 10^{0}$ & $3.04 \times 10^{0}$ & $9.00 \times 10^{-2}$ & $0.00 \times 10^{0}$ & $0.00 \times 10^{0}$ \\
\hline 85 & 7 & $0 \times 10^{2}$ & $2.10 \times 10^{2}$ & $2.28 \times 10^{2}$ & $2.44 \times 10^{2}$ & $2.60 \times 10^{2}$ & $2.82 \times 10^{2}$ & $3.04 \times 10^{2}$ & $3.19 \times 10^{2}$ & $3.14 \times 10^{2}$ & $2.61 \times 10^{2}$ & $1.57 \times 10^{2}$ & $7.38 \times 10^{1}$ & $4.61 \times 10^{1}$ & $0.00 \times 10^{0}$ & $-2.23 \times 10^{1}$ & $3.05 \times 10^{0}$ & $0.00 \times 10^{0}$ & $0.00 \times 10^{0}$ & $0.00 \times 10^{0}$ & $0.00 \times 10^{0}$ \\
\hline 85 & 8 & $1.90 \times 10^{2}$ & $2.11 \times 10^{2}$ & $2.29 \times 10^{2}$ & & & & & & $9.00 \times 10^{-2}$ & $0 \times 10^{-2}$ & $0 \times 10^{-2}$ & $3.00 \times 10^{-2}$ & $00 \times 10^{-2}$ & $00 \times 10^{0}$ & $-1.79 \times 10^{1}$ & $1.94 \times 10^{0}$ & $0.00 \times 10^{0}$ & $00 \times 10^{0}$ & $0.00 \times 10^{0}$ & $0 \times 10^{0}$ \\
\hline 85 & 9 & & & $2.30 \times 10^{2}$ & $2.45 \times 10^{2}$ & $2.62 \times 10^{2}$ & $2.82 \times 10^{2}$ & $3.06 \times 10^{2}$ & $1.20 \times 10^{-1}$ & $5.00 \times 10^{-2}$ & $4.00 \times 10^{-2}$ & $3.00 \times 10^{-2}$ & $2.00 \times 10^{-2}$ & $1.00 \times 10^{-2}$ & $0.00 \times 10^{0}$ & $-1.48 \times 10^{1}$ & $8.30 \times 10^{-1}$ & $0.00 \times 10^{0}$ & $0.00 \times 10^{0}$ & $0.00 \times 10^{0}$ & $0.00 \times 10^{0}$ \\
\hline 85 & 10 & $91 \times 10^{2}$ & $2.12 \times 10^{2}$ & $2.30 \times 10^{2}$ & $2.46 \times 10^{2}$ & $2.62 \times 10^{2}$ & $2.82 \times 10^{2}$ & $3.06 \times 10^{2}$ & $6.00 \times 10^{-2}$ & $5.00 \times 10^{-2}$ & $4.00 \times 10^{-2}$ & $3.00 \times 10^{-2}$ & $2.00 \times 10^{-2}$ & $1.00 \times 10^{-2}$ & $0.00 \times 10^{0}$ & $0.00 \times 10^{0}$ & $3.00 \times 10^{-2}$ & $0.00 \times 10^{0}$ & $0.00 \times 10^{0}$ & $0.00 \times 10^{0}$ & $0.00 \times 10^{0}$ \\
\hline 85 & 11 & $2.88 \times 10^{2}$ & $3.20 \times 10^{2}$ & $3.47 \times 10^{2}$ & $3.70 \times 10^{2}$ & $3.95 \times 10^{2}$ & $4.24 \times 10^{2}$ & $5.81 \times 10^{1}$ & $8.00 \times 10^{-2}$ & $7.00 \times 10^{-2}$ & $7.00 \times 10^{-2}$ & $4.00 \times 10^{-2}$ & $3.00 \times 10^{-2}$ & $1.00 \times 10^{-2}$ & $1.00 \times 10^{-2}$ & $1.00 \times 10^{-2}$ & $0.00 \times 10^{0}$ & $0.00 \times 10^{0}$ & $0.00 \times 10^{0}$ & $0.00 \times 10^{0}$ & $0.00 \times 10^{0}$ \\
\hline 85 & 12 & $1.13 \times 10^{1}$ & $1.50 \times 10^{1}$ & $1.92 \times 10^{1}$ & $2.45 \times 10^{1}$ & $3.22 \times 10^{1}$ & $4.67 \times 10^{1}$ & $6.00 \times 10^{-2}$ & $1.10 \times 10^{-1}$ & $1.00 \times 10^{-1}$ & $9.00 \times 10^{-2}$ & $6.00 \times 10^{-2}$ & $3.00 \times 10^{-2}$ & $1.00 \times 10^{-2}$ & $1.00 \times 10^{-2}$ & $1.60 \times 10^{-1}$ & $0.00 \times 10^{0}$ & $0.00 \times 10^{0}$ & $0.00 \times 10^{0}$ & $0.00 \times 10^{0}$ & $0.00 \times 10^{0}$ \\
\hline 85 & 13 & $00 \times 10^{-2}$ & $2.00 \times 10^{-2}$ & $2.00 \times 10^{-2}$ & $2.00 \times 10^{-2}$ & $2.00 \times 10^{-2}$ & $4.00 \times 10^{-2}$ & $8.00 \times 10^{-2}$ & $1.40 \times 10^{-1}$ & $1.30 \times 10^{-1}$ & $1.20 \times 10^{-1}$ & $8.00 \times 10^{-2}$ & $4.00 \times 10^{-2}$ & $2.00 \times 10^{-2}$ & $3.00 \times 10^{-2}$ & $5.70 \times 10^{-1}$ & $0.00 \times 10^{0}$ & $0.00 \times 10^{0}$ & $0.00 \times 10^{0}$ & $1.60 \times 10^{-1}$ & $3.40 \times 10^{-1}$ \\
\hline 85 & 14 & $3.00 \times 10^{-2}$ & $3.00 \times 10^{-2}$ & $2.00 \times 10^{-2}$ & & & & & & $1.30 \times 10^{-1}$ & & & & $2.00 \times 10^{-2}$ & & & & & $0.00 \times 10^{0}$ & & $3.80 \times 10^{-1}$ \\
\hline 85 & 15 & $4.00 \times 10^{-2}$ & $4.00 \times 10^{-2}$ & $3.00 \times 10^{-2}$ & $3.00 \times 10^{-2}$ & $4.00 \times 10^{-2}$ & $7.00 \times 10^{-2}$ & $1.10 \times 10^{-1}$ & $1.60 \times 10^{-1}$ & $1.60 \times 10^{-1}$ & $1.50 \times 10^{-1}$ & $9.00 \times 10^{-2}$ & $4.00 \times 10^{-2}$ & $2.00 \times 10^{-2}$ & $4.00 \times 10^{-2}$ & $8.00 \times 10^{-2}$ & $1.00 \times 10^{-2}$ & $0.00 \times 10^{0}$ & $0.00 \times 10^{0}$ & $4.30 \times 10^{-1}$ & $4.60 \times 10^{-1}$ \\
\hline
\end{tabular}

Source: DTN: SN0407T0504404.002. 
Table 6-12. Cell-by-Cell Flow Terms ( $\mathrm{m}^{3} / \mathrm{day}$ ) from the 2001 DVRFS Model along the South Boundary of the Site-Scale Model

\begin{tabular}{|c|c|c|c|c|c|c|c|c|c|c|c|c|c|c|c|c|c|c|c|c|c|}
\hline Row & Layer & Col65 & Col66 & Col67 & Col68 & Col69 & Col70 & Col71 & Col72 & Col73 & Col74 & Col75 & Col76 & Col77 & Col78 & Col79 & Col80 & Col81 & Col82 & Col83 & Col84 \\
\hline 115 & 1 & $7.50 \times 10^{-1}$ & $5.27 \times 10^{1}$ & $5.50 \times 10^{1}$ & $1.22 \times 10^{2}$ & $-1.90 \times 10^{2}$ & $-1.31 \times 10^{2}$ & $-1.16 \times 10^{2}$ & $-1.16 \times 10^{2}$ & $-1.13 \times 10^{2}$ & $-1.07 \times 10^{2}$ & $-1.05 \times 10^{2}$ & $-1.11 \times 10^{2}$ & $-1.24 \times 10^{2}$ & $-1.40 \times 10^{2}$ & $-1.37 \times 10^{2}$ & $8.66 \times 10^{0}$ & $4.72 \times 10^{0}$ & $-3.50 \times 10^{-1}$ & $-1.16 \times 10^{0}$ & $-1.31 \times 10^{0}$ \\
\hline 115 & 2 & $7.50 \times 10^{-1}$ & $5.28 \times 10^{1}$ & $5.50 \times 10^{1}$ & $1.22 \times 10^{2}$ & $-1.90 \times 10^{2}$ & $-1.31 \times 10^{2}$ & $-1.16 \times 10^{2}$ & $-1.16 \times 10^{2}$ & $-1.13 \times 10^{2}$ & $-1.07 \times 10^{2}$ & $-1.05 \times 10^{2}$ & $-1.11 \times 10^{2}$ & $-1.24 \times 10^{2}$ & $-1.40 \times 10^{2}$ & $-1.37 \times 10^{2}$ & $8.67 \times 10^{0}$ & $4.73 \times 10^{0}$ & $-3.50 \times 10^{-1}$ & $-1.16 \times 10^{0}$ & $-1.31 \times 10^{0}$ \\
\hline 115 & 3 & $7.50 \times 10^{-1}$ & $2.65 \times 10^{1}$ & $5.50 \times 10^{1}$ & $1.22 \times 10^{2}$ & $-1.90 \times 10^{2}$ & $-1.31 \times 10^{2}$ & $-1.16 \times 10^{2}$ & $-1.16 \times 10^{2}$ & $-1.13 \times 10^{2}$ & $-1.07 \times 10^{2}$ & $-1.05 \times 10^{2}$ & $-1.11 \times 10^{2}$ & $-1.24 \times 10^{2}$ & $-1.40 \times 10^{2}$ & $-1.37 \times 10^{2}$ & $8.68 \times 10^{0}$ & $4.74 \times 10^{0}$ & $-3.50 \times 10^{-1}$ & $-1.16 \times 10^{0}$ & $-1.31 \times 10^{0}$ \\
\hline 115 & 4 & $1.48 \times 10^{0}$ & $1.31 \times 10^{1}$ & $2.12 \times 10^{1}$ & $2.37 \times 10^{2}$ & $-3.79 \times 10^{2}$ & $-2.61 \times 10^{2}$ & $-2.33 \times 10^{2}$ & $-2.33 \times 10^{2}$ & $-2.27 \times 10^{2}$ & $-2.14 \times 10^{2}$ & $-2.10 \times 10^{2}$ & $-2.21 \times 10^{2}$ & $-2.47 \times 10^{2}$ & $-2.80 \times 10^{2}$ & $-2.75 \times 10^{2}$ & $1.74 \times 10^{1}$ & $9.56 \times 10^{0}$ & $-1.42 \times 10^{0}$ & $-2.33 \times 10^{0}$ & $-2.61 \times 10^{0}$ \\
\hline 115 & 5 & $9.06 \times 10^{1}$ & $1.73 \times 10^{1}$ & $8.99 \times 10^{0}$ & $3.55 \times 10^{1}$ & $-3.77 \times 10^{2}$ & $-2.61 \times 10^{2}$ & $-2.32 \times 10^{2}$ & $-2.33 \times 10^{2}$ & $-2.27 \times 10^{2}$ & $-2.13 \times 10^{2}$ & $-2.10 \times 10^{2}$ & $-2.21 \times 10^{2}$ & $-2.48 \times 10^{2}$ & $-2.80 \times 10^{2}$ & $-2.75 \times 10^{2}$ & $1.76 \times 10^{1}$ & $5.67 \times 10^{0}$ & $-2.88 \times 10^{1}$ & $-2.34 \times 10^{0}$ & $-2.61 \times 10^{0}$ \\
\hline 115 & 6 & $8.56 \times 10^{1}$ & $2.02 \times 10^{1}$ & $8.49 \times 10^{0}$ & $1.89 \times 10^{1}$ & $-3.06 \times 10^{2}$ & $-2.60 \times 10^{2}$ & $-2.32 \times 10^{2}$ & $-2.33 \times 10^{2}$ & $-2.28 \times 10^{2}$ & $-2.13 \times 10^{2}$ & $-2.10 \times 10^{2}$ & $-2.21 \times 10^{2}$ & $-2.48 \times 10^{2}$ & $-2.82 \times 10^{2}$ & $-2.76 \times 10^{2}$ & $1.60 \times 10^{1}$ & $1.10 \times 10^{-1}$ & $-7.62 \times 10^{1}$ & $-4.33 \times 10^{0}$ & $-2.61 \times 10^{0}$ \\
\hline 115 & 7 & $8.08 \times 10^{1}$ & $2.22 \times 10^{1}$ & $7.77 \times 10^{0}$ & $1.69 \times 10^{1}$ & $-6.08 \times 10^{1}$ & $-2.59 \times 10^{2}$ & $-2.31 \times 10^{2}$ & $-2.34 \times 10^{2}$ & $-2.28 \times 10^{2}$ & $-2.13 \times 10^{2}$ & $-2.10 \times 10^{2}$ & $-2.22 \times 10^{2}$ & $-2.48 \times 10^{2}$ & $-2.83 \times 10^{2}$ & $-2.76 \times 10^{2}$ & $6.20 \times 10^{-1}$ & $2.00 \times 10^{-2}$ & $-7.64 \times 10^{1}$ & $-4.80 \times 10^{1}$ & $-2.60 \times 10^{0}$ \\
\hline 115 & 8 & $7.65 \times 10^{1}$ & $2.34 \times 10^{1}$ & $6.83 \times 10^{0}$ & $1.52 \times 10^{1}$ & $-6.21 \times 10^{1}$ & $-2.02 \times 10^{2}$ & $-2.31 \times 10^{2}$ & $-2.34 \times 10^{2}$ & & & $-2.09 \times 10^{2}$ & $-2.22 \times 10^{2}$ & $-2.48 \times 10^{2}$ & $-2.51 \times 10^{2}$ & $-4.24 \times 10^{1}$ & $9.10 \times 10^{-1}$ & $1.00 \times 10^{-2}$ & $-7.65 \times 10^{1}$ & $-1.56 \times 10^{2}$ & $0 \times 10^{0}$ \\
\hline 115 & 9 & $7.26 \times 10^{1}$ & $2.41 \times 10^{1}$ & $5.62 \times 10^{0}$ & $1.37 \times 10^{1}$ & $-3.46 \times 10^{1}$ & $-4.22 \times 10^{1}$ & $-2.30 \times 10^{2}$ & $-2.35 \times 10^{2}$ & $-2.30 \times 10^{2}$ & $-2.13 \times 10^{2}$ & $-2.09 \times 10^{2}$ & $-2.22 \times 10^{2}$ & $-2.49 \times 10^{2}$ & $-5.65 \times 10^{0}$ & $-6.04 \times 10^{0}$ & $2.70 \times 10^{-1}$ & $0.00 \times 10^{0}$ & $-7.61 \times 10^{1}$ & $-1.54 \times 10^{2}$ & $-9.07 \times 10^{0}$ \\
\hline 115 & 10 & $6.88 \times 10^{1}$ & $2.45 \times 10^{1}$ & $4.10 \times 10^{0}$ & $1.24 \times 10^{1}$ & $-3.40 \times 10^{1}$ & $-4.42 \times 10^{1}$ & $-2.20 \times 10^{2}$ & $-2.36 \times 10^{2}$ & $-2.31 \times 10^{2}$ & $-2.12 \times 10^{2}$ & $-2.08 \times 10^{2}$ & $-2.22 \times 10^{2}$ & $-2.49 \times 10^{2}$ & $-5.77 \times 10^{0}$ & $-8.70 \times 10^{-1}$ & $1.70 \times 10^{-1}$ & $0.00 \times 10^{0}$ & $-7.51 \times 10^{1}$ & $-1.51 \times 10^{2}$ & $-1.76 \times 10^{2}$ \\
\hline 115 & 11 & $9.57 \times 10^{1}$ & $2.16 \times 10^{1}$ & $2.63 \times 10^{0}$ & $1.63 \times 10^{1}$ & $-4.99 \times 10^{1}$ & $-4.95 \times 10^{1}$ & $-5.28 \times 10^{1}$ & $-3.55 \times 10^{2}$ & $-3.49 \times 10^{2}$ & $-3.18 \times 10^{2}$ & $-3.11 \times 10^{2}$ & $-3.33 \times 10^{2}$ & $-3.73 \times 10^{2}$ & $-9.75 \times 10^{0}$ & $-1.17 \times 10^{0}$ & $2.70 \times 10^{-1}$ & $-2.00 \times 10^{-2}$ & $-1.10 \times 10^{2}$ & $-2.23 \times 10^{2}$ & $-2.60 \times 10^{2}$ \\
\hline 115 & 12 & $1.61 \times 10^{1}$ & $2.00 \times 10^{0}$ & $-3.29 \times 10^{0}$ & $1.82 \times 10^{1}$ & $-6.46 \times 10^{1}$ & $-4.95 \times 10^{1}$ & $-4.16 \times 10^{1}$ & $-3.50 \times 10^{2}$ & $-4.72 \times 10^{2}$ & $-4.22 \times 10^{2}$ & $-4.11 \times 10^{2}$ & $-4.46 \times 10^{2}$ & $-4.98 \times 10^{2}$ & $-4.13 \times 10^{0}$ & $-1.36 \times 10^{0}$ & $3.00 \times 10^{-1}$ & $-3.13 \times 10^{1}$ & $-1.38 \times 10^{2}$ & $-2.90 \times 10^{2}$ & $-3.41 \times 10^{2}$ \\
\hline 115 & 13 & $2.27 \times 10^{0}$ & $2.53 \times 10^{0}$ & $-1.10 \times 10^{1}$ & $1.82 \times 10^{1}$ & $-7.87 \times 10^{1}$ & $-6.16 \times 10^{1}$ & $-5.45 \times 10^{1}$ & $-6.77 \times 10^{1}$ & $-6.42 \times 10^{2}$ & $-5.23 \times 10^{2}$ & $-5.07 \times 10^{2}$ & $-5.59 \times 10^{2}$ & $-1.87 \times 10^{2}$ & $-1.57 \times 10^{0}$ & $-4.35 \times 10^{0}$ & $1.70 \times 10^{-1}$ & $-3.76 \times 10^{1}$ & $-1.57 \times 10^{2}$ & $-3.54 \times 10^{2}$ & $-4.17 \times 10^{2}$ \\
\hline 115 & 14 & $1.26 \times 10^{0}$ & $2.41 \times 10^{0}$ & $-1.50 \times 10^{1}$ & $1.48 \times 10^{1}$ & $-7.74 \times 10^{1}$ & $-6.16 \times 10^{1}$ & $-5.66 \times 10^{1}$ & $-5.88 \times 10^{1}$ & $-8.12 \times 10^{2}$ & $-5.12 \times 10^{2}$ & $-4.96 \times 10^{2}$ & $-5.63 \times 10^{2}$ & $-1.33 \times 10^{0}$ & $-1.87 \times 10^{0}$ & $-4.89 \times 10^{0}$ & $-5.70 \times 10^{-1}$ & $-3.14 \times 10^{1}$ & $-1.48 \times 10^{2}$ & $-3.48 \times 10^{2}$ & $-4.09 \times 10^{2}$ \\
\hline 115 & 15 & $-4.35 \times 10^{2}$ & $1.12 \times 10^{0}$ & $-1.77 \times 10^{1}$ & $1.52 \times 10^{1}$ & $-9.21 \times 10^{1}$ & $-7.40 \times 10^{1}$ & $-6.93 \times 10^{1}$ & $-7.33 \times 10^{1}$ & $-1.21 \times 10^{2}$ & $-1.18 \times 10^{3}$ & $-6.47 \times 10^{2}$ & $-2.05 \times 10^{2}$ & $-2.55 \times 10^{0}$ & $-5.31 \times 10^{0}$ & $-5.94 \times 10^{0}$ & $-2.60 \times 10^{1}$ & $-3.22 \times 10^{1}$ & $-1.69 \times 10^{2}$ & $-4.14 \times 10^{2}$ & $-4.85 \times 10^{2}$ \\
\hline
\end{tabular}

Source: DTN: SN0407T0504404.002. 

West Boundary:

$$
\begin{array}{ll}
\text { from } y=4,046,500 \text { to } 4,052,500: & \text { flux }=-210 . \mathrm{kg} / \mathrm{s} \\
\text { from } y=4,052,500 \text { to } 4,057,000: & \text { flux }=+0.08 \\
\text { from } y=4,057,000 \text { to } 4,067,500: & \text { flux }=+56.1 \\
\text { from } y=4,067,500 \text { to } 4,085,500: & \text { flux }=+1.31 \\
\text { from } y=4,085,500 \text { to } 4,091,500: & \text { flux }=+28.4 \\
& \text { Sum }=-124 .
\end{array}
$$

East Boundary:

$$
\begin{array}{ll}
\text { from } y=4,046,500 \text { to } 4,054,000: & \text { flux }=+69.7 \mathrm{~kg} / \mathrm{s} \\
\text { from } y=4,054,000 \text { to } 4,058,500: & \text { flux }=+0.01 \\
\text { from } y=4,058,500 \text { to } 4,078,000: & \text { flux }=+138.1 \\
\text { from } y=4,078,000 \text { to } 4,084,000: & \text { flux }=-0.09 \\
\text { from } y=4,084,000 \text { to } 4,091,500: & \text { flux }=+1.53 \\
& \text { Sum }=+209 . \\
\text { North Boundary: } & \\
\text { from } x=533,000 \text { to } 545,000: & \text { flux }=+219 . \mathrm{kg} / \mathrm{s} \\
\text { from } x=545,000 \text { to } 552,500: & \text { flux }=+57.1 \\
\text { from } x=552,500 \text { to } 558,500: & \text { flux }=-6.90 \\
\text { from } x=558,500 \text { to } 563,000: & \text { flux }=+1.37 \\
& \text { Sum }=+271 .
\end{array}
$$

South Boundary:

$$
\text { from } x=533,000 \text { to } 563,000: \quad \text { flux }=-430 . \mathrm{kg} / \mathrm{s}
$$

\subsubsection{Differences in Lateral Recharge between 1997 and 2001 DVRFS Models and 1997 and 2003 UZ Site-Scale Flow Models}

Because the number of layers in the 1997 and 2001 DVRFS models are different (three in the 1997 model and 15 in the 2001 model), and because the number and location of segments across the boundary where flows are specified also differ, comparison of these models will be made on a boundary basis. Another reason is that the 1997 model represents conditions from the early 1990s (there are active pumps in the model domain) and the 2001 DVRFS represents predevelopment conditions (no pumping in the model domain). Table 6-13 presents the total fluxes across each of the four boundaries of the SZ site-scale flow model domain within the 1997 and 2001 DVRFS models and the percent difference with respect to the 1997 DVRFS model. Because these fluxes are calibration targets for the SZ site-scale flow model, it is expected that there will be some differences in the resulting SZ site-scale flow fields. 
Recharge and Lateral Groundwater Flow Boundary Conditions for the Saturated Zone Site-Scale Flow and Transport Model

Table 6-13. Comparison of Fluxes (kg/s) through the Four Lateral Boundaries of the 1997 and 2001 DVRFS Models

\begin{tabular}{|l|c|c|c|c|}
\hline \multicolumn{1}{|c|}{ Model } & $\begin{array}{c}\text { East Boundary } \\
(\mathbf{k g} / \mathbf{s})\end{array}$ & $\begin{array}{c}\text { North Boundary } \\
\mathbf{( k g / \mathbf { s } )}\end{array}$ & $\begin{array}{c}\text { West Boundary } \\
(\mathbf{k g} / \mathbf{s})\end{array}$ & $\begin{array}{c}\text { South Boundary } \\
(\mathbf{k g} / \mathbf{s})\end{array}$ \\
\hline 1997 & 561 & 196 & 118 & $-790^{\mathrm{a}}$ \\
\hline 2001 & 209 & 271 & -125 & $-430^{\mathrm{b}}$ \\
\hline$\%$ Difference & $-62.7 \%$ & $38.4 \%$ & $-205 \%{ }^{\mathrm{c}}$ & $45.5 \%$ \\
\hline
\end{tabular}

${ }^{a}$ The flux through the south boundary reflects the inflow through the other three boundaries, the addition of distributed recharge, and the effect of pumping wells in the 1997 DVRFS, which withdraw $101 \mathrm{~kg} / \mathrm{s}$ from the southeast corner of the model domain.

${ }^{\mathrm{b}}$ The flux through the south boundary reflects the inflow through the other three boundaries plus the distributed recharge.

${ }^{\text {c}}$ This large discrepancy is due to the 1997 DVRFS model representing conditions of the early 1990s, which includes pumping, and the 2001 DVRFS model representing predevelopment conditions where there was no pumping.

\subsection{COMPARISON OF RESULTS FROM THE 1997 DVRFS AND 1997 UZ SITE-SCALE FLOW MODELS WITH PREVIOUS RESULTS}

Although the output data from this report relating to the 1997 DVRFS model and 1997 UZ site-scale flow model differ from those discussed in BSC (2001 [DIRS 164648]), the use of DTN: SN9908T0581999.001 has little impact on SZ model calibrations or results. A formal impact analysis follows. Tables A-1 through A-4 in Appendix A quantitatively compares recharge to the SZ site scale model from the UZ site-scale flow model domain calculated in this report and from Revision 0 of this report (DTN: SN 9908T0581999.001).

\subsection{IMPACT ANALYSIS}

Two primary issues are to be addressed in the impact analysis: (1) how a change in the distributed recharge by correctly accounting for MODFLOWP zones affects base-case SZ site-scale flow model calibration and flow paths, and (2) how proper accounting of the pumping wells from the 1997 DVRFS model within the SZ site-scale model domain impacts base-case SZ site-scale flow model calibration and flow paths. In the preceding revision of this report, distributed recharge was improperly calculated due to neglect/oversight of the recharge zones multiplier (equivalent to the Zones file from MODFLOW-2000). Furthermore, the impacts of pumping wells in the 1997 DVRFS within the SZ site-scale model domain were neglected. This leads to a mass balance discrepancy when considering the combined fluxes of the lateral boundaries and distributed recharge and this oversight is addressed in this Scientific Analysis Report revision.

\subsubsection{Corrected Distributed Recharge}

Now that this analysis has been updated to correctly take into account recharge zones in the 1997 DVRFS model, the net distributed recharge (infiltration) to the SZ site-scale flow model is $18.9 \mathrm{~kg} / \mathrm{s}\left(5.96 \times 10^{5} \mathrm{~m}^{3} /\right.$ year) (down from $48.9 \mathrm{~kg} / \mathrm{s}\left[1.54 \times 10^{6} \mathrm{~m}^{3} /\right.$ year]). The expected response of the base-case SZ site-scale flow model is that groundwater specific discharge is decreased, yielding longer radionuclide transport times from the repository. Quantitatively, a 
forward run of the base-case SZ site-scale flow model using the corrected distributed recharge values yields heads that differ from the previously calibrated heads by less than 0.1 percent on average with a maximum discrepancy of -2.3 percent, and root mean square error (RMSE) of 0.5 percent. This indicates that the flow paths are essentially unchanged.

\subsubsection{Correction for Pumping Wells}

Accounting for the pumping wells in the SZ site-scale model is not performed in such a quantitative manner. Fortunately, such a comparison is not needed because the base-case SZ site-scale flow model has implicitly taken into account the effect of these pumping wells through the calibration process to the heads in the southwest corner of the model that already reflect the influence of pumping. That is, although no pumping wells are explicitly included in the SZ site-scale flow model, the potentiometric data to which the model is calibrated include drawdown due to pumping in the Amargosa Valley (i.e., in the southwest region of the model domain). This calibration ultimately results in the base-case SZ site-scale modeling compensating for the absence of explicitly included pumping wells by increasing flux out through the southern boundary (i.e., in direct proportion to what would have otherwise been pumped from wells in the southwest corner). The net effect is minor and local to the southwest corner of the base-case SZ site-scale model where what might have otherwise been pumped water is rerouted a few kilometers south to exit the southern boundary. Overall, the flow paths emanating from the repository are virtually unchanged.

\subsubsection{Changes in Potentiometric Surface and Particle Paths}

To determine the impact on the performance of the SZ as a barrier to the transport of radionuclides from the repository due to a correction in the distributed recharge boundary condition, a comparison of head contours and particle tracks is made between runs of the base-case SZ site-scale flow model subject to both old (erroneous) and new (corrected) distributed recharge data sets. While the recharge data sets differ in both distribution and magnitude, overall, there is a decrease in net recharge in the corrected data set primarily in the northeast corner of the base-case SZ site-scale model domain. Figure 6-13 illustrates head contours of the base-case SZ site-scale flow model subject to the old (erroneous) surface recharge boundary condition (solid blue lines) and the new (corrected) surface recharge boundary condition (dashed red lines). Note that throughout the model domain there is generally quite a good agreement with the only significant change in potentiometric surface in the northeast corner. Interestingly, with the old (erroneous) surface recharge, there is a nonphysical buildup or mound of water in this region. Using the new (corrected) surface recharge eliminates this phenomenon.

When comparing the heads at every node between model runs using the old and new surface recharge boundary conditions, the average difference in heads throughout the model domain was $-6.5 \mathrm{~m}$ ( -0.8 percent) with 95 percent of the differences less than $25 \mathrm{~m}$. The only large differences in head, about $200 \mathrm{~m}$, were in the northeast corner of the model domain. As for the heads at the wells used to calibrate the base-case SZ site-scale flow model, the average change in heads was $-0.8 \mathrm{~m}$ ( -0.1 percent) with the RMSE head difference of $3.8 \mathrm{~m}$ (0.5 percent). 


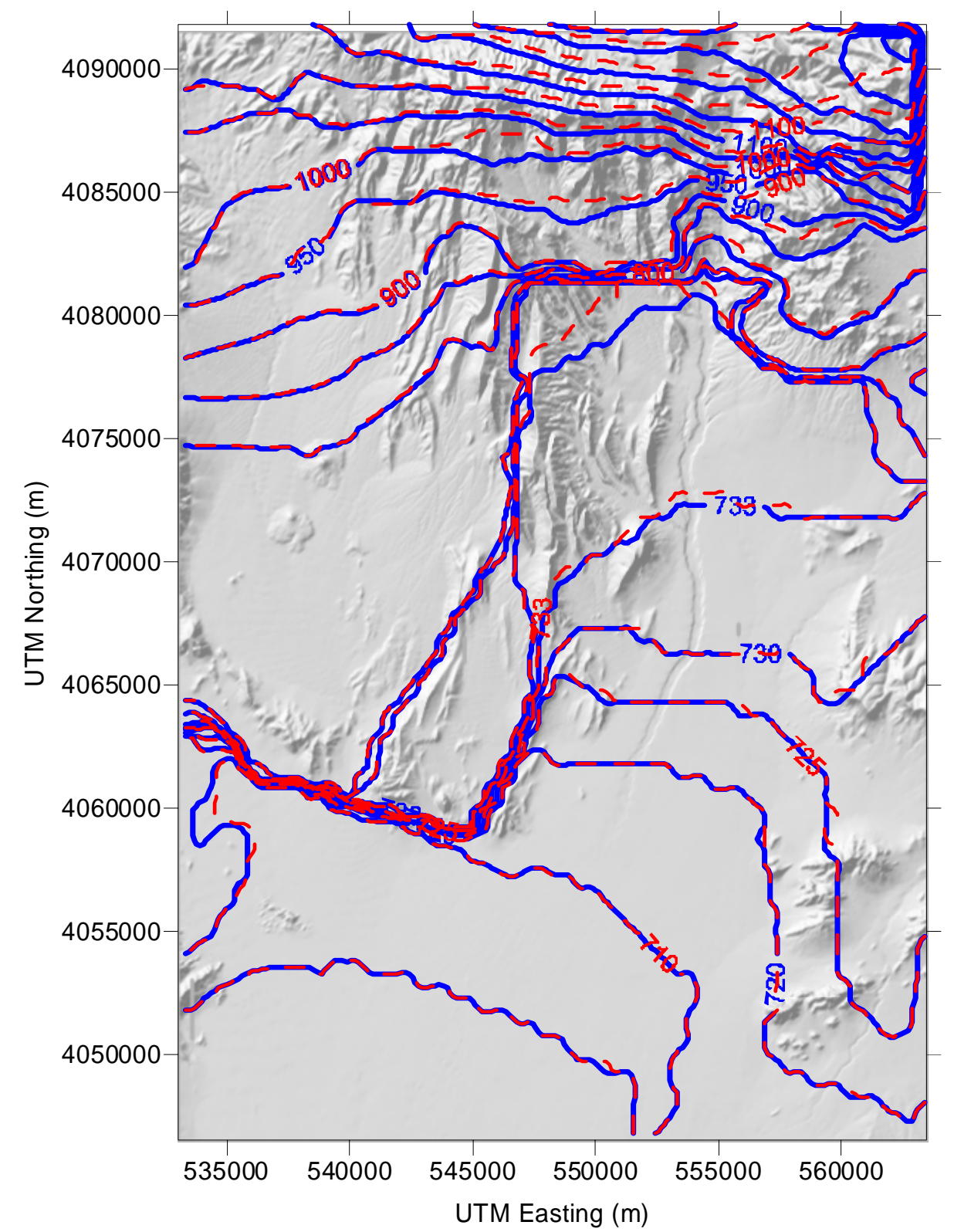

Figure 6-13. Comparison of Simulated Heads Measured in Meters Using the Old (erroneous) Recharge (blue) and the New (corrected) Recharge (red dashed) Boundary Conditions

Particle tracks emanating from below the footprint of the repository were also examined for the base-case SZ site-scale flow model subject to both old and new surface recharge boundary conditions. Figures 6-13 and 6-14 compare both the potentiometric surface and particle paths from old and new surface recharge boundary conditions. It should be noted that this version of the model was run with unit porosity and no matrix diffusion. Results indicate that the difference in head in the northeast of the model domain do not significantly impact particle paths from the repository. It is difficult to discern a difference in particle tracks with the naked eye, but an analysis of the data revealed that on average, of the 100 particles released, those in the model subject to the corrected surface recharge boundary condition had longer transport times 
due to a decreased specific discharge (average velocity). The average specific discharge decreased from 1.555 to $1.551 \mathrm{~m} /$ year, a difference of 0.3 percent. The path lines, however, remained relatively unchanged with the average length only decreasing by $5 \mathrm{~m}$ ( -0.03 percent). Overall, this comparison reveals that the correction to the distributed recharge boundary condition does not significantly impact the performance of the SZ as a barrier to radionuclide transport. Furthermore, where differences are noted, they tend to show improved repository performance through increased transport times and decreased velocities.

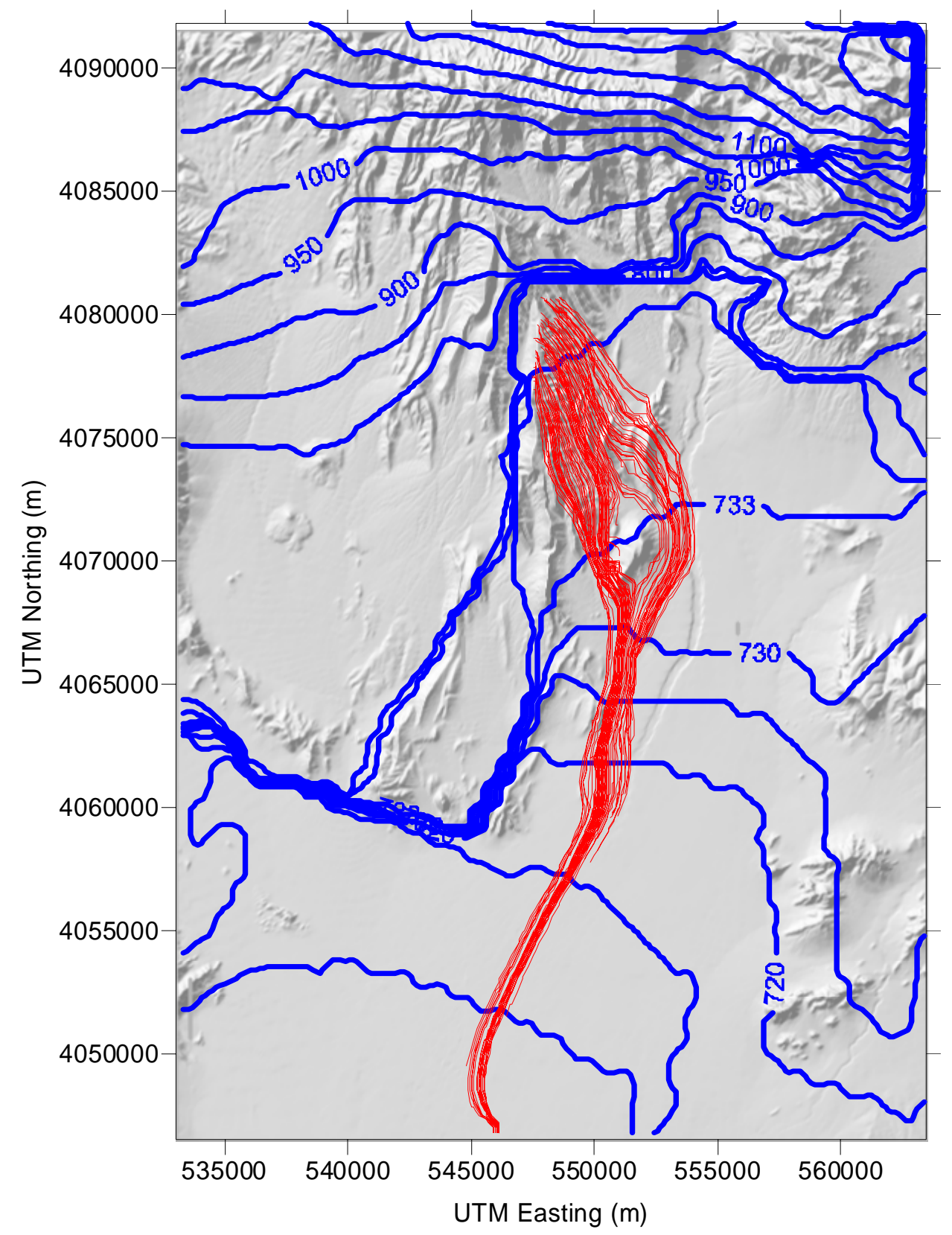

Figure 6-14. Simulated Heads Measured in Meters (blue) and Particle Paths (red) for the Old (erroneous) Recharge 


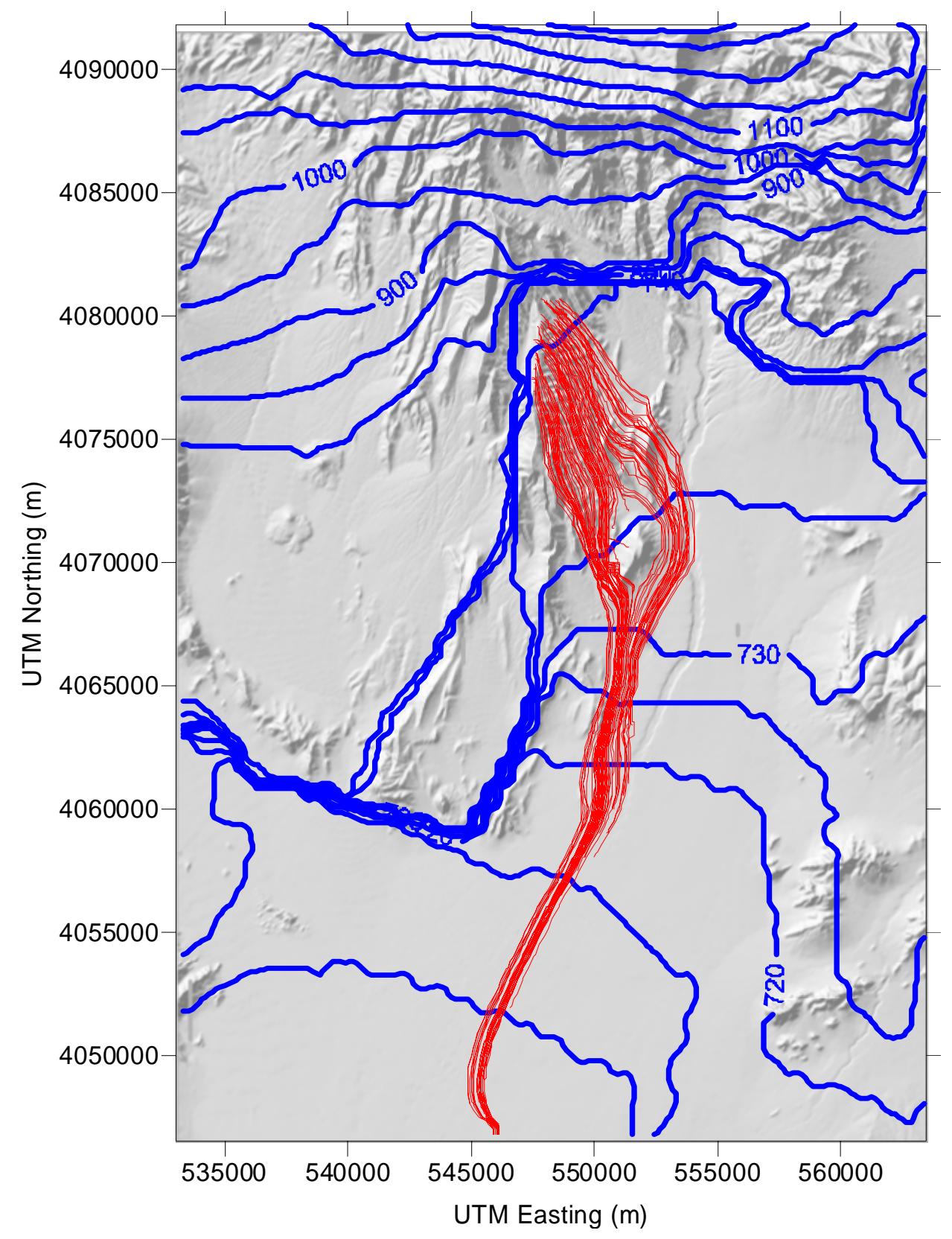

Figure 6-15. Simulated Heads Measured in Meters (blue) and Particle Paths (red) for the Corrected Recharge 


\section{CONCLUSIONS}

\subsection{SUMMARY}

This analysis report produces three sets of distributed recharge and two sets of lateral boundary fluxes for application to SZ site-scale flow models. For application to the base-case SZ site-scale flow model, it extracts distributed recharge from the 1997 DVRFS with additions from the 1997 UZ site-scale flow model and Fortymile Wash replacing the distributed recharge from the 1997 DVRFS in the appropriate locations. Fortymile Wash data were extracted using 500-m grid spacing. These data may be found in wt_flow_500_1997.dat in DTN: SN0407T0504404.002. In addition, the distributed recharge calculated in the previous revision of this report is also presented where zonation in the 1997 DVRFS was neglected thereby yielding an erroneously high distributed recharge from this source. Again, additional recharge from the $1997 \mathrm{UZ}$ site-scale flow model and Fortymile Wash, this time with a $125-\mathrm{m}$ grid, replaced the distributed recharge from the 1997 DVRFS in the appropriate locations. These data, which were used in the base-case SZ site-scale flow model calibration, may be found in wt_flow_500.dat in DTN: SN9908T0581999.001. Finally, distributed recharge from the 2001 DVRFS, 2003 UZ site-scale flow model, and Fortymile Wash were extracted for application to the alternate SZ site-scale flow model and are found in wt_flow_500_2003.dat in DTN: SN0407T0504404.002. Lateral fluxes for the base-case SZ site-scale flow model from the 1997 DVRFS are found in boundaries.xls in both DTN: SN9908T0581999.001. Lateral fluxes for the alternate SZ site-scale flow model from the 2001 DVRFS are found in boundaries.xls in DTN: SN0407T0504404.002.

To clarify, there are two output DTNs from this analysis report: DTN: SN9908T0581999.001 and SN0407T0504404.002. DTN: SN9908T0581999.001 contains both the distributed recharge and lateral flux boundary conditions used to calibrate the base-case SZ site-scale flow model in files wt_flow_500.dat and boundaries.xls, respectively. DTN: SN0407T0504404.002 contains the corrected values for the distributed recharge as well as identical lateral flux boundary conditions in wt_flow_500_1997.dat and boundaries.xls, respectively. In addition, this DTN also contains distributed recharge and lateral flux boundary conditions that can be applied to the alternate SZ site-scale flow model in wt_flow_500_2003.dat and boundaries.xls, respectively.

It should be noted that recharge data extracted from the 1997 and 2003 UZ site-scale flow model, while calculated subject to the same surface rate infiltration, have both different recharge magnitudes (due to a decrease in model domain area in the 2003 UZ site-scale flow model from the 1997 UZ site-scale flow model) and different distributions (due to the UZ focusing flow differently through newly identified and parameterized faults). Distributed recharges from the 1997 and 2001 DVRFS models are significantly different both in magnitude and distribution (see Figures 6-1 and 6-3). Similarly, the lateral flows are also different in magnitude and distribution for these models (compare Tables 6-5 and 6-9, Tables 6-6 and 6-10, Tables 6-7 and 6-11, and Tables 6-8 and 6-12). A note about uncertainty in the lateral and recharge fluxes calculated in this analysis is in order. While no attempt is made to explicitly quantify the uncertainties of the fluxes supplied in output DTN: SN9908T0581999.001 (or DTN: SN0407T0504404.002), clearly they inherit the uncertainties contained in the 1997 DVRFS and 1997 UZ site-scale flow models and recharge estimates. Armed with knowledge of how the base-case SZ site-scale flow model calibration was achieved (BSC 2004 
[DIRS 170037]), it is safe to say that all uncertainties in the flux boundary conditions computed in this model play only a minor role in overall calibration. Specifically, uncertainty in the distributed recharge, which is no more than 6 percent of the net influx into the base-case SZ site-scale flow and transport model, yields far less uncertainty in the site-scale model results than other uncertain parameters (e.g., groundwater specific discharge, flowing interval spacing, and distribution coefficients) (Arnold et al. 2003 [DIRS 163857]). In addition, the lateral fluxes supplied to the SZ site-scale flow model are used in a target calibration capacity only.

\subsection{HOW THE APPLICABLE ACCEPTANCE CRITERIA ARE ADDRESSED}

This section describes how this analysis report addresses the applicable acceptance criteria in the Yucca Mountain Review Plan, Final Report (NRC 2003 [DIRS 163274]). For this analysis report, the applicable acceptance criteria have been identified in Section 4.2.

\section{Acceptance Criteria from Section 2.2.1.3.8.3, Flow Paths in the Saturated Zone}

\section{Acceptance Criterion 1: System Description and Model Integration Are Adequate.}

Subcriterion (1): The TSPA adequately incorporates important physical phenomena and uses consistent and appropriate assumptions, throughout the flow paths in the saturated zone abstraction process to the extent that this report simply extracts lateral and distributed fluxes from other models and published sources. Existing modeling and analysis results are the bases for estimating groundwater flow rates into the saturated zone site-scale model domains, both as recharge at the upper boundary and as underflow at the lateral boundaries.

Subcriterion (2): The description of the aspects of hydrology, geology, geochemistry, design features, physical phenomena, and couplings, that may affect flow paths in the SZ, is adequate to the extent that the description of the aspects of hydrology that may affect flow paths in the saturated zone is described in Section 6.0.

Subcriterion (4): Abstractions are based on boundary conditions consistent with site-scale modeling and regional models of the Death Valley groundwater flow system because the boundary conditions used in the TSPA-LA abstraction of flow paths in the saturated zone are based on boundary conditions consistent with regional models of the Death Valley groundwater flow system as described in Section 6.0.

Subcriterion (10): The document has been developed under NRC (2003 [DIRS 163274]) Quality Assurance Requirements and Description (DOE 2004 [DIRS 171539]) that commits to using the guidance in NUREG-1297 (Altman et al. 1988 [DIRS 103597]) and NUREG-1298 (Altman et al. 1988 [DIRS 103750]), which for these purposes, is incorporated in AP-SIII.9Q, Scientific Analyses. An Internal Data Qualification Report was produced by a Data Qualification Team in accordance with AP-SIII.2Q, Qualification of Unqualified Data, to qualify data from the Death Valley regional groundwater flow model, as described in detail in Appendix B. An Internal Data Qualification Report was produced by a Data Qualification Team in accordance with AP-SIII.2Q, Qualification of Unqualified Data, to qualify data from the 1997 unsaturated zone site-scale model, as described in detail in Appendix C. 


\section{Acceptance Criterion 2: Data Are Sufficient for Model Justification.}

Subcriterion (1): Hydrological values used in the license application to evaluate flow paths in the saturated zone are adequately justified. Section 6.0 shows how the data in the USGS reports were interpreted to support subsequent synthesis into parameters in other reports.

Subcriterion (2): Sufficient data have been collected on the natural system to establish initial boundary conditions for the abstraction of flow paths in the SZ as described by the references in this report to the extensive work by the USGS to develop data for flow paths in the saturated zone. This report compiles that information on the recharge boundary conditions supplied to the saturated zone site-scale flow models listed in Section 4.0.

Subcriterion (3): Data on the hydrology of the saturated zone are based on appropriate techniques because this report relies on extensive work by the USGS, as described in its reports referenced in this report.

Subcriterion (4): Sufficient information is provided in Section 6 to show that proposed models are calibrated and applicable to site conditions. Calibration is inherent because the work relies on the calibration of the base-case saturated zone site-scale flow model. Section 6.2.1 shows how estimates of volumetric groundwater flow rates are justified by comparison with regional-scale flow model results. Section 6.2.2 shows how estimates of recharge from unsaturated zone flow model are made. Section 6.2.3 explains how recharge data from infiltration along Fortymile Wash is based on estimates of stream flow loses. Section 6.2.4 shows how the combined recharge model is used to extract patterns of distributed recharges. Section 6.3 shows how fluxes across lateral boundaries are extracted from flow models. 
Recharge and Lateral Groundwater Flow Boundary Conditions for the Saturated Zone Site-Scale Flow and Transport Model

INTENTIONALLY LEFT BLANK 


\section{INPUTS AND REFERENCES}

The following is a list of the references cited in this document. Column 2 represents the unique six digit numerical identifier (the Document Input Reference System number), which is placed in the text following the reference callout (e.g., BSC 2002 [DIRS 160819]). The purpose of these numbers is to assist in locating a specific reference. Within the reference list, multiple sources by the same author (e.g., BSC 2002) are sorted alphabetically by title.

\subsection{DOCUMENTS CITED}

Altman, W.D.; Donnelly, J.P.; and Kennedy, J.E. 1988. Peer Review for High-Level 103597 Nuclear Waste Repositories: Generic Technical Position. NUREG-1297. Washington, D.C.: U.S. Nuclear Regulatory Commission. TIC: 200651.

Altman, W.D.; Donnelly, J.P.; and Kennedy, J.E. 1988. Qualification of Existing 103750 Data for High-Level Nuclear Waste Repositories: Generic Technical Position. NUREG-1298. Washington, D.C.: U.S. Nuclear Regulatory Commission. TIC: 200652.

Arnold, B.W.; Kuzio, S.P.; and Robinson, B.A. 2003. Radionuclide Transport 163857 Simulation and Uncertainty Analyses with the Saturated-Zone Site-Scale Model at Yucca Mountain, Nevada. Journal of Contaminant Hydrology, 62-63, 401-419. New York, New York: Elsevier. TIC: 254205.

BSC (Bechtel SAIC Company) 2001. Recharge and Lateral Groundwater Flow 164648 Boundary Conditions for the Saturated Zone Site-Scale Flow and Transport Model. ANL-NBS-MD-000010 REV 00 ICN 01. Las Vegas, Nevada: Bechtel SAIC Company. ACC: MOL.20020129.0093.

BSC (Bechtel SAIC Company) 2004. Features, Events, and Processes in SZ Flow and 170013 Transport. ANL-NBS-MD-000002, Rev. 03. Las Vegas, Nevada: Bechtel SAIC Company. TBV: 5998.

BSC 2004. Saturated Zone In-Situ Testing. 170010 ANL-NBS-HS-000039, Rev. 01. Las Vegas, Nevada: Bechtel SAIC Company.

BSC 2004. Saturated Zone Site-Scale Flow Model. MDL-NBS-HS-000011, Rev. 02. Las Vegas, Nevada: Bechtel SAIC Company.

BSC 2004. Technical Work Plan for: Natural System - Saturated Zone Analysis and Model Report Integration. TWP-NBS-MD-000002 REV 02 ICN 01. Las Vegas, Nevada: Bechtel SAIC Company. ACC: DOC.20040818.0004. 
BSC 2004. UZ Flow Models and Submodels. MDL-NBS-HS-000006 REV 02.

169861 Las Vegas, Nevada: Bechtel SAIC Company. ACC: MOL.20040126.0082. TBV-5677

Canori, G.F. and Leitner, M.M. 2003. Project Requirements Document. 166275 TER-MGRMD- 000001 REV 02. Las Vegas, Nevada: Bechtel SAIC Company. ACC: DOC.20031222.0006.

CRWMS M\&O (Civilian Radioactive Waste Management System Management and Operating Contractor) 1999. Development of Flow Boundary Conditions for SZ Flow and Transport Model. Work Direction and Planning Document. Las Vegas, Nevada: CRWMS M\&O. ACC: MOL.19990707.0296.

D'Agnese, F.A.; Faunt, C.C.; Turner, A.K.; and Hill, M.C. 1997. Hydrogeologic 100131 Evaluation and Numerical Simulation of the Death Valley Regional Ground-Water Flow System, Nevada and California. Water-Resources Investigations Report 96-4300. Denver, Colorado: U.S. Geological Survey. ACC: MOL.19980306.0253.

D'Agnese, F.A.; O'Brien, G.M.; Faunt, C.C.; Belcher, W.R.; and San Juan, C. 2002. 158876 A Three-Dimensional Numerical Model of Predevelopment Conditions in the Death Valley Regional Ground-Water Flow System, Nevada and California. WaterResources Investigations Report 02-4102. Denver, Colorado: U.S. Geological Survey. TIC: 253754.

DOE (U.S. Department of Energy) 2004. Quality Assurance Requirements and Description. DOE/RW-0333P, Rev. 16. Washington, D.C.: U.S. Department of Energy, Office of Civilian Radioactive Waste Management.

ACC: DOC.20040907.0002. (Replacement for 171386)

Harbaugh, A.W.; Banta, E.R.; Hill, M.C.; and McDonald, M.G. 2000. 155197 MODFLOW-2000, The U.S. Geological Survey Modular Ground-Water Model-User Guide to Modularization Concepts and the Ground-Water Flow Process. Open-File Report 00-92. Reston, Virginia: U.S. Geological Survey. TIC: 250197.

Maxey, G.B. and Eakin, T.E. 1950. Ground Water in White River Valley, White Pine, Nye, and Lincoln Counties, Nevada. Water Resources Bulletin No. 8. Carson City, Nevada: State of Nevada, Office of the State Engineer. TIC: 216819.

NRC (U.S. Nuclear Regulatory Commission) 2003. Yucca Mountain Review Plan, Final Report. NUREG-1804, Rev. 2. Washington, D.C.: U.S. Nuclear Regulatory Commission, Office of Nuclear Material Safety and Safeguards. TIC: 254568.

Pruess, K. 1987. TOUGH User’s Guide. NUREG/CR-4645. Washington, D.C.: U.S. 100684 Nuclear Regulatory Commission. TIC: 217275. 
Pruess, K. 1991. TOUGH2—A General-Purpose Numerical Simulator for Multiphase 100413 Fluid and Heat Flow. LBL-29400. Berkeley, California: Lawrence Berkeley Laboratory. ACC: NNA.19940202.0088.

Rice, W.A., 1984. Preliminary Two-Dimensional Regional Hydrologic Model of the 101284 Nevada Test Site and Vicinity. SAND83-7466. Albuquerque, New Mexico: Sandia National Laboratories. ACC: NNA.19900810.0286.

Savard, C.S., 1998. Estimated Ground-Water Recharge from Streamflow in Fortymile Wash Near Yucca Mountain, Nevada. Water-Resources Investigations Report 97-4273. Denver, Colorado: U.S. Geological Survey. TIC: 236848.

USGS (U.S. Geological Survey) 2003. Simulation of Net Infiltration for Modern and Potential Future Climates. ANL-NBS-HS-000032 REV 00 ICN 02 [Errata 002].

Denver, Colorado: U.S. Geological Survey. ACC: MOL.20011119.0334;

DOC.20031014.0004; DOC.20031015.0001.

Waddell, R.K. 1982. Two-Dimensional, Steady-State Model of Ground-Water Flow, Nevada Test Site and Vicinity, Nevada-California. Water-Resources Investigations Report 82-4085. Denver, Colorado: U.S. Geological Survey.

ACC: NNA.19870518.0055.

Wilson, C. 2001. Data Qualification Report: Stratigraphic Data Supporting the 155614 Hydrogeologic Framework Model for Use on the Yucca Mountain Project. TDR-NBS-HS-000013 REV 00. Las Vegas, Nevada: Bechtel SAIC Company. ACC: MOL.20010725.0225.

Wu, Y.S.; Ritcey, A.C.; Ahlers, C.F.; Mishra, A.K.; Hinds, J.J.; and Bodvarsson, G.S. 1997. Providing Base-Case Flow Fields for TSPA-VA: Evaluation of Uncertainty of Present-Day Infiltration Rates Using DKM/Base-Case and DKM/Weeps Parameter Sets. Milestone SLX01LB2. Berkeley, California: Lawrence Berkeley National Laboratory. ACC: MOL.19980501.0475.

\subsection{CODES, STANDARDS, REGULATIONS, AND PROCEDURES}

10 CFR 63. Energy: Disposal of High-Level Radioactive Wastes in a Geologic Repository at Yucca Mountain, Nevada. Readily available.

AP-2.22Q, Rev. 1, ICN 1. Classification Analyses and Maintenance of the Q-List. Washington, D.C.: U.S. Department of Energy, Office of Civilian Radioactive Waste Management. ACC: DOC.20040714.0002.

AP-SIII.2Q, Rev. 1, ICN 2. Qualification of Unqualified Data. Washington, D.C.: U.S. Department of Energy, Office of Civilian Radioactive Waste Management. ACC: DOC.20040127.0008. 
AP-SIII.9Q, Rev. 1, ICN 7. Scientific Analyses. Washington, D.C.: U.S. Department of Energy, Office of Civilian Radioactive Waste Management.

ACC: DOC.20040920.0001.

AP-SV.1Q, Rev. 1, ICN 1. Control of the Electronic Management of Information. Washington, D.C.: U.S. Department of Energy, Office of Civilian Radioactive Waste Management. ACC: DOC.20040308.0001.

LP-SI.11Q-BSC, Rev. 0, ICN 0. Software Management. Washington, D.C.: U.S. Department of Energy, Office of Civilian Radioactive Waste Management.

ACC: DOC.20040225.0007.

\subsection{SOURCE DATA, LISTED BY DATA TRACKING NUMBER}

GS040308312144.001. Death Valley Regional Flow System: 2001 Steady State Model 171472 Data. Submittal data : 03/22/04.

GS960808312144.003. Hydrogeologic Evaluation and Numerical Simulation of the Death Valley Regional Ground-Water Flow System, Nevada and California, Using Geoscientific Information Systems. Submittal date: 08/29/1996.

LB03023DSSCP9I.001. 3-D Site Scale UZ Flow Field Simulations for 9 Infiltration Scenarios. Submittal date: 02/28/2003.

LB971212001254.001. DKM Basecase Parameter Set for UZ Model with Mean Fracture Alpha, Present Day Infiltration, and Estimated Welded, Non-Welded and Zeolitic FMX. Submittal date: 12/12/1997.

MO0102DQRGWREC.001. Groundwater Recharge Rate Data for the Four Reaches of Fortymile Wash Near Yucca Mountain, Nevada. Submittal date: 02/26/2001.

MO0407SEPFEPLA.000. LA FEP list. Submittal date: 07/20/2004.

105121

163044

104749

\subsection{OUTPUT DATA, LISTED BY DATA TRACKING NUMBER}

SN9908T0581999.001. Recharge and Lateral Groundwater Flow Boundary Conditions for the Saturated Zone (SZ) Site-Scale Flow and Transport Model. Submittal date: 08/19/1999.

SN0407T0504404.002. Recharge and Lateral Groundwater Flow Boundary Conditions for the Saturated Zone (SZ) Site-Scale Flow and Transport Model from the DVRFS and UZ Site-scale Flow Models. Submittal date: 07/15/2004.

Files included in the DTN: SN0407T0504404.002

boundaries.xls - contains worksheets for 1997 and 2001 DVRFS lateral flux boundaries (targets for FEHM) 
conn_M_1997.out - contains connectivity data from the 1997 UZ site-scale flow model mesh

conn_M_2003.out - contains connectivity data from the 2003 UZ site-scale flow model mesh

extract_F_1997.out - contains fracture flow data from the 1997 UZ site-scale flow model

extract_F_2003.out - contains fracture flow data from the 2003 UZ site-scale flow model

extract_M_1997.out - contains matrix flow data from the 1997 UZ site-scale flow model

extract_M_2003.out - contains matrix flow data from the 2003 UZ site-scale flow model

meshgrep2_1997.out - 1997 UZ area connection data

meshgrep2_2003.out - 2003 UZ area connection datarech_site_1997.dat - 1997

DVRFS water table recharge on $1,500 \mathrm{~m}$ grid

read rchg from MFP.xls - spreadsheet for calculating distributed recharge to the 1997 DVRFS

rech_all_new.xls - spreadsheet with worksheets containing data from all recharge from 1997 DVRFS, 1997 UZ, and Fortymile Wash

rech_all_new_1997.prn - ASCII text file output from rech_all_new.xls (1997 worksheet)

rech_all_new_2003.prn - ASCII text file output from rech_all_new.xls 2003worksheet)

rech_distr_stream_1997.dat - distributed recharge data from the 1997 DVRFS with contribution from Fortymile Wash included

rech_distr_stream_2001.dat - distributed recharge data from the 2001 DVRFS with contribution from Fortymile Wash included

rech_distr_1997.dat - 1997 DVRFS water table recharge on $500 \mathrm{~m}$ grid rech_distr_2001.dat - 2001 DVRFS water table recharge on $500 \mathrm{~m}$ grid rech_site_1997.dat - 1997 DVRFS water table recharge on 1,500 m grid rech_site_2001.dat - 2001 DVRFS water table recharge on 1,500 m grid wt_flow_500_1997.dat - final FEHM input data, water table recharge - 1997 models wt_flow_500_2003.dat - final FEHM input data, water table recharge - 2001 and 2003 models wt_flux_uz.xls - contains 1997 and 2003 worksheet with UZ fluxes 


\subsection{SOFTWARE CODES}

LANL (Los Alamos National Laboratory) 2001. CORPSCON V5.11.08.

155082 10547-5.11.08-00.

LBNL (Lawrence Berkeley National Laboratory) 2000. TOUGH2. V1.4. Sun

146496 Workstation and DEC/ALPHA. 10007-1.4-01.

SNL (Sandia National Laboratories) 2002. EXT_RECH V 1.0. Sun - SunOS 5.7.

163072 10958-1.0-00.

SNL 2002. Extract. V 1.0. Sun UltraSPARC - SunOS 5.7. 10955-1.0-00.

163070

SNL 2002. Extract. V 1.1. Sun UltraSPARC - SunOS 5.7. 10955-1.1-00. 163071

SNL 2002. Mult_Rech V 1.0. Sun UltraSPARC - SunOS 5.7. 10959-1.0-00. 163073

SNL 2002. Xread_Distr_Rech.V 1.0. Sun UltraSPARC - SunOS 5.7. 10960-1.0-00. 163074

SNL 2002. Xread_Distr_Rech.-UZ. V 1.0. Sun UltraSPARC - SunOS 5.7. 10961-1.0- 163075 00 .

SNL 2002. Xread_Reaches. V 1.0. Sun UltraSPARC - SunOS 5.7. 10962-1.0-00. 163076

SNL 2002. Xwrite_Flow_New. V 1.0-125. Sun UltraSPARC - SunOS 5.7. 10963-1.0- 163077 $125-00$.

SNL 2002. Zone. V 1.0. Sun UltraSPARC - SunOS 5.7. 10957-1.0-00. 163078

USGS 1999. MODFLOWP. V2.3. 10144-2.3-00. 150454 
Recharge and Lateral Groundwater Flow Boundary Conditions for the Saturated Zone Site-Scale Flow and Transport Model

APPENDIX A

DATA TABLES 
Recharge and Lateral Groundwater Flow Boundary Conditions for the Saturated Zone Site-Scale Flow and Transport Model 
Recharge and Lateral Groundwater Flow Boundary Conditions for the Saturated Zone Site-Scale Flow and Transport Model

The tables contained in this appendix are reproduced from DTN: SN9908T0581999.001 and represent the erroneous cell-by-cell flows across planes in the 1997 DVRFS corresponding to each of the four boundaries in the SZ site-scale flow model. They are presented to facilitate comparison between the incorrect data set and the new output DTN: SN0407T0504404.002.

Table A-1. Cell-by-Cell Flow Terms ( $\mathrm{m}^{3} /$ day) from the 1997 DVRFS Model along the West Boundary of the Site-Scale Model

\begin{tabular}{|c|c|c|c|c|c|}
\hline Column & Row & Layer1 & Layer2 & Layer3 & Sum \\
\hline 62 & 66 & $3.00 \times 10^{2}$ & $1.16 \times 10^{2}$ & $1.73 \times 10^{2}$ & $5.89 \times 10^{2}$ \\
\hline 62 & 67 & $3.85 \times 10^{2}$ & $1.29 \times 10^{2}$ & $2.84 \times 10^{2}$ & $7.98 \times 10^{2}$ \\
\hline 62 & 68 & $9.13 \times 10^{1}$ & $1.19 \times 10^{2}$ & $1.83 \times 10^{2}$ & $3.93 \times 10^{2}$ \\
\hline 62 & 69 & $8.16 \times 10^{1}$ & $5.29 \times 10^{2}$ & $1.64 \times 10^{2}$ & $7.74 \times 10^{2}$ \\
\hline 62 & 70 & $1.20 \times 10^{2}$ & $7.62 \times 10^{2}$ & $1.18 \times 10^{2}$ & $9.99 \times 10^{2}$ \\
\hline 62 & 71 & $1.02 \times 10^{2}$ & $2.26 \times 10^{2}$ & $1.77 \times 10^{2}$ & $5.06 \times 10^{2}$ \\
\hline 62 & 72 & $3.59 \times 10^{0}$ & $4.58 \times 10^{0}$ & $4.59 \times 10^{0}$ & $1.28 \times 10^{1}$ \\
\hline 62 & 73 & $9.55 \times 10^{-1}$ & $1.60 \times 10^{0}$ & $-2.02 \times 10^{-1}$ & $2.35 \times 10^{0}$ \\
\hline 62 & 74 & $-4.32 \times 10^{1}$ & $-7.44 \times 10^{-1}$ & $2.24 \times 10^{-1}$ & $-4.37 \times 10^{1}$ \\
\hline 62 & 75 & $-2.30 \times 10^{1}$ & $-5.38 \times 10^{-1}$ & $1.96 \times 10^{0}$ & $-2.15 \times 10^{1}$ \\
\hline 62 & 76 & $-2.66 \times 10^{1}$ & $-5.57 \times 10^{-1}$ & $2.17 \times 10^{0}$ & $-2.50 \times 10^{1}$ \\
\hline 62 & 77 & $-1.33 \times 10^{2}$ & $-6.12 \times 10^{-1}$ & $1.85 \times 10^{0}$ & $-1.31 \times 10^{2}$ \\
\hline 62 & 78 & $-3.07 \times 10^{1}$ & $-1.97 \times 10^{-1}$ & $1.39 \times 10^{0}$ & $-2.95 \times 10^{1}$ \\
\hline 62 & 79 & $6.78 \times 10^{1}$ & $1.51 \times 10^{-1}$ & $1.05 \times 10^{0}$ & $6.90 \times 10^{1}$ \\
\hline 62 & 80 & $9.91 \times 10^{1}$ & $2.88 \times 10^{-1}$ & $9.30 \times 10^{-1}$ & $1.00 \times 10^{2}$ \\
\hline 62 & 81 & $1.03 \times 10^{2}$ & $2.19 \times 10^{-1}$ & $6.03 \times 10^{-1}$ & $1.03 \times 10^{2}$ \\
\hline 62 & 82 & $1.51 \times 10^{2}$ & $5.85 \times 10^{-1}$ & $4.22 \times 10^{-1}$ & $1.52 \times 10^{2}$ \\
\hline 62 & 83 & $3.38 \times 10^{1}$ & $4.75 \times 10^{-1}$ & $6.81 \times 10^{-1}$ & $3.50 \times 10^{1}$ \\
\hline 62 & 84 & $2.35 \times 10^{1}$ & $1.12 \times 10^{2}$ & $8.07 \times 10^{-1}$ & $1.36 \times 10^{2}$ \\
\hline 62 & 85 & $1.16 \times 10^{2}$ & $1.57 \times 10^{2}$ & $4.55 \times 10^{1}$ & $3.18 \times 10^{2}$ \\
\hline 62 & 86 & $5.45 \times 10^{2}$ & $2.27 \times 10^{2}$ & $6.57 \times 10^{2}$ & $1.43 \times 10^{3}$ \\
\hline 62 & 87 & $4.35 \times 10^{2}$ & $6.45 \times 10^{2}$ & $7.99 \times 10^{2}$ & $1.88 \times 10^{3}$ \\
\hline 62 & 88 & $3.89 \times 10^{2}$ & $5.83 \times 10^{2}$ & $3.17 \times 10^{1}$ & $1.00 \times 10^{3}$ \\
\hline 62 & 89 & $3.40 \times 10^{2}$ & $4.82 \times 10^{2}$ & $1.60 \times 10^{1}$ & $8.38 \times 10^{2}$ \\
\hline 62 & 90 & $6.31 \times 10^{1}$ & $6.05 \times 10^{2}$ & $-1.81 \times 10^{0}$ & $6.66 \times 10^{2}$ \\
\hline 62 & 91 & $-7.49 \times 10^{-1}$ & $7.44 \times 10^{0}$ & $-1.93 \times 10^{0}$ & $4.75 \times 10^{0}$ \\
\hline 62 & 92 & $-5.17 \times 10^{1}$ & $-1.19 \times 10^{0}$ & $-2.17 \times 10^{0}$ & $-5.51 \times 10^{1}$ \\
\hline 62 & 93 & $-5.98 \times 10^{1}$ & $-2.57 \times 10^{0}$ & $-2.68 \times 10^{0}$ & $-6.51 \times 10^{1}$ \\
\hline 62 & 94 & $-8.07 \times 10^{1}$ & $-3.55 \times 10^{0}$ & $-3.71 \times 10^{0}$ & $-8.80 \times 10^{1}$ \\
\hline 62 & 95 & $-8.60 \times 10^{1}$ & $-4.20 \times 10^{0}$ & $-4.31 \times 10^{0}$ & $-9.45 \times 10^{1}$ \\
\hline
\end{tabular}

Source: DTN: SN9908T0581999.001 [DIRS 132867] in file boundaries.xIs. 
Recharge and Lateral Groundwater Flow Boundary Conditions for the Saturated Zone Site-Scale Flow and Transport Model

Table A-2. Cell-by-Cell Flow Terms ( $\mathrm{m}^{3} /$ day) from the 1997 DVRFS Model along the East Boundary of the Site-Scale Model

\begin{tabular}{|c|c|c|c|c|c|}
\hline Column & Row & Layer1 & Layer2 & Layer3 & Sum \\
\hline 82 & 66 & $3.51 \times 10^{1}$ & $1.04 \times 10^{2}$ & $1.03 \times 10^{0}$ & $1.40 \times 10^{2}$ \\
\hline 82 & 67 & $3.25 \times 10^{1}$ & $5.95 \times 10^{1}$ & $2.87 \times 10^{0}$ & $9.49 \times 10^{1}$ \\
\hline 82 & 68 & $1.03 \times 10^{1}$ & $1.79 \times 10^{1}$ & $1.85 \times 10^{0}$ & $3.01 \times 10^{1}$ \\
\hline 82 & 69 & $-3.49 \times 10^{0}$ & $-6.73 \times 10^{0}$ & $1.90 \times 10^{-3}$ & $-1.02 \times 10^{1}$ \\
\hline 82 & 70 & $-2.13 \times 10^{1}$ & $-3.07 \times 10^{1}$ & $1.63 \times 10^{-2}$ & $-5.19 \times 10^{1}$ \\
\hline 82 & 71 & $-3.12 \times 10^{1}$ & $-4.06 \times 10^{1}$ & $2.09 \times 10^{-2}$ & $-7.18 \times 10^{1}$ \\
\hline 82 & 72 & $-9.51 \times 10^{1}$ & $-1.51 \times 10^{-2}$ & $8.80 \times 10^{-3}$ & $-9.51 \times 10^{1}$ \\
\hline 82 & 73 & $9.57 \times 10^{-2}$ & $2.22 \times 10^{1}$ & $1.12 \times 10^{-1}$ & $2.24 \times 10^{1}$ \\
\hline 82 & 74 & $-2.53 \times 10^{-2}$ & $-4.91 \times 10^{0}$ & $3.11 \times 10^{-1}$ & $-4.63 \times 10^{0}$ \\
\hline 82 & 75 & $5.17 \times 10^{0}$ & $3.82 \times 10^{1}$ & $3.19 \times 10^{-1}$ & $4.36 \times 10^{1}$ \\
\hline 82 & 76 & $5.32 \times 10^{0}$ & $3.25 \times 10^{1}$ & $1.42 \times 10^{1}$ & $5.21 \times 10^{1}$ \\
\hline 82 & 77 & $2.31 \times 10^{1}$ & $2.99 \times 10^{1}$ & $3.69 \times 10^{1}$ & $8.99 \times 10^{1}$ \\
\hline 82 & 78 & $2.12 \times 10^{1}$ & $1.98 \times 10^{1}$ & $1.42 \times 10^{1}$ & $5.52 \times 10^{1}$ \\
\hline 82 & 79 & $5.62 \times 10^{0}$ & $1.58 \times 10^{1}$ & $4.42 \times 10^{0}$ & $2.58 \times 10^{1}$ \\
\hline 82 & 80 & $1.43 \times 10^{0}$ & $1.89 \times 10^{0}$ & $-6.96 \times 10^{-1}$ & $2.62 \times 10^{0}$ \\
\hline 82 & 81 & $4.41 \times 10^{0}$ & $1.34 \times 10^{0}$ & $-4.22 \times 10^{-2}$ & $5.71 \times 10^{0}$ \\
\hline 82 & 82 & $1.43 \times 10^{1}$ & $3.25 \times 10^{0}$ & $4.38 \times 10^{-2}$ & $1.76 \times 10^{1}$ \\
\hline 82 & 83 & $1.34 \times 10^{1}$ & $3.52 \times 10^{0}$ & $-7.69 \times 10^{-1}$ & $1.61 \times 10^{1}$ \\
\hline 82 & 84 & $7.09 \times 10^{0}$ & $2.99 \times 10^{0}$ & $-1.49 \times 10^{0}$ & $8.59 \times 10^{0}$ \\
\hline 82 & 85 & $6.22 \times 10^{0}$ & $5.05 \times 10^{0}$ & $1.85 \times 10^{-1}$ & $1.14 \times 10^{1}$ \\
\hline 82 & 86 & $2.93 \times 10^{1}$ & $5.40 \times 10^{0}$ & $3.13 \times 10^{1}$ & $6.61 \times 10^{1}$ \\
\hline 82 & 87 & $1.97 \times 10^{0}$ & $1.62 \times 10^{1}$ & $4.11 \times 10^{1}$ & $5.93 \times 10^{1}$ \\
\hline 82 & 88 & $2.85 \times 10^{-1}$ & $1.55 \times 10^{3}$ & $3.12 \times 10^{3}$ & $4.67 \times 10^{3}$ \\
\hline 82 & 89 & $3.89 \times 10^{-1}$ & $2.09 \times 10^{3}$ & $4.15 \times 10^{3}$ & $6.24 \times 10^{3}$ \\
\hline 82 & 90 & $4.16 \times 10^{-1}$ & $2.23 \times 10^{3}$ & $4.42 \times 10^{3}$ & $6.65 \times 10^{3}$ \\
\hline 82 & 91 & $4.11 \times 10^{-1}$ & $2.20 \times 10^{3}$ & $4.39 \times 10^{3}$ & $6.59 \times 10^{3}$ \\
\hline 82 & 92 & $3.20 \times 10^{0}$ & $2.14 \times 10^{3}$ & $4.30 \times 10^{3}$ & $6.45 \times 10^{3}$ \\
\hline 82 & 93 & $5.17 \times 10^{0}$ & $2.06 \times 10^{3}$ & $4.21 \times 10^{3}$ & $6.27 \times 10^{3}$ \\
\hline 82 & 94 & $1.45 \times 10^{1}$ & $1.85 \times 10^{3}$ & $3.99 \times 10^{3}$ & $5.86 \times 10^{3}$ \\
\hline 82 & 95 & $1.38 \times 10^{1}$ & $1.56 \times 10^{3}$ & $3.69 \times 10^{3}$ & $5.26 \times 10^{3}$ \\
\hline
\end{tabular}

Source: DTN: SN9908T0581999.001 [DIRS 132867] in file boundaries.xIs. 
Recharge and Lateral Groundwater Flow Boundary Conditions for the Saturated Zone Site-Scale Flow and Transport Model

Table A-3. Cell-by-Cell Flow Terms ( $\mathrm{m}^{3} /$ day) from the 1997 DVRFS Model along the North Boundary of the Site-Scale Model

\begin{tabular}{|l|l|c|c|c|c|}
\hline Column & Row & Layer1 & Layer2 & Layer3 & Sum \\
\hline 63 & 65 & $4.37 \times 10^{2}$ & $1.59 \times 10^{2}$ & $8.89 \times 10^{1}$ & $6.84 \times 10^{2}$ \\
\hline 64 & 65 & $4.45 \times 10^{2}$ & $6.66 \times 10^{2}$ & $1.27 \times 10^{2}$ & $1.24 \times 10^{3}$ \\
\hline 65 & 65 & $4.70 \times 10^{2}$ & $7.05 \times 10^{2}$ & $1.42 \times 10^{2}$ & $1.32 \times 10^{3}$ \\
\hline 66 & 65 & $4.97 \times 10^{2}$ & $7.43 \times 10^{2}$ & $1.46 \times 10^{2}$ & $1.39 \times 10^{3}$ \\
\hline 67 & 65 & $5.11 \times 10^{2}$ & $7.67 \times 10^{2}$ & $1.41 \times 10^{2}$ & $1.42 \times 10^{3}$ \\
\hline 68 & 65 & $5.13 \times 10^{2}$ & $7.71 \times 10^{2}$ & $1.31 \times 10^{2}$ & $1.42 \times 10^{3}$ \\
\hline 69 & 65 & $5.00 \times 10^{2}$ & $7.03 \times 10^{2}$ & $1.17 \times 10^{2}$ & $1.32 \times 10^{3}$ \\
\hline 70 & 65 & $9.00 \times 10^{1}$ & $1.24 \times 10^{2}$ & $9.94 \times 10^{1}$ & $3.14 \times 10^{2}$ \\
\hline 71 & 65 & $9.43 \times 10^{1}$ & $1.36 \times 10^{2}$ & $7.92 \times 10^{1}$ & $3.09 \times 10^{2}$ \\
\hline 72 & 65 & $8.19 \times 10^{1}$ & $1.26 \times 10^{2}$ & $5.47 \times 10^{1}$ & $2.63 \times 10^{2}$ \\
\hline 73 & 65 & $7.92 \times 10^{1}$ & $1.22 \times 10^{2}$ & $4.55 \times 10^{1}$ & $2.47 \times 10^{2}$ \\
\hline 74 & 65 & $8.18 \times 10^{1}$ & $1.24 \times 10^{2}$ & $2.46 \times 10^{0}$ & $2.08 \times 10^{2}$ \\
\hline 75 & 65 & $7.81 \times 10^{1}$ & $2.08 \times 10^{2}$ & $3.32 \times 10^{0}$ & $2.89 \times 10^{2}$ \\
\hline 76 & 65 & $7.14 \times 10^{1}$ & $8.35 \times 10^{2}$ & $2.45 \times 10^{1}$ & $9.31 \times 10^{2}$ \\
\hline 77 & 65 & $7.71 \times 10^{1}$ & $9.12 \times 10^{2}$ & $2.49 \times 10^{1}$ & $1.01 \times 10^{3}$ \\
\hline 78 & 65 & $8.48 \times 10^{1}$ & $9.90 \times 10^{2}$ & $2.64 \times 10^{1}$ & $1.10 \times 10^{3}$ \\
\hline 79 & 65 & $1.61 \times 10^{2}$ & $1.06 \times 10^{3}$ & $2.73 \times 10^{1}$ & $1.25 \times 10^{3}$ \\
\hline 80 & 65 & $1.67 \times 10^{2}$ & $1.10 \times 10^{3}$ & $2.75 \times 10^{1}$ & $1.30 \times 10^{3}$ \\
\hline 81 & 65 & $2.05 \times 10^{2}$ & $3.22 \times 10^{2}$ & $3.82 \times 10^{1}$ & $5.65 \times 10^{2}$ \\
\hline 82 & 65 & $8.24 \times 10^{1}$ & $2.26 \times 10^{2}$ & $4.55 \times 10^{1}$ & $3.54 \times 10^{2}$ \\
\hline
\end{tabular}

Source: DTN: SN9908T0581999.001 [DIRS 132867] in file boundaries.xls. 
Recharge and Lateral Groundwater Flow Boundary Conditions for the Saturated Zone Site-Scale Flow and Transport Model

Table A-4. Cell-by-Cell flow Terms ( $\mathrm{m}^{3 /}$ day) from the 1997 DVRFS Model along the South Boundary of the Site-Scale Model

\begin{tabular}{|l|l|c|c|c|c|}
\hline Column & \multicolumn{1}{|c|}{ Row } & Layer1 & Layer2 & Layer3 & Sum \\
\hline 63 & 95 & $-1.02 \times 10^{1}$ & $-2.70 \times 10^{1}$ & $-2.39 \times 10^{0}$ & $-3.96 \times 10^{1}$ \\
\hline 64 & 95 & $-1.62 \times 10^{2}$ & $-6.53 \times 10^{1}$ & $-3.15 \times 10^{0}$ & $-2.31 \times 10^{2}$ \\
\hline 65 & 95 & $-8.26 \times 10^{1}$ & $-7.57 \times 10^{2}$ & $-1.66 \times 10^{2}$ & $-1.01 \times 10^{3}$ \\
\hline 66 & 95 & $-3.59 \times 10^{2}$ & $-6.01 \times 10^{2}$ & $-1.93 \times 10^{2}$ & $-1.15 \times 10^{3}$ \\
\hline 67 & 95 & $-3.71 \times 10^{2}$ & $-6.12 \times 10^{2}$ & $-2.43 \times 10^{2}$ & $-1.23 \times 10^{3}$ \\
\hline 68 & 95 & $-5.12 \times 10^{2}$ & $-7.55 \times 10^{2}$ & $-2.49 \times 10^{2}$ & $-1.52 \times 10^{3}$ \\
\hline 69 & 95 & $-5.56 \times 10^{2}$ & $-8.30 \times 10^{2}$ & $-1.31 \times 10^{3}$ & $-2.70 \times 10^{3}$ \\
\hline 70 & 95 & $-5.92 \times 10^{2}$ & $-8.86 \times 10^{2}$ & $-1.35 \times 10^{3}$ & $-2.82 \times 10^{3}$ \\
\hline 71 & 95 & $-6.10 \times 10^{2}$ & $-9.14 \times 10^{2}$ & $-1.43 \times 10^{3}$ & $-2.96 \times 10^{3}$ \\
\hline 72 & 95 & $-5.58 \times 10^{2}$ & $-8.54 \times 10^{2}$ & $-1.37 \times 10^{3}$ & $-2.78 \times 10^{3}$ \\
\hline 73 & 95 & $-4.87 \times 10^{2}$ & $-7.49 \times 10^{2}$ & $-1.28 \times 10^{3}$ & $-2.52 \times 10^{3}$ \\
\hline 74 & 95 & $-2.97 \times 10^{2}$ & $-4.63 \times 10^{2}$ & $-1.19 \times 10^{3}$ & $-1.95 \times 10^{3}$ \\
\hline 75 & 95 & $-1.34 \times 10^{2}$ & $-4.55 \times 10^{1}$ & $-1.07 \times 10^{3}$ & $-1.25 \times 10^{3}$ \\
\hline 76 & 95 & $-7.59 \times 10^{1}$ & $-3.54 \times 10^{1}$ & $-5.42 \times 10^{1}$ & $-1.66 \times 10^{2}$ \\
\hline 77 & 95 & $-1.03 \times 10^{0}$ & $1.62 \times 10^{1}$ & $2.18 \times 10^{1}$ & $3.70 \times 10^{1}$ \\
\hline 78 & 95 & $-1.02 \times 10^{1}$ & $-9.78 \times 10^{1}$ & $-1.52 \times 10^{2}$ & $-2.60 \times 10^{2}$ \\
\hline 79 & 95 & $-6.43 \times 10^{0}$ & $-3.47 \times 10^{3}$ & $-7.41 \times 10^{3}$ & $-1.09 \times 10^{4}$ \\
\hline 80 & 95 & $-5.33 \times 10^{0}$ & $-3.42 \times 10^{3}$ & $-7.54 \times 10^{3}$ & $-1.10 \times 10^{4}$ \\
\hline 81 & 95 & $-3.20 \times 10^{1}$ & $-3.66 \times 10^{3}$ & $-7.83 \times 10^{3}$ & $-1.15 \times 10^{4}$ \\
\hline 82 & 95 & $-3.58 \times 10^{1}$ & $-4.12 \times 10^{3}$ & $-8.15 \times 10^{3}$ & $-1.23 \times 10^{4}$ \\
\hline
\end{tabular}

Source: DTN: SN9908T0581999.001 [DIRS 132867] in file boundaries.xIs. 
Recharge and Lateral Groundwater Flow Boundary Conditions for the Saturated Zone Site-Scale Flow and Transport Model

\section{APPENDIX B}

ONE-TIME USE OF QUALIFICATION OF DTN: GS960808312144.003 
Recharge and Lateral Groundwater Flow Boundary Conditions for the Saturated Zone Site-Scale Flow and Transport Model 


\section{B1. INTRODUCTION}

This Internal Data Qualification Report uses technical assessment methods to evaluate the appropriateness of unqualified data from the Death Valley regional groundwater flow model (D’Agnese et al. 1997 [DIRS 100131]) for use in report S0010, Recharge and Lateral Groundwater Flow Boundary Conditions for the Saturated Zone Site-Scale Flow and Transport Model, Revision 01. This qualification report was prepared as an attachment to this report in conformance with AP-SIII.2Q, Qualification of Unqualified Data. The Death Valley regional groundwater flow model was prepared by the U.S. Geological Survey and has been published by the U.S. Geological Survey as a Water Resources Investigations Report. Inputs to the regional model were used to identify groundwater recharge across the upper surface of the Yucca Mountain Site Project's saturated zone site-scale flow and transport model, and outputs from the regional model were used to identify groundwater flow across the lateral boundaries of the site-scale model. Specifically, the data to be qualified are found in DTN: GS960808312144.003 [DIRS 105121], which contains the input and output files from the work of D'Agnese et al. (1997 [DIRS 100131]).

The Data Qualification Team found the Death Valley regional flow model database to be well researched, the model to be appropriately constructed, and the resulting output to provide a reasonable simulation of regional groundwater flow. Several approaches to estimating recharge from precipitation were evaluated by the regional model's authors before deciding on a modification of an empirical relationship developed by Maxey and Eakin (1950 [DIRS 100598]). Shortcomings of other, more recent techniques were identified, particularly for application to desert areas where small amounts of recharge were ignored. Within the area of the saturated zone site-scale model, the recharge fluxes from the regional model are consistent with similar magnitude fluxes independently estimated from the unsaturated zone flow model and from focused recharge from Fortymile Wash. The Maxey-Eakin method is widely used and accepted by the technical community and is appropriate for use in the regional model.

The effective residual between actual and simulated heads was determined to be $45 \mathrm{~m}$ for most wells in the regional model. The Data Qualification Team considers this overall goodness-of-fit to be moderate, but acceptable. Because the goodness-of-fit is a measure of the model's accuracy, a degree of uncertainty must be associated with the regional model outputs used to identify lateral flux boundary conditions for the site-scale model. These uncertainties were adequately addressed by using the regional model fluxes, not as absolute values, but as target boundary conditions during site-scale model calibration. Specifying the fluxes absolutely would also over-constrain the site-scale model and interfere with its calibration.

The Data Qualification Team has concluded that the Death Valley regional flow model provides a qualified source of data for establishing recharge and lateral flux boundary conditions for the base-case SZ site-scale flow and transport model. In accordance with AP-SIII.2Q, this finding qualifies these data only for their intended uses in this report. The regional model's source DTN: GS960808312144.003 [DIRS 105121] will remain unqualified for other uses. 


\section{B1.1 PURPOSE}

This Internal Data Qualification Report evaluates the appropriateness of unqualified data from the U.S. Geological Survey (USGS) flow model of the Death Valley regional groundwater system for use in this report, Recharge and Lateral Groundwater Flow Boundary Conditions for the Saturated Zone Site-Scale Flow and Transport Model, Revision 01. This qualification report was prepared as an appendix to this report.

The regional model was developed in part to support site-scale modeling for the YMP. Inputs to the regional model were used in this report to identify groundwater recharge across the upper surface of the site-scale model and outputs from the regional model were used to identify groundwater flow targets across the lateral boundaries of the site-scale model. This evaluation was performed in accordance with the internal data qualification requirements of AP-SIII.2Q, Qualification of Unqualified Data. A finding that the regional model is internally qualified means that it is qualified to support the license application, but only for the uses made in Scientific Analysis Report S0010. The appropriateness and limitations of the data with respect to intended use are addressed in this appendix.

\section{B1.2 SCOPE}

This appendix was prepared according to the guidelines in AP-SIII.2Q. The Internal Data Qualification Plan identifies one data tracking number (DTN) containing unqualified, developed hydrogeological data associated with the Death Valley regional flow model. These data were collected by the USGS and are cited in a USGS Water Resources Investigations Report (WRIR) by D'Agnese et al. (1997 [DIRS 100131]). The data evaluated in the plan are presented in the DTN: GS960808312144.003 [DIRS 105121] titled Hydrogeologic Evaluation and Numerical Simulation of the Death Valley Regional Ground-Water Flow System, Nevada and California, Using Geoscientific Information Systems.

The foregoing DTN is unqualified because it summarizes a study performed for the YMP and contains data collected by nonYMP personnel. In addition to the recharge and lateral flow data used in this report, the data set contains other information that was not directly used in that Scientific Analysis Report and is not within the scope of this qualification activity. This qualification report focuses on the specific data selected to support the SZ site-scale groundwater flow model in this report. To the extent that only subsets of data within this DTN were used in the this report (e.g., cell-by-cell fluxes were extracted from the 1997 DVRFS model at positions corresponding to the boundaries of the SZ site-scale flow model), only those data are evaluated for qualification. 


\section{B1.3 DATA QUALIFICATION TEAM}

Chairperson: The Chairperson for this internal data qualification, Scott C. James, is the originator of this report.

Team Member: The team member for this internal data qualification is Thomas S. Lowry.

\section{B1.4 BACKGROUND}

The data from DTN: GS960808312144.003 [DIRS 105121] that were used in this report are presented in USGS WRIR 96-4300, Hydrogeologic Evaluation and Numerical Simulation of the Death Valley Regional Ground-Water Flow System, Nevada and California (D’Agnese et al. 1997 [DIRS 100131]). Although that report is unqualified, the model construction and review were performed in accordance with YMP quality assurance procedures, the model was developed and reviewed in accordance with USGS policy, and the model results were formally published in a WRIR after receiving the USGS Director's approval (D'Agnese et al. 1997 [DIRS 100131], p. 4).

The domain of the YMP SZ site-scale flow and transport model lies entirely within the larger domain of the Death Valley regional flow model. Three sources of information were used in this report to develop estimates of groundwater recharge across the upper surface of the base-case SZ site-scale model: distributed recharge as used in the 1997 DVRFS, flux at the bottom boundary of the 1997 UZ site-scale flow model, and data from infiltration through Fortymile Wash (CRWMS M\&O 1999 [DIRS 124552], p. 6). The first of these was the regional model's input database, which contains estimates of recharge across the entire Death Valley region including the area of the base-case SZ site-scale flow model. The second information source for recharge was the flux across the lower, water table boundary, of the 1997 UZ site-scale flow model. The domain of the UZ site-scale model lies entirely within the larger domain of the base-case SZ site-scale flow model. Within the UZ site-scale flow model domain, recharge from the UZ models replaces recharge from the DVRFS models. The third information source is a USGS WRIR that provides an estimate of focused recharge along Fortymile Wash (Savard 1998 [DIRS 102213]). Within the area of Fortymile Wash, recharge to the SZ site-scale model is equal to the estimated recharge from flow in the wash. Only the first of these data sources, the 1997 DVRFS model, is addressed in this appendix. Outflow from the UZ model is technical product output, and the estimates of recharge from Fortymile Wash have been separately qualified (Wilson 2001 [DIRS 155614]).

Output from the regional model was used in this report to develop estimates of groundwater flow across the lateral boundaries of the base-case SZ site-scale flow model. This report uses a nested model approach, where uncertainties in boundary conditions for the smaller model are reduced by developing them from internal flow patterns calculated within a larger model. The increased precision and accuracy required in a site-specific study, such as at Yucca Mountain, requires fine grid resolution, which can be computationally expensive. To increase computational efficiency, the site model is reduced in size (area of model footprint) with the consequence that the model boundaries are often not optimally located where groundwater flow conditions are well understood. Thus, it is common to develop the boundary conditions from a larger, lower 
resolution model that has boundaries that are more optimally located, for example, at groundwater divides. This is the process followed in this report by using the regional model to develop boundary conditions for the SZ site-scale model.

\section{B2. QUALIFICATION APPROACH}

\section{B2.1 QUALIFICATION METHODS}

The regional model is unqualified because its input data are unqualified. The regional hydrologic and geologic data required for the model were collected outside the YMP because no other data were available (D'Agnese et al. 1997 [DIRS 100131], p. 4). However, model construction and review were performed in accordance with accepted YMP quality assurance procedures and USGS policy (D'Agnese et al. 1997 [DIRS 100131], p. 4). In view of these conditions and the unique status of the model in depicting regional groundwater flow, the data were evaluated for their intended use in this report by method number 5 of AP-SIII.2Q, Attachment 3, Technical Assessment.

The Data Qualification Team evaluated the appropriateness and accuracy of the methods used by the USGS to develop the regional model inputs and outputs used in this report. Technical assessments focused on the methodology used to prepare the model inputs and perform the modeling. The assessments also considered the appropriateness of the model results for the applied uses in this report and the accuracy requirements associated with those uses. Because the modeling was performed on a regional basis in an area with unevenly distributed data and complex hydrogeology, the modeling results are necessarily approximate. Such results can be appropriately used so long as consideration is given to limitations on their accuracy, precision, and applicability for an intended use.

\section{B2.2 EVALUATION CRITERIA}

Evaluation Criteria: The unqualified data were evaluated for use in thie report based on consideration of the following evaluation criteria. These criteria were selected to incorporate the considerations in AP-SIII.2Q, Attachment 3, Considerations for Determining Qualification Methods, and AP-SIII.2Q, Attachment 4, Qualification Process Attributes.

1. Are the methods used to develop the Death Valley regional groundwater model reasonable and generally accepted by the technical community?

2. Are the methods used in this report to develop boundary conditions from the regional modeling results reasonable and generally accepted by the technical community?

3. Are there more appropriate sources of information for developing the boundary conditions required in this report?

4. Are the boundary condition data and their associated uncertainties acceptable for their intended use? 
Recommendation Criteria: A recommendation for internal qualification is based on the satisfactory resolution of the evaluation criteria. Although these criteria are considered in determining whether the data are appropriate for their intended use in this report, the conclusions of the Data Qualification Team are based on expert judgment, and not all of the evaluation criteria may be applied.

\section{B3. EVALUATION RESULTS}

A technical assessment of the Death Valley regional flow model (D'Agnese et al. 1997 [DIRS 100131]) was performed by evaluating the approach used to develop the model's input database, the code selection and model development processes, and the assessment of the model output. Each of these elements of the review is discussed in the following sections of this appendix.

\section{B3.1 INPUT DATABASE}

The methods used to compile the regional model's input database were reviewed with special emphasis on the recharge data that were directly used in this report. The model was constructed using methods that have been widely accepted within the technical community. The model was based primarily on existing data, accompanied by extensive analysis and synthesis. In compiling the input database, heavy reliance was placed on the USGS National Water Information System database and on formal USGS publications, such as Professional Papers, Water Resources Investigations Reports, and Water Supply Papers. These are considered established fact by the YMP. New methods of storage, retrieval, and analysis of the complex input database were used that take advantage of recent advances in the technology of Geoscientific Information Systems (GSIS). Emphasis on the input database focused on identifying regional discharge, recharge, and interbasin flows, the regional hydrogeologic framework, and the regional patterns of groundwater movement.

\section{B3.1.1 Discharge Component}

The discharge component of groundwater movement within the region was quantified by measuring spring flows, estimating evapotranspiration by phreatophytes and wet playas, and estimating groundwater pumping (D’Agnese et al. 1997 [DIRS 100131], p. 43). Trained USGS professional geologists performed all studies and collected all data in accord with standard USGS procedures of the time. These methods and procedures are standard to the industry and provide acceptable resolution and accuracy for their use in this report. The greatest discharges were found to be evaporation from wet playas and evapotranspiration by plants. Detailed maps of the distributions of specific phreatophytes were developed for this study that included all areas in the region where significant groundwater discharges may occur from vegetation or moist, bare soil. Springs that discharge from the regional groundwater flow system were included in this study (D’Agnese et al. 1997 [DIRS 100131], p. 44). These springs typically emerge from the valley fill and carbonate aquifer at low elevations along the borders or on the floor of some valleys. Groundwater pumping was estimated based on average annual consumptive use for the various commercial, irrigation, mining, and domestic applications in the region. Although these 
average rates were based on different time periods, they were believed to offer the best available estimate of pumping rates (D’Agnese et al. 1997 [DIRS 100131], p. 47).

\section{B3.1.2 Recharge Component}

The recharge component of groundwater movement was quantified from precipitation data and estimates of interbasin flows at the model boundaries. Because of the uncertainty in some significant elements of the water balance, such as evapotranspiration rates and interbasin flows, the smaller contributions of surface water runoff and irrigation return flows were ignored in the study. Several approaches to estimating recharge from precipitation were evaluated by D’Agnese et al. (1997 [DIRS 100131]) before deciding on a modification of the empirical relationship developed by Maxey and Eakin (1950 [DIRS 100598]). The modification to the Maxey-Eakin method is based on a straightforward scaling of the original result by constants defined by the local zones of altitude, slope, permeability, and vegetation. Shortcomings of other, more recent techniques were discussed, particularly for application to desert areas where small amounts of recharge, such as the amount that probably occurs at Yucca Mountain, were ignored (D’Agnese et al. 1997 [DIRS 100131], p. 51). Although acknowledged to provide an empirical relationship, the Maxey-Eakin method is widely used and accepted by the technical community and was also used in preparing report U0010, Simulation of Net Infiltration for Modern and Potential Future Climates (USGS 2001 [DIRS 166518]).

The basic premise of the Maxey-Eakin recharge estimate is that groundwater recharge is proportional to annual precipitation. The method is best suited for arid environments, where high elevations typically experience much greater annual rainfall than low elevations. Recharge estimates using the Maxey-Eakin method require predicting how precipitation (rain and snow) varies with elevation change on an annual basis in localized areas. In the work of D'Agnese et al. (1997 [DIRS 100131]), the Maxey-Eakin method was made more sensitive to the four critical potential recharge indicators within the region: altitude, slope-aspect, relative rock and soil permeability, and vegetation (D’Agnese et al. 1997 [DIRS 100131], p. 52). Regional maps were prepared for each of these indicators and the recharge potential for each area was classified on a six-point scale. The four maps were then overlaid to produce a single map that combined the recharge ratings and a final recharge database, reclassified into six zones, was prepared. As with the Maxey-Eakin method, these recharge potential classes were assigned distinctive percentages of mean annual precipitation that are expected to contribute to recharge. Within the study area, these percentages ranged from zero in areas of no (or very low) recharge potential to 30 percent in areas of highest potential.

The accuracy and suitability of the refined Maxey-Eakin method were evaluated by D'Agnese et al. (1997 [DIRS 100131], p. 55). The locations of low-temperature springs (indicative of shallow groundwater flow) were assumed to indicate greater uphill recharge potentials. Areas uphill from low temperature springs, regardless of altitude, were found to coincide with predicted regional recharge areas. Also, because of the vegetation constraints imposed, all predicted recharge areas were restricted to zones classified as coniferous forests, piñon-juniper woodlands, or mixed transition shrublands. The suitability of the method was also evaluated by comparing total recharge volumes in individual hydrographic basins with those estimated in 
previous investigations. Generally, higher rates were estimated for the regional model in higher elevation basins and generally lower rates were estimated in the central and southern parts of the region. This is illustrated in Figures 6-1 and 6-2 of Scientific Analysis Report S00010. Overall, the D’Agnese et al. (1997 [DIRS 100131], p. 55) estimates were 30 percent higher than if the unmodified Maxey-Eakin method had been used. Reasons forwarded for this difference include a slightly higher estimated average annual rainfall, greater recharge potential in high elevation areas than previously estimated, and a reduced accuracy of the Maxey-Eakin method outside the area of the northern Great Basin where the empirical relationships were developed (D'Agnese et al. 1997 [DIRS 100131], p. 55). In terms of model impact, the increased recharge estimate is conservative in that increasing recharge in high elevation areas translates into a higher flux of groundwater. D’Agnese et al. (1997 [DIRS 100131], p. 55) conclude that while the prepared maps may not exactly describe recharge locations on a local scale, they appear to be appropriate for delineating large-scale zones of recharge. They note, however, that even with the better defined potential recharge areas, the rates are still based on an empirical relationship rather than actual measurements and reflect a significant unknown flux in the regional modeling (D'Agnese et al. 1997 [DIRS 100131], p. 55).

The recharge fluxes from the regional model are consistent with similar magnitude fluxes independently estimated from the UZ site-scale flow model and from the focused recharge from Fortymile Wash. The correlation between topography and recharge is similar in the regional and the UZ models, both of which show decreasing recharge with decreasing elevations to the south. The magnitudes of recharge are also similar, ranging from near zero to 8 or $9 \mathrm{~mm} /$ year. In addition, the more refined UZ site-scale flow model and Fortymile Wash analysis supplement the coarser, regional-scale analysis. The regional model focus is on broad topographical and vegetal considerations. It does not account for the refined topography of Yucca Mountain captured in the UZ site-scale flow model, nor does it specifically account for localized recharge from runoff in Fortymile Wash. Although residual uncertainties affect the recharge data, the total recharge mass fluxes of about $18.9 \mathrm{~kg} / \mathrm{s}$ into the base-case SZ flow model from the 1997 DVRFS is small compared to the total lateral mass influx of about $863.2 \mathrm{~kg} / \mathrm{s}$ calculated for the lateral boundaries of the model. Residual uncertainties in the recharge will therefore have relatively little impact on the overall modeling results. However, it is noted that beneath the repository site, where vertical seepage may be an important transport mechanism for migrating radionuclides, the recharge is comprehensively defined and integrated into the upper boundary of the base-case SZ site-scale flow and transport model.

Most lateral boundaries of the regional model were located where no groundwater flow occurs. Most of these boundaries result from the presence of low-permeability bedrock. Interbasin flows occur where the permeability of the bedrock is high enough to allow significant groundwater flow and where a hydraulic gradient exists across the boundary. Significant inflows may occur into the modeled region at ten different locations, most of which have little of the data needed to estimate flow rates (D’Agnese et al. 1997 [DIRS 100131], p. 59). No significant discharge from the region is thought to occur through interbasin flow. Although flows were estimated for each of these areas based on available information and the uncertainties in these estimates are high (D’Agnese et al. 1997 [DIRS 100131], p. 71), the flows from these sources are believed to be small compared to infiltration from precipitation. That is, the high uncertainty in the small 
boundary fluxes are insufficient to impact the overall model performance because the effects of infiltration (and uncertainties in infiltration) are so much greater.

\section{B3.1.3 Regional Hydrogeologic Framework}

The regional hydrogeologic framework accounts for the influences of stratigraphy and geologic structure on groundwater movement, the hydrologic properties of the hydrogeologic units, and the regional potentiometric surface. The framework is a geometrical configuration of the regional hydrogeologic structure designed to support the regional model. A regional digital elevation model was combined with geologic maps to provide a three-dimensional series of points locating the outcrops of individual geologic formations, geologic cross sections, and borehole lithologic logs. The surface and subsurface data were then interpolated to define the tops of hydrogeologic units (D’Agnese et al. 1997 [DIRS 100131], p. 33). Minor faults and other structures that were not considered to influence regional hydrology were not generally included in the model.

The distribution of hydraulic conductivity values was defined as part of the hydrogeologic framework. The conductivities initially assigned to each model cell were varied by rock type, depth, degree of faulting, degree of weathering, grain size, and degree of welding, as appropriate to the rock type (D’Agnese et al. 1997 [DIRS 100131], p. 42).

A new potentiometric surface was constructed for this study using regional water level data from wells, boundaries of perennial marshes and ponds, topographic elevations, regional spring locations, the locations of recharge and discharge areas, and hydrogeologic information (D’Agnese et al. 1997 [DIRS 100131], p. 56). In this sparsely populated area, well data are concentrated in alluvial valleys and data are generally lacking in consolidated bedrock. Supplemental information was developed from other sources such as the elevations of perennial marshes and ponds, and the elevations of regional springs and playa discharge areas. Manual adjustments to the potentiometric surface were made to reflect the steeper hydraulic gradients in lower permeability rocks and the development of groundwater highs in regional recharge areas.

GSIS methods were used to represent the considerable array of three-dimensional data used in constructing the regional model. The GSIS is a three-dimensional extension of the traditional two-dimensional Geographic Information System (GIS), and its development and application to the Death Valley regional modeling is extensively described by D’Agnese et al. (1997 [DIRS 100131], pp. 22 to 33).

\section{B3.1.4 Regional Groundwater Movement}

For purposes of discussing groundwater movement, the regional system was divided into three subregional flow systems. Conceptual descriptions of groundwater movement in each of these systems are presented by D’Agnese et al. (1997 [DIRS 100131], p. 62) and are used to help evaluate the modeling results. Compilations of inflows and outflows from these subregions were used by D’Agnese et al. (1997 [DIRS 100131], p. 71) to prepare an estimated water budget for the region. The Data Qualification Team concurs with D'Agnese et al. (1997 [DIRS 100131], p. 71) that because of the uncertainties involved, water budgets generally 
provide only gross indications of the accuracy of the major flow components. Based only on the aforementioned estimates of inflows and outflows and not on modeling results, regional outflows $\left(374,000 \mathrm{~m}^{3} /\right.$ day) were found to exceed regional inflows $\left(344,200 \mathrm{~m}^{3} /\right.$ day) by $29,800 \mathrm{~m}^{3} /$ day (D’Agnese et al. 1997 [DIRS 100131], Table 13). Not included in the water budget is an estimated $89,400 \mathrm{~m}^{3} /$ day groundwater pumping which is represented as a change in storage. However, because the regional model is steady-state, changes in storage cannot be accommodated because they represent nonequilibrium conditions (D’Agnese et al. 1997 [DIRS 100131], p. 72). The pumping was treated as a groundwater discharge in the final model.

\section{B3.1.5 Discussion}

The Data Qualification Team found that the regional model's input database was diligently compiled using appropriate methodologies that take into account the difficulties of handling large amounts of data for a large and complex region, as well as the uncertainties that are present in much of the developed information. Data collection methods were based on standard scientific work practices using USGS procedures. The care taken in developing the regional hydrogeologic framework was appreciated, as was the use of the new GSIS techniques for managing the data.

Discharges from evapotranspiration, playa evaporation, spring flow, and pumping were well researched, particularly the evapotranspiration component which constituted the largest single source of discharge. Recharge was dominated by infiltration of precipitation, which remained somewhat uncertain despite the large effort put into its quantification. The effort expended by D’Agnese et al. (1997 [DIRS 100131]) to corroborate the various model inputs lent credibility to their results. Given that the average estimated regional recharge from infiltration of 312,300 m³/day (D'Agnese et al. 1997 [DIRS 100131], Table 13) amounts to over 90 percent of the total regional inflow, it is not surprising that the model should be quite sensitive to this parameter (D’Agnese et al. 1997 [DIRS 100131], Figure 43). D'Agnese et al. (1997 [DIRS 100131], p. 55) make the statement that the "recharge rates are still based on empirical estimates rather than actual measured rates and reflect a significant unknown flux in modeling this region.” The Data Qualification Team believes that this statement is overly cautious. While the uncertainty associated with this parameter is certainly high, its value is based on reasonable science and is far from being unknown. Although a high degree of uncertainty is also associated with interbasin flow at the model boundaries, the volumes involved are estimated to be small and the modeling results are not expected to be sensitive to this parameter.

The Data Qualification Team shares D’Agnese et al.’s (1997 [DIRS 100131], p. 72) concern about the inability of a steady state model to adequately incorporate changes in the volume of groundwater in storage from pumping. By incorporating such withdrawals as discharges in a steady state model, other discharges are proportionately reduced so that a balance between recharge and discharge is maintained. While this may, in part, explain the model's tendency to underestimate discharges from the larger springs, inclusion of pumping as a constant discharge in the model will tend to make it more representative of long term, developed conditions that are of primary interest to performance assessment at Yucca Mountain. 


\section{B3.2 CODE SELECTION AND MODEL DEVELOPMENT}

The MODFLOWP code was used for the Death Valley regional flow study. This code has been added to the YMP software baseline and can be used in qualified calculations. MODFLOWP is an adaptation of the USGS MODFLOW code that allows nonlinear regression to be used in the calibration process (D’Agnese et al. 1997 [DIRS 100131], p. 72). Although more refined interim databases were developed, the final model was constructed with three hydrogeologic unit layers (D’Agnese et al. 1997 [DIRS 100131], p. 75) and a 1,500-m grid spacing (D’Agnese et al. 1997 [DIRS 100131], p. 37). D'Agnese et al. (1997 [DIRS 100131], p. 37) found this configuration to be sufficiently detailed to support the regional modeling effort and allowed the entire area to be displayed as a single model using available computers. The first two model layers simulate local and subregional flow mostly within valley-fill alluvium, volcanic rocks, and shallow carbonate rocks. The third layer simulates regional flow in volcanic, carbonate, and clastic rocks (D’Agnese et al. 1997 [DIRS 100131], p. 75). Each model layer contains several hydrogeologic framework model units (D’Agnese et al. 1997 [DIRS 100131], p. 77). The bottom of the model is located 2,750 $\mathrm{m}$ below the interpreted water table (D'Agnese et al. 1997 [DIRS 100131], p. 75).

The mapped input databases were resampled to a 1,500-m lateral grid spacing and reclassified to simplify the final model. For example, simplification of the hydraulic conductivity database in the final model resulted in the definition of four hydraulic conductivity zones representing very small to large conductivity values. The 50th percentile conductivity values were used as initial estimates in the model (D’Agnese et al. 1997 [DIRS 100131], p. 77). This simplified the number of parameters that were varied in the calibration process. The model was calibrated by varying the locations and types of boundary conditions, recharge parameters, and the interpretation of the hydrogeologic framework until acceptable matches were made with measured hydraulic heads

and spring flows. Nonlinear regression methods were used to estimate parameter values that produced the best fit to observed heads and flows (D’Agnese et al. 1997 [DIRS 100131], p. 72). Hydraulic conductivities, vertical anisotropy ratios, recharge potentials, spring conductance, and groundwater pumping were varied during the calibration process (D'Agnese et al. 1997 [DIRS 100131], p. 84). No modifications were made to conceptual models during calibration simply to improve the model fit (D'Agnese et al. 1997 [DIRS 100131], p. 86) and the parameter values estimated by the regression process remained reasonable. Supporting independent hydrogeologic criteria were needed before modifications were made (D'Agnese et al. 1997 [DIRS 100131], p. 86). Detailed analysis of the calibration results identified previously overlooked spurious data, such as head observations from perched zones, incorrectly recorded head data, springs that issued from local instead of regional groundwater, and incorrect spring altitudes.

The Data Qualification Team considers use of the MODFLOWP code in constructing the model to be appropriate. MODFLOW has become the industry standard with regards to simulating saturated zone groundwater flow and the advantages of the MODFLOWP adaptation in simplifying the calibration process and evaluating the model results are clearly explained by D’Agnese et al. (1997 [DIRS 100131], p. 95). It is always regretful when a detailed model database has to be simplified to accommodate operational constraints, but the reasons for such 
simplification are understood. Overall, D’Agnese et al. (1997 [DIRS 100131]) do not modify the model without supporting hydrogeologic criteria and they maintaining the hydraulic parameter values within reasonable bounds.

\section{B3.3 MODEL OUTPUT}

The regional flow model was validated by comparing model outputs with the regional potentiometric surface, hydraulic head measurements in individual wells, hydraulic gradients, and spring discharges (D’Agnese et al. 1997 [DIRS 100131], p. 94). D’Agnese et al. (1997 [DIRS 100131], p. 104) conclude that a general comparison of the simulated hydraulic heads with the regional potentiometric surface map indicates that the regional model depicts major features of the head distribution well (thus there is corroboration). Although this conclusion was confirmed by a comparison of the estimated potentiometric surface by D’Agnese et al. (1997 [DIRS 100131], Figure 27) with the simulated surfaces shown in the same work (D’Agnese et al. 1997 [DIRS 100131], Figures 48 to 53), the simulated surfaces are considerably smoother and do not exhibit the variability of the estimated surface.

In areas of flatter hydraulic gradients, simulated heads were within $75 \mathrm{~m}$ of observed well levels everywhere in the model and generally within $50 \mathrm{~m}$. Based on the standard error of the regression of simulated and observed heads, the effective model fit for most wells is $45 \mathrm{~m}$ (D’Agnese et al. 1997 [DIRS 100131], p. 94). In areas of steep gradients, the differences between simulated and measured heads are as large as $300 \mathrm{~m}$. D'Agnese et al. (1997 [DIRS 100131], p. 94) consider this match to be good in view of the 2,000-m head drop across the system. D'Agnese et al. (1997 [DIRS 100131], p. 104) consider good fits to have residuals of less than $20 \mathrm{~m}$ ( 1 percent of the total head drop), moderate fits to have residuals of 20 to $60 \mathrm{~m}$, and poor fits to have residuals greater than $60 \mathrm{~m}$. By this definition, the overall goodness-of-fit would be considered moderate. Matching spring flows was found to be difficult and the measured values were generally underestimated. The sum of all simulated spring flows is $51,700 \mathrm{~m}^{3} /$ day, whereas the sum of all observed spring flows is $120,000 \mathrm{~m}^{3} /$ day (D'Agnese et al. 1997 [DIRS 100131], p. 94). These comparisons can be misleading, however, because not all observations have been measured with the same accuracy. Nevertheless, even with acknowledged errors in the model output, they are still acceptable for their intended use as input to the base-case SZ site-scale flow model because they are small enough to not significantly impact model calibration. The fitting techniques of D'Agnese et al. (1997 [DIRS 100131]) were considered state-of-the-art at the time of the publication of his report.

D’Agnese et al. (1997 [DIRS 100131], p. 104) note that an indication of nonrandom distribution of head residuals in the model subregions suggests that the model may be in error. However, across the entire model the residuals do generally vary randomly about zero (D'Agnese et al. 1997 [DIRS 100131], Figure 56). The overall water budget for the model is good, with inflows balancing outflows within 2,000 $\mathrm{m}^{3}$ /day (D'Agnese et al. 1997 [DIRS 100131], Table 17). In this water budget calculation, pumping is included among the regional discharges.

The Data Qualification Team concurs with D’Agnese et al.’s (1997 [DIRS 100131], p. 104) definitions of goodness-of-fit and concludes that this model provides a moderately accurate simulation of the DVRFS. Considering the large size of the region, the hydrogeologic 
complexity, and the sparse data, achieving any better overall validation accuracy would have been surprising. The team found that the Death Valley regional flow model database was well researched, the model was appropriately constructed, and the resulting output provides a reasonable simulation of regional groundwater flow despite the possibility of model error indicated by the authors (D’Agnese et al. 1997 [DIRS 100131], p. 112).

The residual uncertainty in the model simulations is well described by its authors (D'Agnese et al. 1997 [DIRS 100131], pp. 95 to 112). Uncertainties in the model output are of potential concern to the Data Qualification Team because the simulated fluxes along the boundaries of the SZ site-scale flow models account for most of the flow through those models. In this report, the fluxes in the three regional model layers were combined to provide total flow across the boundary for vertical panels of various widths extending from the water table to a depth of $2,750 \mathrm{~m}$ below the water table. The uncertainties are incorporated into the SZ site-scale models by treating the fluxes as target values during model calibration (BSC 2004 [DIRS 170037]). Fixed head boundary conditions were derived around the perimeter of the SZ site-scale models from regional water level and head data, where heads were varied laterally along the model perimeter, but were held constant in the vertical direction and in BSC 2004 [DIRS 170037]). Other targets were also considered during base-case SZ site-scale flow model calibration that affect fluxes, including rock permeabilities and specific discharge estimates given by the Saturated Zone Expert Elicitation Panel (BSC 2004 [DIRS 170037]). A comparison of the resulting calibrated boundary fluxes of the site-scale model with those determined from the regional model shows a reasonable match of total boundary fluxes, but greater differences, some on the order of 100 percent, for individual boundary segments (BSC 2004 [DIRS 170037]). These differences are attributed primarily to the greater resolution of the site-scale model (BSC 2004 [DIRS 170037]). In addition, the pumping wells modeled in the 1997 DVRFS are not incorporated directly into the base-case SZ site-scale flow model. Thus, these discharges are effectively replaced by additional flux through the southern boundary of the base-case SZ site-scale flow model (which also made it difficult for the SZ model to match the target boundary conditions during calibration). Use of the regional model flux data as target rather than absolute values in the site-scale model is appropriate considering the uncertainties inherent in those data.

Upon review of the alternative models (e.g., Waddell 1982 [DIRS 101062] and Rice 1984 [DIRS 101284]), the Death Valley regional flow model was found to be the most appropriate source of information for both distributed recharge and lateral flow boundary conditions for the base-case SZ site-scale flow and transport model.

\section{B3.4 SUMMARY OF EVALUATION RESULTS}

The Data Qualification Team found the Death Valley regional flow model database to be well researched, the model to be appropriately constructed, and the resulting output to provide a reasonable simulation of regional groundwater flow. Quantification of the recharge component of flow was reviewed in particular detail because of the reliance placed on those data in this report. Several approaches to estimating recharge from precipitation were evaluated by the regional model's authors before deciding on a modification of an empirical relationship developed by Maxey and Eakin (1950 [DIRS 100598]). This straightforward modification 
consisted of scaling different zones within the model based upon local climate, slope, permeability, and vegetation. This is an entirely reasonable technique because it takes into account the specific terrain within the model domain and avoids blindly assign a single empirical expression for distributed recharge. Shortcomings of other, more recent techniques were identified, particularly for application to desert areas where small amounts of recharge are ignored. The Data Qualification Team notes that a modified Maxey-Eakin method was also used by the YMP in preparing report U0010, Simulation of Net Infiltration for Modern and Potential Future Climates (USGS 2001 [DIRS 166518]), and that the method is widely used and accepted by the technical community.

The Maxey-Eakin method was modified in the regional model to make it more sensitive to the four critical potential recharge indicators within the region: altitude, slope-aspect, relative rock and soil permeability, and vegetation. Regional maps were prepared for each of these indicators and through a series of steps a final recharge database was produced. The accuracy and suitability of the database were evaluated by the model authors and found to be appropriate for regional modeling. It is noted, however, that even with the better-defined potential recharge areas, the rates are still based on an empirical relationship rather than actual measurements. Therefore, there is a significant uncertainty in the regional modeling.

Within the area of the base-case SZ site-scale flow and transport model, the recharge fluxes from the regional model are consistent with similar magnitude fluxes independently estimated from the 1997 UZ site-scale flow model and with focused recharge from Fortymile Wash. The correlation between topography and recharge is similar in the regional and the UZ models. The magnitudes of recharge are also similar, ranging from near zero to 8 or $9 \mathrm{~mm} /$ year. Recharge rates from Fortymile Wash show a similar range and topographic influence as the other two sources.

The Data Qualification Team found that the regional model's input database was diligently compiled using appropriate methodologies that take into account the difficulties of handling large amounts of data for a large region as well as the relatively large uncertainties that are present in much of the developed information. Discharges from evapotranspiration, playa evaporation, spring flow, and pumping were well researched, particularly the evapotranspiration component which constituted the largest single source of discharge. As expected, recharge was dominated by infiltration of precipitation. The effort expended by the model authors to corroborate the various model inputs lent credibility to their results.

The Data Qualification Team considers use of the MODFLOWP code in constructing the model to be appropriate. At the time of report preparation, the MODFLOW code had become an industry standard and the advantages of the MODFLOWP adaptation in simplifying the calibration process and evaluating the model results were important. The model authors do not modify the model without supporting hydrogeologic criteria and they maintaining the hydraulic parameter values within reasonable bounds.

Based on the standard error of the regression of simulated and observed heads, the effective residual between actual and simulated heads was $45 \mathrm{~m}$ for most wells. The Data Qualification Team concurs with the model authors' observation that good fits have residuals of less than $20 \mathrm{~m}$ 
(1 percent of the total head drop), moderate fits have residuals of 20 to $60 \mathrm{~m}$, and poor fits have residuals greater than $60 \mathrm{~m}$. By these definitions, the overall goodness-of-fit of the regional model would be considered moderate. As a result, a degree of uncertainty must be associated with the model outputs. Nevertheless, the output from the 1997 DVRFS model is relevant and appropriate for its intended use.

Uncertainties in the simulated fluxes along the lateral boundaries of the base-case SZ site-scale flow model are potentially significant because these fluxes constitute the greatest sources of flow in the site-scale model and they are not independently corroborated. However, these uncertainties were recognized in calibrating the site-scale model by using the regional model fluxes along with other data sources in a generalized manner as calibration targets rather than as fixed model inputs. Actual boundary conditions in the site-scale model were defined by fixed heads, which are better known than the boundary fluxes. This approach made the fluxes largely a function of the calibrated model permeabilities. A comparison of the resulting calibrated regional and site-scale model boundary fluxes shows reasonable matching of total fluxes, but also greater differences, some on the order of 100 percent, for individual boundary segments. These observations indicate that the use of the regional model flux data in the site-scale model is appropriately generalized considering the uncertainties inherent in those data.

\section{B4. EVALUATION CONCLUSIONS}

The conclusions of the Data Qualification Team's review of the regional model are presented below in terms of the evaluation criteria presented in the controlling plan, AP-SIII.2Q.

1. Are the methods used to develop the Death Valley regional groundwater model reasonable and generally accepted by the technical community?

The methods used to develop the database, the choice of models, the methods of calibration, and the analysis of the results are all reasonable and generally accepted by the technical community. The use of GSIS to store, manipulate, and analyze the data is also accepted by the technical community.

2. Are the methods used in this report to develop boundary conditions from the regional modeling results reasonable and generally accepted by the technical community?

The nested model approach for obtaining lateral flux boundary conditions for smaller models is well established and accepted by the technical community. The recharge boundary for the regional model was developed using a modified Maxey-Eakin method, which is also well established and accepted by the technical community.

3. Are there more appropriate sources of information for developing the boundary conditions required in this report? 
Other sources of similar information are older and less well developed than the Death Valley regional flow model. The regional model was developed, in part, to support site-scale modeling. It provides a reasonable and comprehensive simulation of regional flow, and is an appropriate source of information for developing hydrologic boundary conditions for the site-scale model.

4. Are the boundary condition data and their associated uncertainties acceptable for their intended use?

Uncertainties in the lateral boundary condition data have been appropriately addressed by making them target values for base-case SZ site-scale flow model calibration. The calibration has been successfully completed using this approach, indicating that the boundary condition data have been successfully used and are therefore acceptable for their intended use. In addition, much of the source data for the regional model are YMP-accepted data, the MODFLOWP code has been qualified for project use, the regional model has been validated and residual uncertainties have been identified, and the modeling effort was adequately reviewed and documented. Furthermore, it should be noted that differences between the 1997 DVRFS and the 2001 DVRFS models, while not extraordinary, can largely be attributed to the fact that the 1997 DVRFS model simulates conditions found in the early 1990s (includes groundwater pumping) and the 2001 DVRFS model simulates predevelopment conditions (no pumping).

\section{B5. RECOMMENDATIONS}

The Data Qualification Team has concluded that the Death Valley regional flow model database was well researched, the model was appropriately constructed, and the resulting output provides a reasonable simulation of regional groundwater flow based on application of all evaluation criteria. At the time of publication, this model was the most recent and best-supported SZ flow model of the Yucca Mountain region. It incorporated updated geological and hydrogeological data, it benefited from contemporary geological and hydrogeological conceptual models, and it provided a three-dimensional representation of the region. Upon review of the alternatives, the Death Valley regional flow model was found to be an appropriate source of information for both recharge and lateral flux boundary conditions for the SZ site-scale flow and transport model.

Based on the foregoing evaluation, the Data Qualification Team has concluded that the Death Valley regional flow model provides a qualified source of data for establishing recharge and lateral flux boundary conditions for the SZ site-scale flow and transport model. In accordance with AP-SIII-2Q, this finding qualifies these data only for their intended uses in this report. The source DTN: GS960808312144.003 [DIRS 105121] will remain unqualified for other uses. 
Recharge and Lateral Groundwater Flow Boundary Conditions for the Saturated Zone Site-Scale Flow and Transport Model

INTENTIONALLY LEFT BLANK 
Recharge and Lateral Groundwater Flow Boundary Conditions for the Saturated Zone Site-Scale Flow and Transport Model

\section{APPENDIX C}

ONE-TIME USE QUALIFICATION OF DTN: LB971212001254.001 
Recharge and Lateral Groundwater Flow Boundary Conditions for the Saturated Zone Site-Scale Flow and Transport Model 


\section{C1. INTRODUCTION}

\section{C1.1 PURPOSE}

This Internal Data Qualification Report evaluates the appropriateness of unqualified data from the 1997 UZ site-scale flow model for use in this report, Recharge and Lateral Groundwater Flow Boundary Conditions for the Saturated Zone Site-Scale Flow and Transport Model, Revision 01. This qualification report was prepared as an appendix to this report.

The UZ site-scale model was developed to complete the base-case flow field simulations for the total system performance analysis for viability assessment. 39 steady-state flow fields were developed for this purpose with separate groups of these fields presented in separate reports. These simulations were intended to consider the ranges and uncertainties of present and future infiltration rates and different fracture-matrix interaction models. Outputs from the 1997 and 2003 UZ site-scale models were used in this report to identify groundwater recharge from the UZ to the SZ. Because the 2003 UZ site-scale model is already qualified, this evaluation pertains only to those data used from the 1997 version and is performed in accordance with the internal data qualification requirements of AP-SIII.2Q, Qualification of Unqualified Data. Qualification will be performed through a combination of corroboration of data and technical assessment as described in Attachment 3 of AP-SIII.2Q. Qualification of these data will support the license application, but only for the uses detailed in this report.

\section{C1.2 SCOPE}

This appendix was prepared according to the Internal Data Qualification Plan presented in the Technical Work Plan for: Natural System - Saturated Zone Analysis and Model Report Integration (BSC 2004 [DIRS 171421]). The Internal Data Qualification Plan identifies one data tracking number (DTN: LB971212001254.001 [DIRS 104749]) containing unqualified, developed hydrogeological data associated with the 1997 UZ site-scale model, which is used in this report. DTN: LB971212001254.001 [DIRS 104749] is entitled Recharge from the 1997 UZ Site-Scale Flow Model Area.

\section{C1.3 DATA QUALIFICATION TEAM}

Chairperson. The Chairperson for this internal data qualification, Scott C. James, is the originator of this report.

Team Member. The team member for this internal data qualification is Thomas S. Lowry.

\section{C1.4 BACKGROUND}

The data from DTN: LB971212001254.001 [DIRS 104749] that were used in this report are presented by Wu et al. (1997 [DIRS 156453]), in Providing Base-Case Flow Fields for TSPA-VA: Evaluation of Uncertainty of Present Day Infiltration Rates Using DKM/Base-Case and $D K M /$ Weeps Parameter Sets. Although that report is unqualified, the data sources it draws 
from as well as the software used for the simulations are qualified in accordance with standard YMP quality assurance requirements.

Wu et al. (1997 [DIRS 156453]) present 29 steady-state flow fields generated using ten different parameter sets calibrated using three difference infiltration scenarios and two fracture-matrix interaction models. DTN: LB97121200124.001 is from Run \#7, labeled flow field \#LBL-FF\#17 (Wu et al. 1997 [DIRS 156453], Table 6.1, p. 11), and represents the present-day infiltration rate under the base-case mesh. The flow fields are based on steady-state solutions of two-phase water and gas-flow equations of the TOUGH2 code (Pruess 1987 [DIRS 100684] and 1991 [DIRS 100413]). DTN: LB97121200124.001 is used in this report to quantitatively assess differences between recharge from updated flow models (i.e., the 2001 DVRFS and 2003 UZ site-scale flow models with Fortymile Wash) and those that will be used in the base-case SZ site-scale flow model (i.e., the 1997 DVRFS and UZ site-scale flow models with Fortymile Wash). Therefore, qualification of DTN: LB97121200124.001 is necessary for the analysis.

\section{C2. QUALIFICATION APPROACH}

\section{C2.1 QUALIFICATION METHODS}

A combination of two methods, as outlined in Attachment 3 of AP-SIII.2Q, is used to qualify DTN: LB97121200124.001. First, DTN: LB97121200124.001 will be qualified by corroboratively comparing it to the output from the qualified 2003 version of the UZ site-scale model. Secondly, additional support will be given to the qualification through technical assessment of the approach and methods used by Wu et al. (1997 [DIRS 156453]).

\section{C2.2 EVALUATION CRITERIA}

Evaluation Criteria: The unqualified data were evaluated for use in this report based on consideration of the following evaluation criteria. These criteria were selected to incorporate the considerations in AP-SIII.2Q, Attachment 3, Considerations for Determining Qualification Methods, and AP-SIII.2Q, Attachment 4, Qualification Process Attributes.

1. Are the methods used to develop the 1997 UZ site-scale model reasonable and generally accepted by the technical community?

2. Are there data comparisons that can substantiate or confirm the validity of DTN:LB97121200124.001?

3. Are there more appropriate sources of information for developing the boundary conditions required in this report?

4. Are the boundary condition data and their associated uncertainties acceptable for their intended use? 
Recommendation Criteria: A recommendation for internal qualification is based on the satisfactory resolution of one or more of the evaluation criteria. Although these criteria are considered in determining whether the data are appropriate for their intended use in this report, the conclusions of the Data Qualification Team are based on expert judgment, even though all evaluation criteria are met.

\section{C3. EVALUATION RESULTS}

A technical assessment of the 1997 UZ site-scale model (Wu et al. 1997 [DIRS 156453]) was performed by evaluating the qualified status of the model's input database and code used for the simulation. Additionally, corroboration to DTN: LB03023DSSCP9I.001 [DIRS 163044], which is the present day infiltration rate from the qualified 2003 UZ site-scale flow model, are made. Each of these elements of the review is discussed in the following sections of this appendix.

\section{C3.1 QUALIFIED STATUS}

Inputs to the UZ site-scale flow model consist mainly of geologic, hydrogeologic, and geochemistry data. Table 2.1 from Wu et al. (1997 [DIRS 156453], p. 7) lists 22 data sources, their Q status, as well as their DTNs. In every case, the data input source is qualified under approved YMP Quality Assurance Procedures. In addition, the flow fields generated by $\mathrm{Wu}$ et al. (1997 [DIRS 156453]) are based on steady-state solutions of two-phase water and gas-flow equations in the TOUGH2 code (Pruess 1987 [DIRS 100684]; 1991 [DIRS 100413]), which is a fully qualified code that has since been successfully used for many YMP calculations.

\section{C3.2 CORROBORATION}

The 2003 data (DTN:LB03023DSSCP9I.001 [DIRS 163044]) are described in BSC (2004 [DIRS 169861]) and is fully qualified. This version of the UZ site-scale model was enhanced from the 1997 version by incorporating the conceptual repository design with new grids, recalibration of property sets, and a more comprehensive validation effort (BSC 2004 [DIRS 169861], p. 1-1). The flow fields developed are spatially varying maps representing the mean, lower, and upper bounds of estimated net infiltration for the current climate and two projected future climates (monsoon and glacial transition), resulting in a total of nine base-case flow fields. This differs from the 29 flow fields generated by Wu et al. (1997 [DIRS 156453]). As in the work of Wu et al. (1997 [DIRS 156453]), TOUGH2 V1.4 was used to generate flow fields and three-dimensional gas flow (LBNL 2000 [DIRS 146496]). Additionally, the grid used in the 2003 UZ site-scale model is approximately 16 percent smaller than that used in the 1997 version.

\section{C3.3 ANALYSIS}

With regards to the qualified status of the work of Wu et al. (1997 [DIRS 156453]), it is apparent that the document remained unqualified because it was not subsequently used for further analysis. The Data Qualification Team could find no documented evidence as to why the work of Wu et al. (1997 [DIRS 156453]) could not or should not be unqualified. That fact, coupled 
with our confidence in the approach and methodology used by Wu et al. (1997 [DIRS 156453]), presents a sound case for the qualification of DTN: LB97121200124.001.

A more quantitative argument can be made through corroborative comparison of the numerical results of the 1997 and 2003 models. The main difference between the two models is not in the flux through the bottom of the UZ site-scale models, which are within 1 percent of each other on a per area basis, but rather, it is the spatial distribution of the infiltration that is different. The agreement between fluxes out the bottom of each model is expected because the recharge rate applied to the top of each model is the same for both versions. This confirms the consistency of the TOUGH2 (Pruess 1987 [DIRS 100684] and 1991 [DIRS 100413]) calculations. The difference in the spatial distribution of the flux through the bottom of the model is also expected due to the change in grid configuration and the inclusion of faults in the 2003 model. Visually, the 1997 model, as shown in Figure 6-4, shows a more even distribution as compared to the 2003 model (Figure 6-5), which shows infiltration concentrating along fault lines.

The difference in the spatial distribution of the two models is reduced when the infiltration rates are upscaled to the coarser $500 \times 500 \mathrm{~m}^{2}$ grid of the SZ site-scale model. This is illustrated in Figures 6-10 and 6-12. The $1997 \mathrm{UZ}$ model, when upscaled to the larger grid, shows higher rates of recharge in the northwest region of the UZ site-scale model domain, while the 2003 version shows slightly higher rates towards the northeast region of its domain. However, in relation to the SZ modeling domains, the differences in spatial infiltration shift the areas of high infiltration by only a couple of cell widths.

Furthermore, when comparing the two infiltration patterns on the SZ site-scale grids (Figures 6-7 and 6-9), the relative impact of the UZ site-scale model input is clearly seen. Overall, the 1997 and 2003 UZ site-scale flow models supply about 28 percent and 7 percent of the total recharge to the SZ site-scale models when recharge for the areas outside the UZ site-scale flow model domain are taken from the 1997 and 2001 DVRFS models, respectively . This means that the impact of uncertainty in the UZ infiltration rates is minor compared to other inputs to the model. This impact is further reduced when one considers the UZ inflow as a percentage of inflow from the lateral boundaries ( 0.8 percent and 1.2 percent for the 1997 UZ/DVRFS models and the 2003 UZ/2001 DVRFS models, respectively).

Because of the averaging effect of the upscaling process from the UZ site-scale models to the SZ model, the agreement in total flux between the 1997 and 2003 versions, and the relatively minor contribution of the UZ infiltration to the overall water budget, the Data Qualification Team believes that DTN: LB97121200124.001 is of quality origin and represents the best estimate of recharge distribution in that area, given the limitations and purposes of the model.

\section{C4. EVALUATION CONCLUSIONS}

The conclusions of the Data Qualification Team's review of the regional model are presented below in terms of the evaluation criteria presented in the controlling plan (BSC 2004 [DIRS 171421]). 
1. Are the methods used to develop the $1997 \mathrm{UZ}$ site-scale model reasonable and generally accepted by the technical community?

The 1997 UZ site-scale flow model follow accepted and standard modeling practices. The fact that the inputs and the modeling code are all qualified under standard YMP quality assurance procedures supports the validity of the approach.

2. Are there data comparisons that can substantiate or confirm the validity of DTN: LB97121200124.001?

DTN: LB97121200124.001 compares favorably to DTN:LB03023DSSCP9I.001 [DIRS: 163044], which is the output from the qualified 2003 version of the UZ site-scale flow model. The magnitude of the bottom boundary outflow rates are within 1 percent of each other on a per area basis with the main differences being the spatial distribution of the outflow. The 2003 model shows outflow concentrated mainly along fault lines while the 1997 version shows a more even distribution. However, given the intent and inputs of each model, this change in spatial distribution is to be expected.

3. Are there more appropriate sources of information for developing the boundary conditions required in this report?

Both the 1997 and 2003 versions of the UZ site-scale model represent adequate estimates of recharge flux and distribution, considering the uncertainties within each model. In addition, the recharges to this area from the corresponding location in the DVRFS models are of the same order of magnitude, but considered less accurate with respect to their distribution.

4. Are the boundary condition data and their associated uncertainties acceptable for their intended use?

As mentioned above, the 1997 and 2003 versions of the UZ site-scale model represent adequate estimates of recharge flux and distribution for the area under the UZ model footprint. Use of outflow from one model (the UZ site-scale model) as input to another model (SZ model) is standard practice in the modeling community. Uncertainties in the flux rate and distribution are inherent in the UZ site-scale models, but these uncertainties have been minimized using qualified input data as well as the use of qualified codes. There exists no other method for determining the flux rate and distribution through this area that would produce an appreciable reduction in uncertainty.

\section{C5. RECOMMENDATIONS}

The Data Qualification Team has concluded that the 1997 UZ site-scale model (Wu et al. 1997 [DIRS 156453]) was well researched, the model was appropriately constructed, and the resulting output provides a reasonable simulation of flow from the UZ to the SZ in the immediate repository area. All inputs to the model, as well as the simulation software of the model, are 
qualified under standard YMP quality assurance procedures and the results corroborate well with the qualified 2003 version of the model. Based on the foregoing evaluation, the Data Qualification Team has concluded that the $1997 \mathrm{UZ}$ site-scale model (Wu et al. 1997 [DIRS 156453]), provides a qualified source of data for establishing recharge to the SZ flow and transport model. In accordance with AP-SIII-2Q, this finding qualifies these data only for their intended uses in this report. The source DTN:LB97121200124.001 will remain unqualified for other uses. 